\title{
Molecular phylogenetics and systematic revision of the south-eastern Australian Helicario- nidae (Gastropoda, Stylommatophora)
}

\author{
Isabel T. Hyman ${ }^{1}$, Irantzu de la Iglesia Lamborena ${ }^{1}$, Frank Köhler ${ }^{1,2}$ \\ ${ }^{1}$ Australian Museum, 1 William St, Sydney NSW 2010, Australia \\ ${ }^{2}$ E-mail:Frank.Koehler@austmus.gov.au
}

Key words: Helicarionoidea, land snail, mitochondrial DNA, morphology, taxonomy

\begin{abstract}
The south-eastern Australian helicarionid clade currently comprises six genera of snails and semislugs united by genital characters, including an epiphallic flagellum that produces a spiraling, spinose spermatophore, the absence of an epiphallic caecum, and the presence of at most a very short vagina. We comprehensively revise the taxonomy of this group based on comparative analyses of key morphological features and mitochondrial markers COI and $16 \mathrm{~S}$, revise the placement of several species described recently on the basis of shell morphology alone, and describe new taxa. The snail genus Brevisentis is monophyletic as currently understood, but includes an additional undescribed species from Wollemi National Park, New South Wales. Mysticarion is shown to contain four arboreal semislugs with wide, disjunct ranges, including one new species (Mysticarion obscurior sp. nov.). We synonymise Fastosarion staffordorum with Mysticarion hyalinus. The semislug Desidarion is synonymised with Parmavitrina, and we describe two new species of this genus, $P$. flavocarinata sp. nov. and P. maculosa sp. nov. The semi-arboreal semislug Cucullarion is herein included in the south-eastern Australian helicarionid clade based on morphological and genetic evidence, despite its more northerly distribution. Two small semislugs so far placed in Peloparion do not group together and a new genus, Ubiquitarion gen. nov., is described for Peloparion iridis. All of these genera, together with the semislug Helicarion (not included here), form a monophyletic radiation endemic to southeastern Australia.
\end{abstract}

\section{Contents}

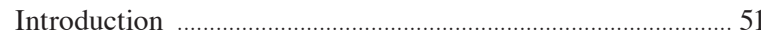

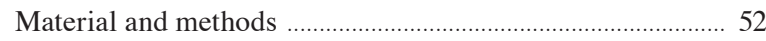

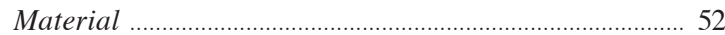

Morphological studies ..................................................... 52

Molecular studies and phylogenetic analyses ................. 53

Species identification and delineation .............................. 53

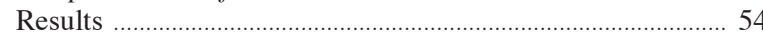

Comparative morphology ................................................... 54

Molecular analyses .............................................................. 56

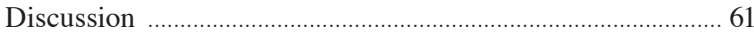

Phylogenetic relationships and genus-level taxonomy .... 61

Systematic significance of reproductive characteristics 62
Significance of morphological and mitochondrial

characters in species delimitation .................................... 63

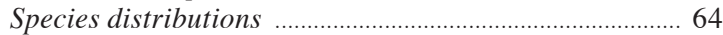

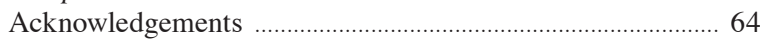

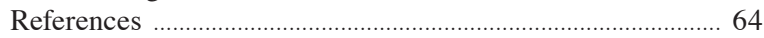

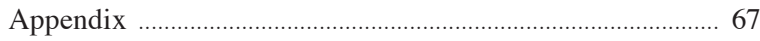

\section{Introduction}

The Helicarionidae is a group of land snails in which shell reduction, or limacisation, appears to have evolved repeatedly (Hyman et al., 2007). As a result this group harbours a wide range of morphological diversity, and includes snails with a full shell as well as semislugs, animals with a reduced, ear-shaped shell into which they cannot fully retract. The shells of all species, both snails and semislugs, are thin and glossy with reduced sculpture. Early species descriptions were primarily based on shells (e.g., Pfeiffer, 1849, 1850, 1852, 1853; Cox, 1864, 1868, 1871, 1873; Brazier, 1875a, 1875b, 1876b), as was the taxonomic framework put together in a series of papers by Iredale (1933, 1937a, 1937b, 1941, 1942), which included descriptions of 19 new, mostly monotypic genera. Subsequently, a number of small-scale anatomical investigations into single genera or species were published (Dartnall and Kershaw, 1978; Kershaw, 1979, 1981, 1982, 1988; Stanisic, 1993a, 1993b; Scott, 1995), but the underlying taxonomy essentially remained unchanged. More recently, a more comprehensive overview of Australian Helicarionidae was undertaken by Hyman and co-authors (Hyman, 2007; Hyman et al., 2007; Hyman and Ponder, 2010, 2016) utilizing both morphological data and mitochondrial DNA sequences. These studies resulted in the addition of several new species and genera as well as evidence to support the monophyly of some smaller subgroups among the Australian Helicarionidae. However, only around a quarter of Australia's estimated 
150 described species was included in these studies, with a high proportion from New South Wales (NSW), leaving the taxonomic structure of the entire group still unclear. Stanisic et al. (2010) documented the basic shell morphology and distributions of the NSW and Queensland (Qld) helicarionids and described 47 new species and 15 new genera based exclusively on their shell. This has raised the number of described species in Australia to 102. However, for more than half of these no anatomical data are known and their phylogenetic relationships have essentially remained unresolved.

Numerous studies in Australian land snail groups, such as the Camaenidae, have revealed the presence of both widespread conservatism in shell morphology, and in other cases, high levels of convergence (Stankowski, 2011; Criscione and Köhler, 2013a; Köhler and Criscione, 2015). Shell characters, such as shape, size and colour, appear to be closely linked to the adaptation to different habitat types, and therefore may be constrained by environment or lifestyle rather than by shared ancestry. Hence, these characters cannot reliably be used as a sole basis for a phylogenetic classification. There is evidence that shell reduction has evolved several times in the Helicarionidae (Hyman et al., 2007). As well as casting further doubt on the reliability of shell morphology in this group, this convergence in shell and body shape suggests that care must also be taken with the examination of anatomical characters, which are usually accepted as more reliable than shell morphology. During the process of limacisation, the size of the pallial cavity is reduced and some reproductive and digestive organs are moved into the foot. This can lead to convergence in anatomical characters; for example, many semislugs have developed an additional oesophageal crop, which is not present in snails (Tillier, 1984; Hyman and Ponder, 2010). The need to fit reproductive organs into a reduced space may also lead to convergence in genital morphology. For this reason, the use of molecular data, which already underpins much of modern taxonomy, is crucial to reliably resolve the systematic relationships among helicarionids.

The majority of Australian species live in rainforest habitats along the eastern coast. Although this group's highest diversity is in the Wet Tropics region of northern Queensland, helicarionid species are also present in the subtropical and temperate rainforests of southeastern and mid-eastern Australia. A single clade made up of six genera dominates the helicarionid fauna of this region (Hyman et al., 2007; Hyman and Ponder,
2010). While the relationships among the Helicarionidae are in general poorly understood, this southeastern Australian clade, comprising the genera Helicarion Férussac, 1821, Mysticarion Iredale, 1941, Desidarion Iredale, 1941, Parmavitrina Iredale, 1937, Peloparion Iredale, 1937 and Brevisentis Hyman, 2007, groups together with strong support based on both morphology and on mitochondrial phylogeny (Hyman et al., 2007; Hyman and Ponder, 2010). The southernmost genus, Helicarion, is found from Tasmania to central NSW and will be the subject of a future paper. The remaining five currently recognized genera and one additional genus, Cucullarion Stanisic, 1998, including the fourteen species they contain, form the subject of this revision.

Anatomical data are available for eight species (Stanisic, 1998; Hyman, 2007; Hyman and Ponder, 2010); however, the remaining six species, some of which were recently described by Stanisic et al. (2010), are known only by their shell morphology. For several of these species a single specimen has been sequenced previously (COI and 16S; Hyman et al., 2007), for a phylogenetic study that was not concerned with resolving the species-level taxonomy. Herein, we comprehensively revise the taxonomy relationships of these six helicarionid genera from southeastern Australia based on comparative examination of the anatomy and morphology of all described species and some currently undescribed candidate taxa as well as analyses of partial sequences of the mitochondrial genes cytochrome $c$ oxidase subunit I (COI) and 16S rRNA (16S) that sought to estimate the amounts of mitochondrial differentiation within and between species and to resolve their phylogenetic relationships.

\section{Material and methods}

\section{Material}

This study is based on the examination of ethanol-preserved specimens and supplementary dry material from the Australian Museum (AM), the Queensland Museum (QM) and Museum Victoria (MV), including freshly collected material from eastern NSW and southeastern QLD.

\section{Morphological studies}

Adult specimens were selected for examination. Maturity was determined by ascertaining, through dissec- 
tion, the whorl count at which specimens were found to have a mature reproductive system. Genital anatomy was examined through dissection of ethanol-preserved specimens using a Leica MZ8 stereo microscope with a drawing apparatus. Prior to dissection, the shell was removed and mounted on carbon tabs for scanning electron microscopy (SEM). Spermatophores were removed from the bursa copulatrix and cleaned by rinsing and the removal of extraneous tissue with fine forceps.

Shells were measured with calipers with a precision of $0.1 \mathrm{~mm}$. Dimensions measured were height $(\mathrm{H}=$ maximum dimension parallel to axis of coiling), diameter ( $\mathrm{D}=$ maximum dimension perpendicular to $\mathrm{H}$ ), aperture height $(\mathrm{AH}=$ maximum dimension of aperture parallel to axis of coiling), aperture width (AW = maximum dimension of aperture perpendicular to $\mathrm{H}$ ) and number of whorls ( $\mathrm{NW}=$ whorl count using method shown by Köhler (2011)).

Analyses of covariance (ANOVA) of morphometric parameters were performed using XLStatistics (Rodney Carr 1997-2011, Deakin University).

\section{Molecular studies and phylogenetic analyses}

DNA was extracted from small pieces of foot muscle from representative specimens by use of a QIAGEN DNA extraction kit for animal tissue (Qiagen, Hilden) following the standard procedure of the manual. An approximately 900 base pair long fragment of the $16 \mathrm{~S}$ gene was amplified by PCR using the primers $16 \mathrm{~S} 3 \mathrm{~F}$ and 16S4Ra (Hyman et al., 2007). Whenever we failed to amplify the whole fragment due to DNA fragmentation as typically encountered in extracts from older museum specimens, we amplified two overlapping shorter fragments or even performed nested PCRs by using the internal primers 16S3R and 16S4F (Hyman et al., 2007). In addition, an 823 base pair long fragment of the COI gene was amplified by using the primers LCOH1940 (Folmer et al., 1994) and COI-H865 (5'- TACYATTGTRGCAGCTGTAAA-3'; designed herein). For samples with highly fragmented DNA we performed a nested PCR using the primers LCOH1490 and HCOI2198 (Folmer et al., 1994) to amplify a 655 base pair long fragment. Reactions were performed using standard protocols with annealing temperatures / elongation times of $55^{\circ} \mathrm{C} / 90 \mathrm{~s}$ for $16 \mathrm{~S}$ and $60 \mathrm{~s} 50^{\circ} \mathrm{C}$ / $60 \mathrm{~s}$ for COI, respectively. Both strands of PCR fragments were purified and cycle sequenced by use of the PCR primers. Electropherograms were corrected for misreads and forward and reverse strands were merged into one sequence file using CodonCode Aligner v. 3.6.1 (CodonCode Corp., Dedham, MA). Sequences of the previous helicarionid study Hyman et al. (2007) were retrieved from GenBank and included in our dataset while all newly produced sequences have been deposited in GenBank under the accession numbers KY662298-662378, KY662388-KY662468.

The 16S sequences were aligned using the online version of MAFFT (version 7) available at www. http:// mafft.cbrc.jp/alignment/server/ by employing the iterative refinement method E-INS-i suitable for sequences with multiple conserved domains and long gaps (Katoh et al., 2002). Uncorrected p-distances between sequences were calculated by using the phylogenetic software MEGA7 (Kumar et al., 2016) under the option 'pair-wise deletion of gaps'. Prior to the phylogenetic analysis, we used the online version of Gblocks (Castresana, 2000) available at www. http://molevol. cmima.csic.es/castresana/Gblocks_server.html to remove ambiguously aligned positions from the $16 \mathrm{~S}$ alignment by enabling all options allowing for a less stringent selection. Each mtDNA fragment was checked for saturation using the test implemented in DAMBE (Xia and Lemey, 2009). The best-fit model of nucleotide substitution was identified for each gene partition separately using the model proposal function of MEGA7.

The aligned $16 \mathrm{~S}$ and COI sequences were then concatenated into one partitioned data set and a maximum likelihood-based method of tree reconstruction was employed to estimate phylogenetic relationships. We analysed the concatenated and partitioned sequence dataset using the program raxMLgui (version 1.5) (Silvestro and Michalak, 2012). Nodal support of the best ML tree was estimated by performing 10 independent runs each with 200 thorough bootstrap replicates.

\section{Species identification and delineation}

Our operational criterion for the delimitation of species has been to test whether candidate species were phenotypically and genotypically distinct from each other (Sites and Marshall, 2004). Specimens have initially been grouped into morphospecies based on external morphology, including shell characters. These groups have been associated with already described species with respect to morphological similarity and distribution as based on comparison with types and/or topotypes. Morphospecies that could not be assigned to an available species name were treated as candidates for new species. Subsequently, we employed basic statistics of morphometric characters and comparative 
reproductive anatomy to assess the amounts of phenotypic differentiation within and between the so recognized morphospecies. In a final step we employed analyses of DNA sequences to assess the amount of mitochondrial differentiation within and between morphospecies.

\section{Results}

\section{Comparative morphology}

All species described in this paper share some features of the reproductive system, which distinguish them from other Australian helicarionids: They all have a very short or absent vagina, the epiphallus lacks a caecum, and the epiphallic flagellum produces a spermatophore which has a spiralling shape and branched spines (with the exception of Cucullarion, which has just a single unbranched spine near the junction of the capsule and tail-pipe). Correspondingly, the flagellum has internal cryptae matching the shapes of the branches. Within this so delimited group the reproductive system is quite conserved, with the majority of differences occurring in the penial complex. However, the genera also exhibit variation in the shape of the albumen gland, the degree of folding of the spermoviduct, the presence or absence of a short vagina, and the length

\section{A - Brevisentis}

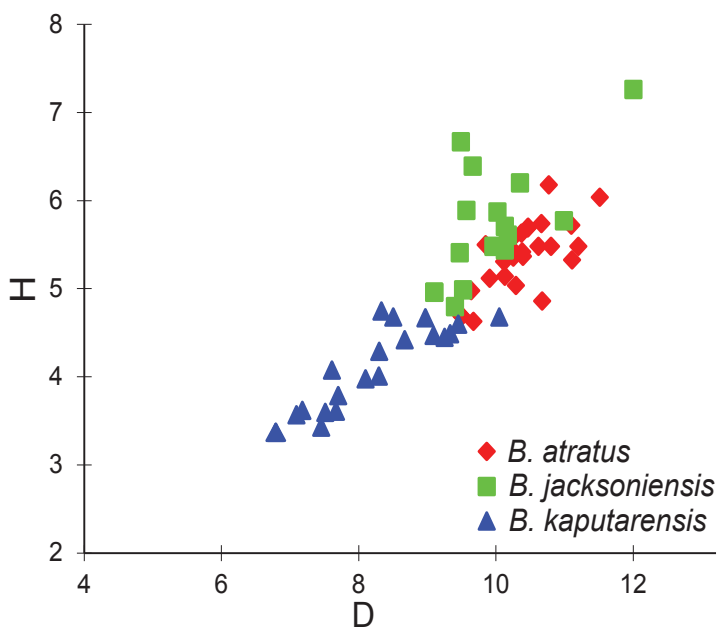

\section{C - Parmavitrina}

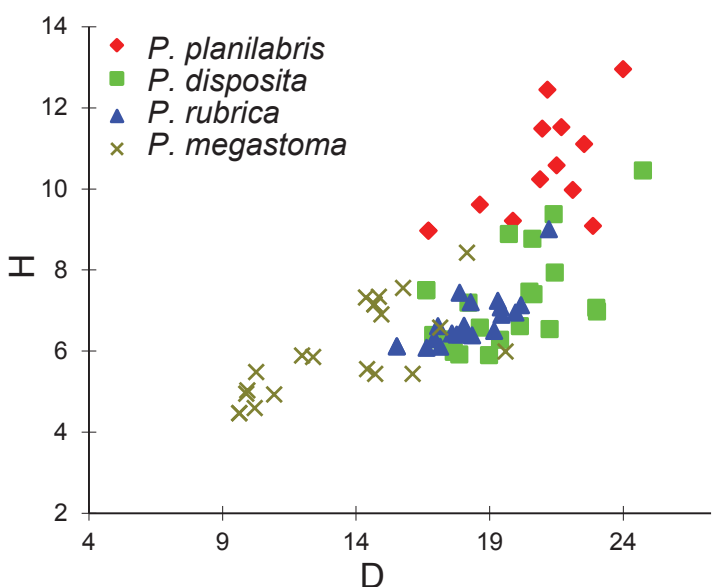

\section{B - Mysticarion}

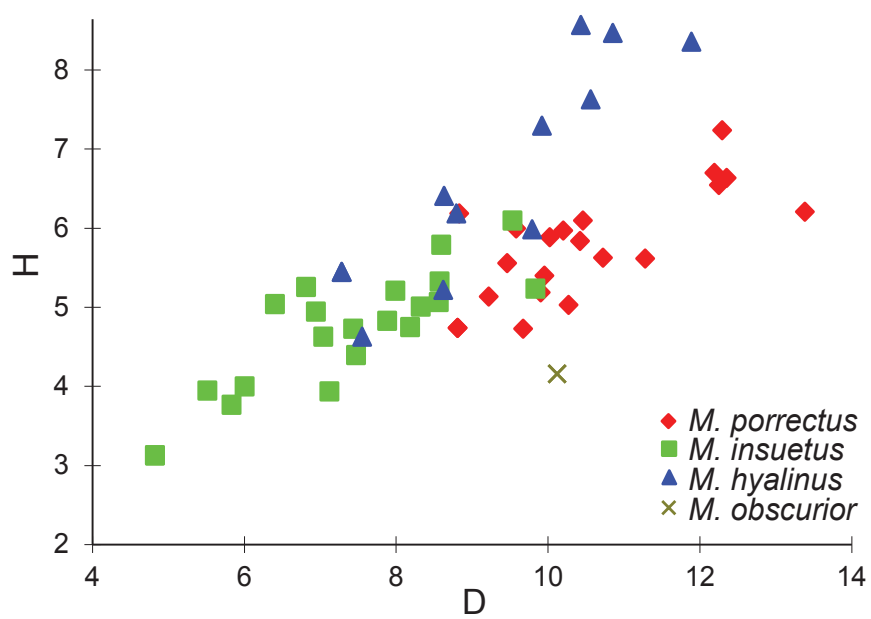

\section{D - Peloparion, Ubiquitarion}

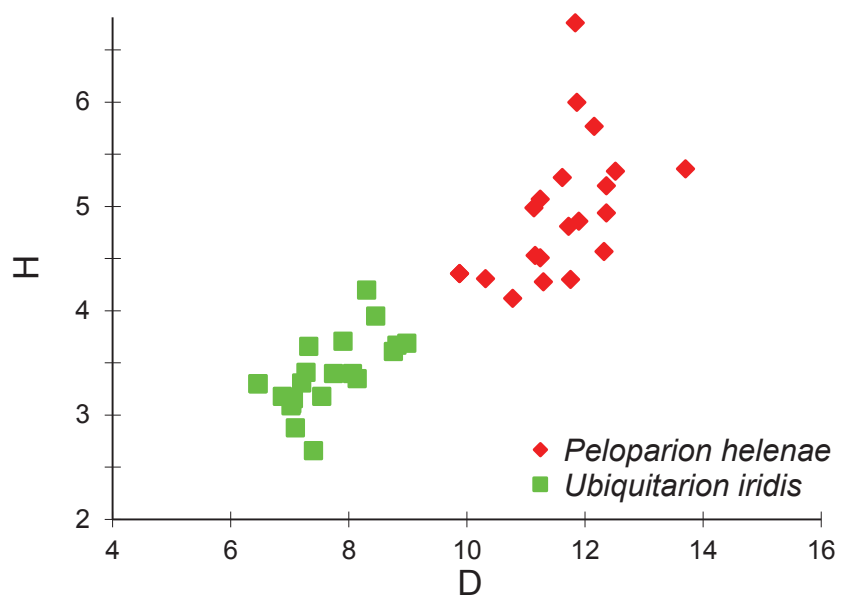

Fig. 1. Comparative analyses of shell shapes by plotting shell height (H) against shell diameter (D). A. Brevisentis, B. Mysticarion, C. Parmavitrina, D. Peloparion and Ubiquitarion. 
and shape of the bursa copulatrix. Some of these differences may relate to shell reduction. In particular, the folding of the spermoviduct is absent or minimal in Brevisentis and Mysticarion, the groups with the least shell reduction, and much more advanced in the remaining genera. Similarly, the albumen gland is an elongate triangle in Brevisentis (similar to the shape seen in other helicarionid snails), a less elongate triangle in Mysticarion, Peloparion and Ubiquitarion, and a modified, rounded shape in Parmavitrina. The bursa copulatrix is longest (relative to the length of the spermoviduct) in Brevisentis and shortest in Parmavitrina.

Brevisentis is the only snail genus included in this study. It is characterized by its glossy, discoidal to depressedly globose shell of 4.6-5.3 whorls with a rounded whorl profile. Unique aspects of its reproductive system include a penis with a verge and internally sculptured with a combination of longitudinal ridges and pustules or anastomosing ridges, and a tightly coiled spermatophore with short branching spines covering the entire tail-pipe. Within Brevisentis, the three species can be differentiated by shell shape (Fig. 1A): B. kaputarensis is significantly smaller than both B. jacksoniensis and B. atratus $(\mathrm{P}<0.0001$ for both SH and SD), and while the latter two species are similar to one another in size, B. atratus is flatter than $B$. jacksoniensis, which has a slightly raised spire (H/D ratio: $\mathrm{P}<0.0001)$. Brevisentis kaputarensis is similar in shell shape to B. atratus, but has a flatter shell than $B$. jacksoniensis (H/D ratio: $\mathrm{P}<0.0001)$.

The three congeners can also be differentiated by the length and shape of the penis (shorter, proximally swollen in B. jacksoniensis; longer, with internal narrowing in B.atratus; short, tubular in B. kaputarensis), by the internal sculpture of the penis (longitudinal pilasters becoming pustulose in B. jacksoniensis and $B$. atratus, anastomosing ridges in B. kaputarensis), and by the length and shape of the penial verge. The length of the penial verge is variable in $B$. kaputarensis and $B$. jacksoniensis but is always short in B. atratus.

The arboreal semislugs belonging to Mysticarion are united by their golden, globose shell of 3.0-4.5 whorls and generally pale body colour (with the exception of M.obscurior sp. nov., which has a more heavily pigmented body). In all species, the penis is relatively long and the epiphallus short. The penis interior contains longitudinal pilasters and a penial verge. The flagellum produces a spermatophore with branched spines present on the base of the capsule and continuing on the tail-pipe. The four species of Mysticarion can be differentiated by shell shape (visible on an H/D scat- terplot; Fig. 1B) and body colour. Mysticarion obscurior sp. nov. could not be included in statistical tests due to insufficient material. M. porrectus is larger than its congeners, and is flatter and less globose than the other species, differing significantly in H/D ratio from both $M$. insuetus $(\mathrm{P}<0.0001)$ and $M$. hyalinus $(\mathrm{P}<$ $0.0001)$. Mysticarion hyalinus is only slightly smaller than $M$. porrectus, with only a weakly significant difference in shell diameter $(\mathrm{P}<0.05)$. Mysticarion obscurior sp. nov. is slightly smaller again, and is flatter than either M. hyalinus or M. porrectus; and M. insuetus is the smallest species, differing significantly in shell diameter from both M. porrectus and M. hyalinus $(\mathrm{P}<0.001)$, with a relatively high spire. Anatomical differences include the flagellum and spermatophore shape (particularly the number of branches on the spermatophore and, correspondingly, the number of cryptae in the flagellum), the relative length of the penis and epiphallus, and the internal sculpture in the penis and size and shape of the penial verge.

The large semislugs of the genus Parmavitrina have flattened shells of 2.5-4.0 whorls with a wide aperture and, in some species, a membraneous base. All species have a strongly keeled tail and a cephalic shield. The genital morphology defining this group consists of a penis with primarily longitudinal sculpture and sometimes with a penial verge, a short vagina and bursa copulatrix, distinct cryptae in the flagellum and adjacent epiphallus, and a spermatophore with branching spines present on the capsule and a short, smooth tail-pipe. Each species can be separated from its congeners by a combination of penis size and shape, presence and shape of a penial verge, and sculpture of the penis interior, and thickness of the penis and penial sheath. Some of the species can be distinguished based on shell shape (although we have insufficient measurement data for P. maculosa sp. nov. and P. flavocarinata sp. nov.). For example, P. megastoma and P. flavocarinata sp. nov. are smaller than the remaining taxa (P. megastoma differs significantly in SD from $P$. planilabris, $P$. disposita and $P$. rubrica, $\mathrm{P}<0.0001$ ). Parmavitrina planilabris has a significantly higher $\mathrm{H} / \mathrm{D}$ ratio than $P$. rubrica and $P$. disposita (in both cases $\mathrm{P}<0.0001$ ), indicating a taller shell. However, $P$. rubrica and $P$. disposita cannot be separated based on shell shape alone, with no significant differences between $\mathrm{SH}$ and $\mathrm{H} / \mathrm{D}$ ratio and only a weak difference in $\mathrm{SD}(\mathrm{P}<0.01)$ (Fig. 1C).

Parmavitrina encompasses two morphologically distinct groups, each containing three similar species: the planilabris-group ( $P$. planilabris, $P$. rubrica, $P$. 
disposita), and the megastoma-group (P. megastoma, $P$. maculosa sp. nov., $P$. flavocarinata sp. nov.). Species in the planilabris-group are larger with a higher whorl count (3.5-4.0), have a large penis, very short vagina and bursa copulatrix, and longer spines on the spermatophore. In contrast, the species in the megastoma-group are smaller, with shells of fewer than 3.0 whorls, have a slender penial complex, a longer vagina and bursa copulatrix, and short, highly branched spines on the spermatophore. However, the two groups are also unified by numerous morphological characters as outlined above.

Cucullarion, another group of moderately large semislugs, contains two species with very reduced shells that are covered by extensive mantle lobes. This group represents the most northerly representative of the southeastern Australian radiation, exhibiting the highest degree of shell reduction. The two species, $C$. parkini and $C$. albimaculosus, are unified by their reduced shell, retaining calcium only on the plate-like dorsal surface, and slender bodies. Due to the degenerate shell, only shell diameter and number of whorls were measured, and due to lack of sufficient material no statistical comparisons could be made. Both species have a highly folded spermoviduct and a moderately long bursa copulatrix with an elongate sac. The flagellum is long and slender with only a single internal crypt in the adjacent epiphallus, indicating a spermatophore with a single unbranched spine. The penial anatomy varies between the two species and features a combination of longitudinal pilasters and circular pilasters or pustules.

Two small semislugs so far placed together in the genus Peloparion are similar in shell shape and size and both have rounded, black-lined shell lappets. However, while they cannot be separated based on their shell shape $(\mathrm{P}>0.2)$, Ubiquitarion iridis is significantly smaller (SH, SD: P < 0.0001) and they can be clearly distinguished on an H/D scatterplot (Fig. 1D). Their genital anatomy is also rather similar, with a medium length, tubular penis, a short vagina and a moderate length bursa copulatrix. However, the epiphallus, flagellum, spermatophore and penis interior differ considerably.

\section{Molecular analyses}

The final concatenated sequence dataset contained a total of 96 sequences of $16 \mathrm{~S}$, including 14 Genbank sequences, and $93 \mathrm{COI}$ sequences, including 12 Genbank sequences. Some samples have been represented by ei- ther only the COI or $16 \mathrm{~S}$ sequence while the lacking sequence fragment was coded as missing data. However, we had usually at least one complete set of sequences for each species identified by comparative morphology. The final 16S alignment had a total length of 1,123 aligned nucleotide positions. This alignment was used to calculate uncorrected p-distances between all sequences. Of these 1,123 alignment positions, 859 were retained after removing ambiguous alignment positions with Gblocks for subsequent phylogenetic analysis.

The time-reversible model with invariant sites and a gamma distribution of rates (GTR+I+G; Tavaré, 1986) has been found to be the best-fit model of sequence evolution for both the $16 \mathrm{~S}$ and COI sequence datasets by means of both the Bayesian and Akaike Information Criterion. Xia's et al. (2003) test indicated no or little saturation in both mitochondrial fragments (Iss < Iss.c with $\mathrm{P}<0.001$ ).

The best maximum likelihood tree (Fig. 2) was rooted by using the designated out-group sequences, which were selected based on the phylogenetic tree presented by Hyman et al. (2007). Among the in-group, the southeastern Australian helicarionid radiation, some but not all genera as currently circumscribed have been retrieved as monophyletic groups. While the monophyly of Brevisentis, and Cucullarion as presently delimited has been confirmed with high nodal support, the genera Mysticarion, Peloparion, Parmavitrina and Desidarion have each been found to be polyphyletic with generally high bootstrapping support.

The analysis of the concatenated dataset revealed the sister pair of Helicarion spp. and 'Peloparion' iridis to form the most basal offshoot among the southeastern Australian radiation. Cucullarion was found to be the sister of all remaining in-group clades containing Parmavitrina+Desidarion, Brevisentis, Peloparion helenae, and Mysticarion, respectively (Fig. 2). However, there was usually only weak nodal support for the principal branching patterns in the phylogenetic tree. In order to explore this instability further, we have analysed the two sequence datasets separately. These analyses revealed that the two mitochondrial fragments supported vastly different topologies with respect to the relationships between the principal clades (Figs 3-4). In particular the COI tree is characterized by extremely low nodal support for the relationships among the principal clades. Moreover, the in-group was non-monophyletic as Helicarion clustered among the out-group taxa (Fig. 3). By contrast, in the $16 \mathrm{~S}$ tree the monophyly of the in-group is wellsupported while the relationships among its principal 


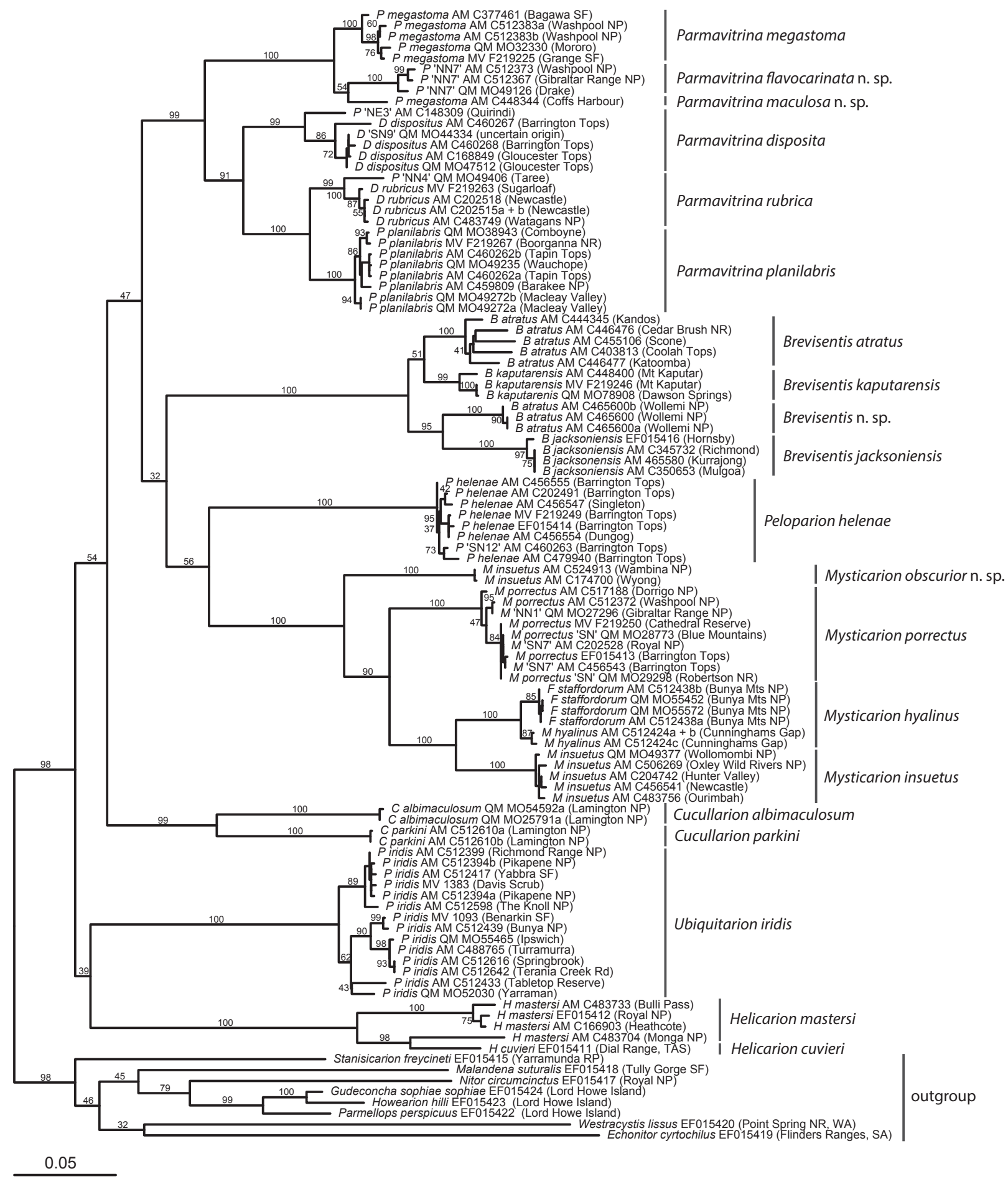

Fig. 2. Best maximum likelihood tree based on analysis of the concatenated data set of fragments of the mitochondrial genes $16 \mathrm{~S}$ and COI. Ambiguous alignment sites in $16 \mathrm{~S}$ removed by using Gblocks. Numbers on branches indicate nodal support based on 200 thorough bootstrap replicates for a total of 10 independent runs. Scale bar indicating $5 \%$ of modelled sequence divergence. 


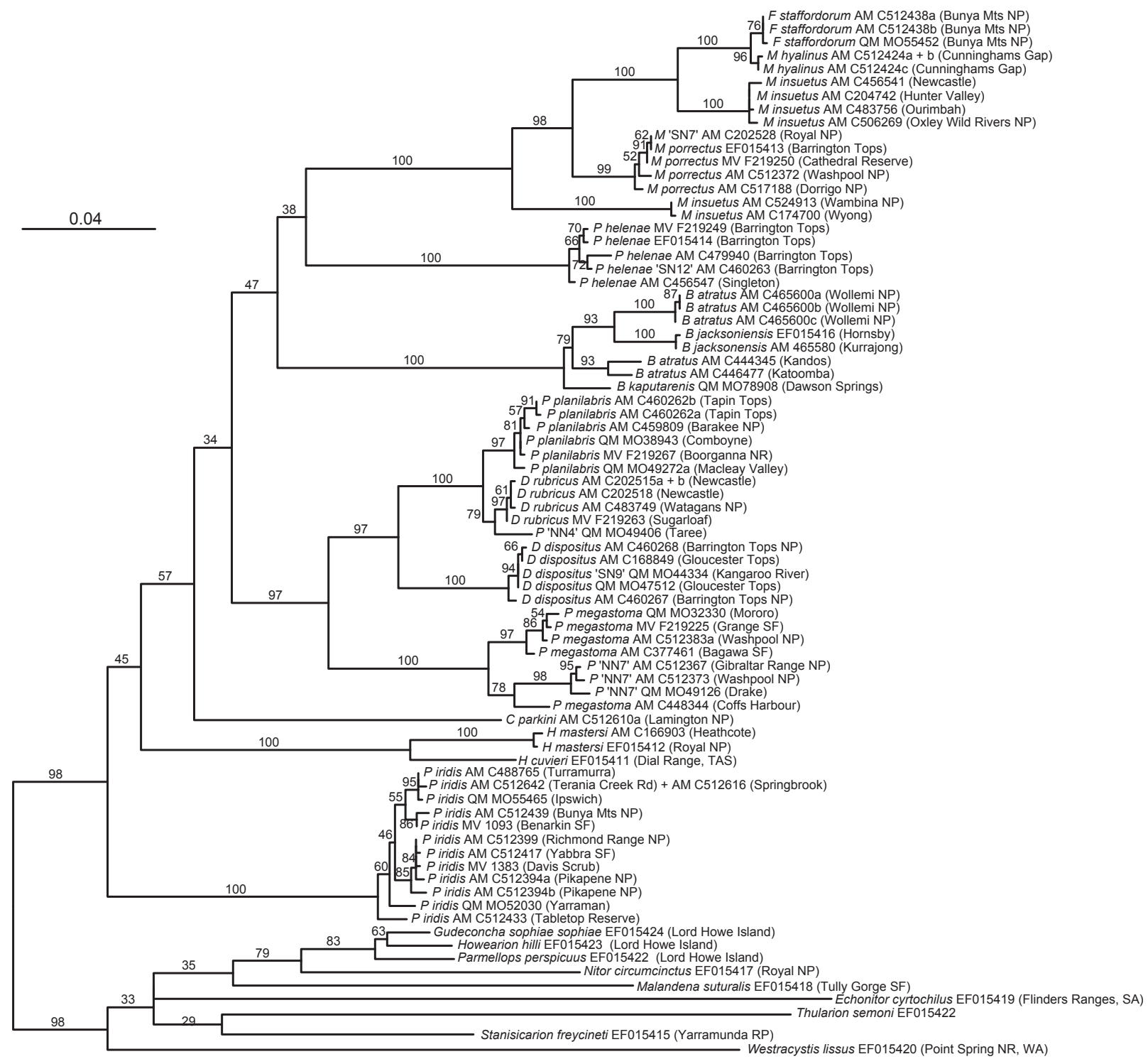

Fig. 3. Best maximum likelihood tree based on analysis of the fragment of the mitochondrial gene COI. Numbers on branches indicate nodal support based on 200 thorough bootstrap replicates for a total of 10 independent runs. Scale bar indicating $4 \%$ of modelled sequence divergence.

clades attracted weak nodal support only (Fig. 4).

By contrast to relationships among principal branches, the relationships among the tips of the tree are consistently well-supported and there has been little, if any, conflict between the topologies produced for different data sets. Some noteworthy findings are that among Brevisentis, specimens from Wollemi NP identified as B. atratus do not cluster with any of the three currently recognized species, and are thought to represent a yet undescribed species. However, because of the lack of reproductively mature specimens, we currently refrain from naming this species.

We also found that Mysticarion is monophyletic only if Fastosarion staffordorum is included. Sequences of this taxon group closely with $M$. hyalinus with very little genetic differentiation (Tables 1-2). The rather small amount of genetic differentiation confirms that $M$. porrectus, once suggested to be a species complex, is simply a widely distributed species. Specimens initially identified as $M$. insuetus occupied two highly 


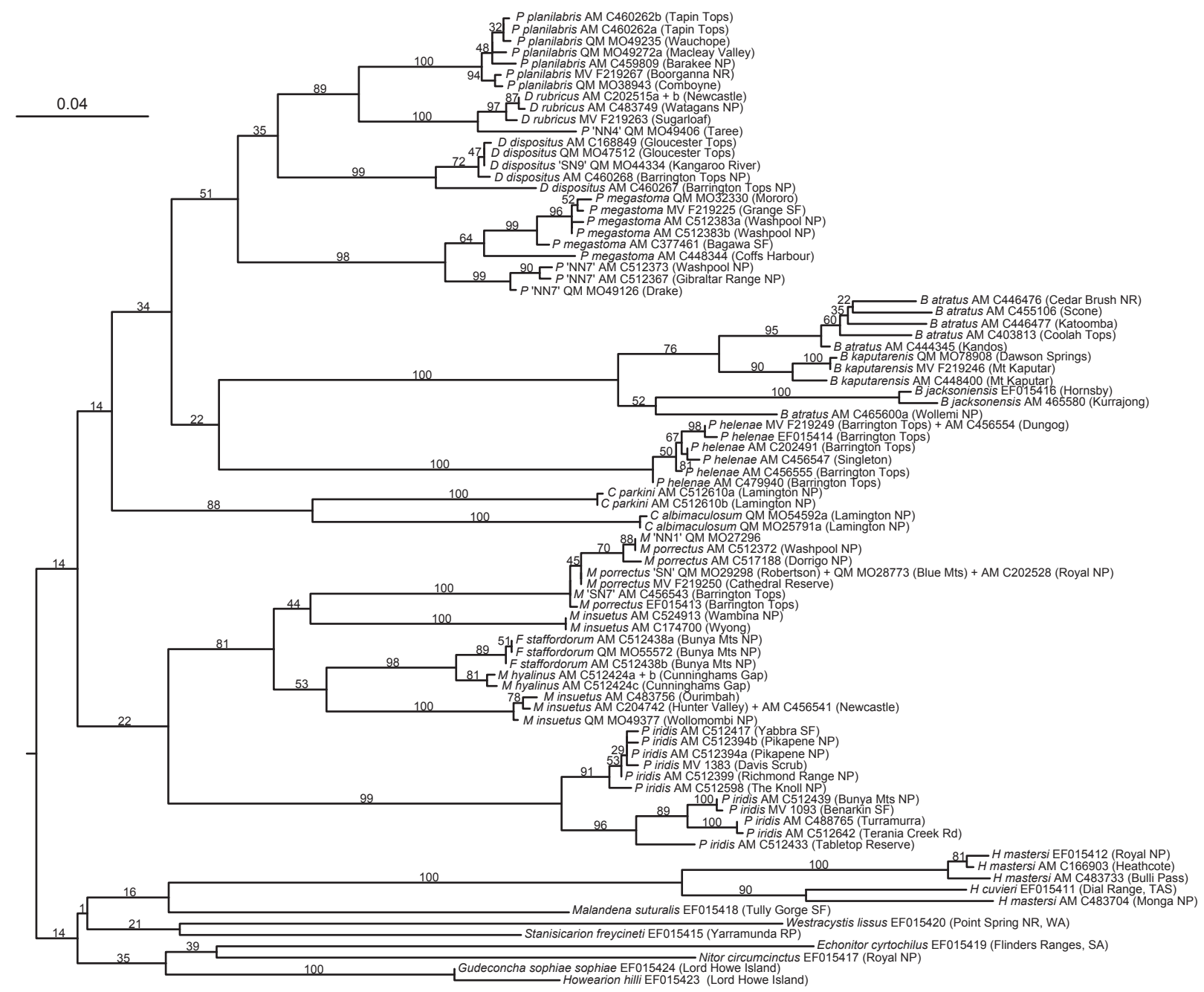

Fig. 4. Best maximum likelihood tree based on analysis of the fragment of the mitochondrial gene 16S. Ambiguous alignment sites removed by using Gblocks. Numbers on branches indicate nodal support based on 200 thorough bootstrap replicates for a total of 10 independent runs. Scale bar indicating $4 \%$ of modelled sequence divergence.

distinct clades. This genetic differentiation is underpinned by subtle morphological differences that are in support of the taxonomic distinctiveness of these two previously unrecognized groups. Based on the specimens from the Hunter Valley, we describe a new species, M. obscurior sp. nov., below. Neither Desidarion nor Parmavitrina are monophyletic: Parmavitrina planilabris groups very closely with both $D$. rubricus and $D$. dispositus. The two Desidarion species also share a number of morphological characters with
Parmavitrina; based on these similarities we treat both genus names as synonyms below. One population of D. rubricus from around Taree shows some genetic divergence. However, this is accompanied by insignificant anatomical differences. The two new species $P$. maculosa sp. nov. and $P$. flavocarinata sp. nov., recognized by their morphology, group closely with P. megastoma. The two species currently placed in Peloparion, $P$. helenae and $P$. iridis, do not group together; based on this and on considerable anatomical differences, 
Table 1. Average pairwise distances in $16 \mathrm{~S}$ within and between species under pairwise removal of gaps.

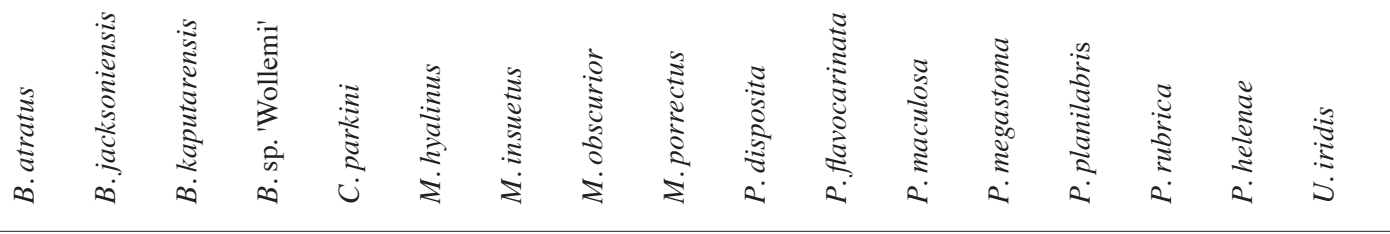

\begin{tabular}{|c|c|c|c|c|c|c|c|c|c|c|c|c|c|c|c|c|c|}
\hline B. atratus & 0.022 & & & & & & & & & & & & & & & & \\
\hline B.jacksoniensis & 0.046 & 0.002 & & & & & & & & & & & & & & & \\
\hline B. kaputarensis & 0.042 & 0.045 & 0.001 & & & & & & & & & & & & & & \\
\hline B. sp. 'Wollemi' & 0.058 & 0.042 & 0.052 & 0.001 & & & & & & & & & & & & & \\
\hline C.parkini & 0.151 & 0.157 & 0.157 & 0.172 & 0.000 & & & & & & & & & & & & \\
\hline M. hyalinus & 0.149 & 0.159 & 0.151 & 0.162 & 0.154 & 0.005 & & & & & & & & & & & \\
\hline M. insuetus & 0.159 & 0.164 & 0.160 & 0.171 & 0.159 & 0.051 & 0.004 & & & & & & & & & & \\
\hline M. obscurior & 0.157 & 0.157 & 0.156 & 0.163 & 0.148 & 0.097 & 0.104 & 0.001 & & & & & & & & & \\
\hline M.porrectus & 0.137 & 0.138 & 0.132 & 0.149 & 0.136 & 0.071 & 0.070 & 0.078 & 0.005 & & & & & & & & \\
\hline P. disposita & 0.150 & 0.152 & 0.150 & 0.163 & 0.134 & 0.160 & 0.173 & 0.155 & 0.137 & 0.009 & & & & & & & \\
\hline P. flavocarinata & 0.156 & 0.153 & 0.156 & 0.167 & 0.141 & 0.178 & 0.189 & 0.171 & 0.150 & 0.100 & 0.007 & & & & & & \\
\hline P. maculosa & 0.148 & 0.146 & 0.145 & 0.158 & 0.143 & 0.173 & 0.186 & 0.168 & 0.144 & 0.095 & 0.032 & - & & & & & \\
\hline P. megastoma & 0.145 & 0.144 & 0.143 & 0.159 & 0.144 & 0.171 & 0.179 & 0.170 & 0.138 & 0.096 & 0.046 & 0.033 & 0.006 & & & & \\
\hline P. planilabris & 0.147 & 0.143 & 0.144 & 0.155 & 0.146 & 0.174 & 0.189 & 0.164 & 0.149 & 0.070 & 0.112 & 0.110 & 0.114 & 0.006 & & & \\
\hline P. rubrica & 0.146 & 0.142 & 0.144 & 0.160 & 0.141 & 0.169 & 0.184 & 0.162 & 0.145 & 0.065 & 0.104 & 0.101 & 0.109 & 0.029 & 0.007 & & \\
\hline P. helenae & 0.135 & 0.129 & 0.129 & 0.144 & 0.135 & 0.147 & 0.165 & 0.140 & 0.124 & 0.124 & 0.140 & 0.133 & 0.135 & 0.130 & 0.128 & 0.007 & \\
\hline$U$. iridis & 0.163 & 0.158 & 0.160 & 0.168 & 0.145 & 0.176 & 0.194 & 0.164 & 0.150 & 0.139 & 0.146 & 0.147 & 0.148 & 0.151 & 0.147 & 0.141 & 0.016 \\
\hline
\end{tabular}
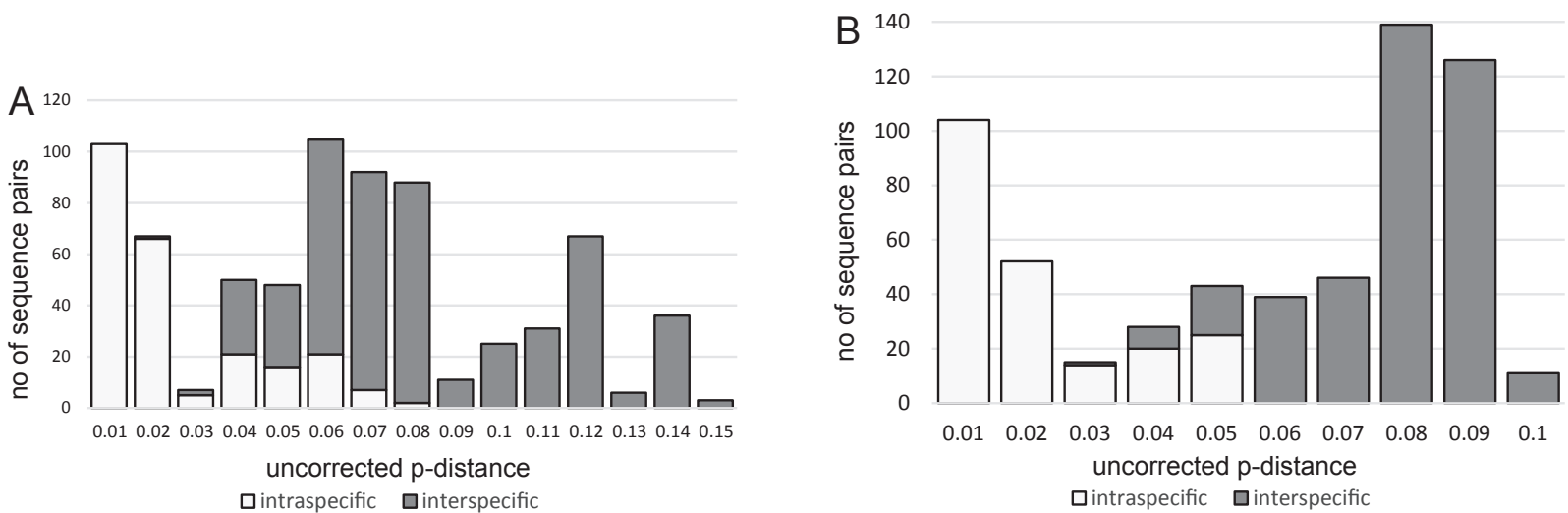

Fig. 5. Comparison of intra- and interspecific genetic p-distances for the two mitochondrial fragments analysed. A. Frequency distributions of distances in COI. B. Frequency distributions of distances in $16 \mathrm{~S}$.

we describe a new genus for $P$. iridis below.

The evolutionary divergence within and between species was estimated by calculating uncorrected pairwise distances across all sequences. We found that range of intraspecific distances in COI (0-0.04) and $16 \mathrm{~S}(0-0.72)$ overlapped with the range of interspecific distances in both genes to some degree (COI: 0.029-
0.157; 16S: 0.02-0.234) (Fig. 5, Tables 1-2). However, there has been no overlap between the average intraspecific distances per species $(<0.028$, on average 0.011 in $\mathrm{COI} ;<0.022$, on average 0.006 in $16 \mathrm{~S}$ ) and the average interspecific distance between any two congeners (0.036-0.095, on average 0.072 in COI; $0.029-0.114$, on average 0.073 in $16 \mathrm{~S}$ ). 
Table 2. Average pairwise distances in COI within and between species.

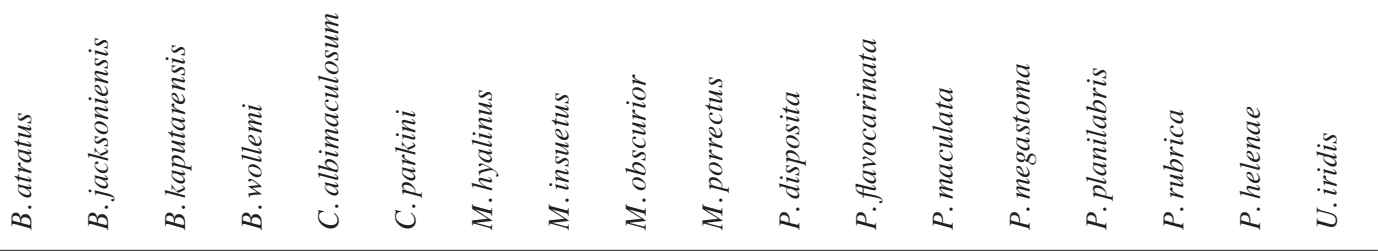

\section{$\begin{array}{ll}\text { B. atratus } & \mathbf{0 . 0 2 8} \\ \text { B. jacksoniensis } & 0.086 \mathbf{0 . 0 1}\end{array}$}

B. kaputarensis $0.054 \quad 0.083 \mathbf{0 . 0 1 2}$

$\begin{array}{lllll}\text { B.wollemi } & 0.065 & 0.067 & 0.067 & \text { - }\end{array}$

$\begin{array}{llllll}\text { C. albimaculosum } & 0.151 & 0.136 & 0.134 & 0.132 & \mathbf{0 . 0 0 2}\end{array}$

$\begin{array}{llllllll}\text { C. parkini } & 0.135 & 0.137 & 0.131 & 0.122 & 0.095 & \mathbf{0 . 0 0 1}\end{array}$

$\begin{array}{lllllllll}\text { M.hyalinus } & 0.124 & 0.124 & 0.115 & 0.106 & 0.112 & 0.121 & \mathbf{0 . 0 1 1}\end{array}$

$\begin{array}{lllllllll}M \text {. insuetus } & 0.131 & 0.142 & 0.128 & 0.121 & 0.131 & 0.128 & 0.063 & \mathbf{0 . 0 0 4}\end{array}$

$\begin{array}{llllllllll}\text { M. obscurior } & 0.127 & 0.135 & 0.129 & 0.122 & 0.130 & 0.111 & 0.077 & 0.081 & \mathbf{0}\end{array}$

$\begin{array}{llllllllllll}M . \text { porrectus } & 0.132 & 0.137 & 0.128 & 0.120 & 0.130 & 0.125 & 0.071 & 0.086 & 0.077 & \mathbf{0 . 0 0 7}\end{array}$

$\begin{array}{llllllllllll}\text { P. disposita } & 0.120 & 0.121 & 0.112 & 0.107 & 0.104 & 0.103 & 0.099 & 0.109 & 0.108 & 0.112 & \mathbf{0 . 0 1 4}\end{array}$

$\begin{array}{lllllllllllll}\text { P.flavocarinata } & 0.118 & 0.109 & 0.113 & 0.117 & 0.113 & 0.116 & 0.112 & 0.111 & 0.119 & 0.122 & 0.079 & \mathbf{0 . 0 0 8}\end{array}$

$\begin{array}{llllllllllllll}\text { P. maculata } & 0.119 & 0.115 & 0.115 & 0.104 & 0.115 & 0.118 & 0.103 & 0.112 & 0.114 & 0.114 & 0.079 & 0.041 & \text { - }\end{array}$

$\begin{array}{lllllllllllllll}\text { P. megastoma } & 0.112 & 0.112 & 0.113 & 0.107 & 0.118 & 0.122 & 0.108 & 0.108 & 0.121 & 0.119 & 0.081 & 0.041 & 0.036 & \mathbf{0 . 0 0 7}\end{array}$

$\begin{array}{llllllllllllllll}\text { P.planilabris } & 0.124 & 0.125 & 0.113 & 0.118 & 0.111 & 0.103 & 0.093 & 0.093 & 0.095 & 0.100 & 0.075 & 0.081 & 0.081 & 0.084 & \mathbf{0 . 0 0 8}\end{array}$

$\begin{array}{lllllllllllllllll}P . \text { rubrica } & 0.121 & 0.120 & 0.119 & 0.110 & 0.118 & 0.110 & 0.097 & 0.096 & 0.104 & 0.104 & 0.072 & 0.079 & 0.079 & 0.085 & 0.053 & \mathbf{0 . 0 1 3}\end{array}$

$\begin{array}{llllllllllllllllll}P . \text { helenae } & 0.129 & 0.132 & 0.130 & 0.125 & 0.129 & 0.117 & 0.103 & 0.104 & 0.099 & 0.105 & 0.094 & 0.110 & 0.103 & 0.110 & 0.106 & 0.100 & \mathbf{0 . 0 0 7}\end{array}$

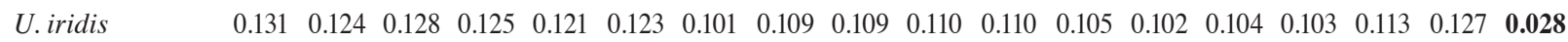

\section{Discussion}

\section{Phylogenetic relationships and genus-level taxonomy}

The southeastern Australian helicarionid clade has previously been identified as a monophyletic radiation (Hyman et al., 2007; Hyman and Ponder, 2010) containing at least five genera (Helicarion, Brevisentis, Mysticarion, Parmavitrina and Peloparion). Here we expand this group to include Cucullarion and Ubiquitarion gen. nov. Synapomorphies of this clade include a spermatophore with spirally arranged branched spines, an epiphallic flagellum with internal cryptae, the absence of an epiphallic caecum and the presence of at most a very short vagina.

The reproductive characters that define this group occur singly or in combination in a number of other helicarionid taxa. For example, some species from northeastern Queensland have a spiraling, spinose spermatophore (e.g. Pravonitor kreffti, Hyman and Ponder, 2010) but do not share the other morphological characters. There are also several species with no epiphallic caecum (e.g. Levidens, Tarocystis, Sheaia, Hyman and Ponder, 2010). However, whether these similarities are symplesiomorphies of a larger helicarionid radiation or have indeed been acquired in convergence can only be resolved in the framework of a more complete phylogenetic analysis of the Australian Helicarionidae.

The members of the southeastern Australian clade represent a significant proportion of the ecological and morphological diversity of all Australian Helicarionidae. Members of this group are either leaf litter dwellers with fully developed shells (Brevisentis), small, arboreal or semi-arboreal semislugs (Peloparion, Ubiqutarion, Mysticarion), small to large litter-dwelling semislugs (Helicarion, Parmavitrina), or mediumsized semi-arboreal semislugs with a strongly reduced shell (Cucullarion).

Due to these significant differences in their general morphology and ecology, the south-eastern Australian helicarionids provide a suitable model to study evolutionary phenomena which have also occurred in the broader Australian Helicarionid radiation, such as limacisation.

Within this group, we found that all genera as now delimited formed well-supported (in terms of nodal support) and well-individualized (in terms of branch lengths) clades in the mitochondrial phylogenies. 
A

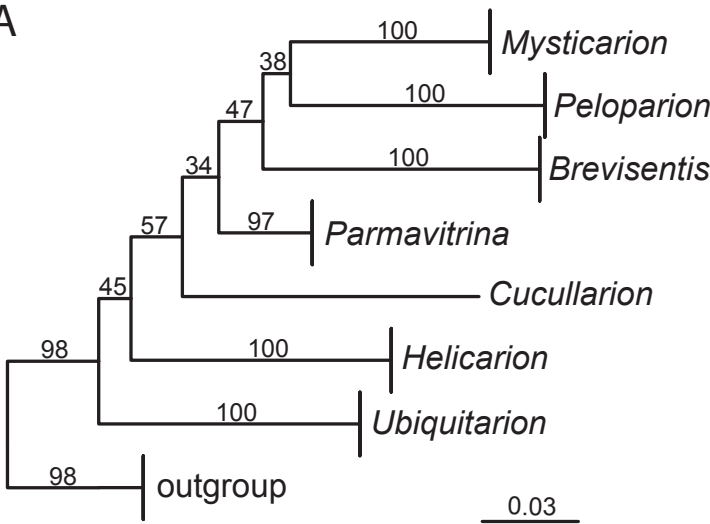

B

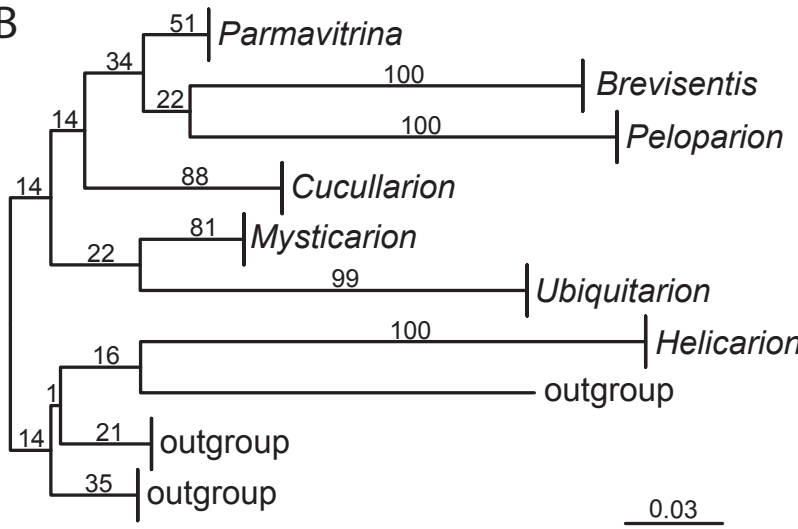

Fig. 6. Comparison of principal branching patterns of the best maximum likelihood trees produced for the single gene data sets (tips collapsed at genus-level). A. Backbone tree for 16S. B. Backbone tree for COI. Numbers on branches indicate nodal support based on 200 thorough bootstrap replicates for a total of 10 independent runs. Scale bar indicating $3 \%$ of modelled sequence divergence.

However, the phylogenetic relationships between these clades were poorly supported by bootstrapping, leading to substantially inconsistent topologies produced for different sequence datasets (COI, 16S, concatenated; Fig. 6). This lack of confidence in principal divisions in the phylogenetic tree poses a challenge to the inference of evolutionary trends among the southeastern helicarionid radiation.

However, it is still possible to draw some general inferences relating to character evolution in this group. Brevisentis, the only snail genus included in this study, was never the sister taxon to the rest of the clade. Consequently, under the premise that a fully developed shell represents the ancestral character state in this clade, shell reduction must have either been reversed in Brevisentis or has independently evolved multiple times within this clade. Some signs of slight shell reduction have been observed in the digestive and reproductive systems of Brevisentis jacksoniensis (Hyman, submitted), which may indicate a reversal of limacisation in Brevisentis. In any case, given the variability of body form in this group, shell reduction has evolved to a higher degree in some lineages (e.g., the rainforest semislugs belonging to Cucullarion and the Parmavitrina megastoma group) than in others (e.g., Mysticarion).

\section{Systematic significance of reproductive characteristics}

The southeastern helicarionid radiation is characterized by several morphological characters, including the absence of an epiphallic caecum, a flagellum producing a spinose spermatophore, and a short or absent vagina (Hyman and Ponder, 2010). The function of the epiphallus and epiphallic flagellum is to produce the spermatophore, the tail-pipe forming in the flagellum and the capsule in the epiphallus. The epiphallic caecum is believed to function in turning the spermatophore so that the tail-pipe is moved into the penis first (Dasen, 1933; Van Mol, 1970). In this group, the absence of the epipahllic caecum may be compensated for by the presence of a spermatophore with a relatively short tail-pipe. In Australian helicarionids that do have an epiphallic caecum, a considerably longer flagellum (and therefore a longer spermatophore tail-pipe) is present (e.g., Nitor, Fastosarion, Westracystis; Hyman and Ponder, 2010). There are also a number of species that lack both the epiphallic flagellum and the epiphallic caecum (e.g., Levidens, Sheaia, Tarocystis, Echonitor, Periclocystis). This may indicate a correlation between the presence of the epiphallic caecum and the length of the spermatophore tail-pipe in Helicarionidae.

The presence of the epiphallic flagellum and caecum characterizes the superfamily Helicarionoidea (Helicarionidae, Ariophantidae, Urocyclidae), but both organs have probably been repeatedly lost in all three groups (Hausdorf, 1998; Hyman and Ponder, 2010).

Similarly, genital characters, such as flagellum, epiphallus, and penial sheath, have repeatedly been lost (and possibly been regained occasionally) by members of Camaenidae (Köhler and Criscione, 2015). These findings highlight the evolutionary plasticity of land snail genitalia in general and underpin the conclusion that while usually useful at lower taxonomic levels, 
they should be used with care and in conjunction with other characters when defining broader taxonomic groups.

\section{Significance of morphological and mitochondrial characters in species delimitation}

The most consistent and reliable character for species delimitation in every group was the internal anatomy of the penis, along with other genital characters relating to the penis, epiphallus and spermatophore. The sculpture of the penis interior was informative at both genus and species level, with a general pattern observed within a genus (for example, longitudinal pilasters and the presence of a penial verge in Mysticarion) and a unique, highly consistent anatomy in each species (for example, number and shape of longitudinal pilasters, size and shape of penial verge). Similarly, the spermatophore provided useful characters at both genus and species level; however, the small number of spermatophores collected limited the value of this character somewhat. Variation in the spermatophore is reflected in the shape of the flagellum, and although less detail is available, in some cases differences in the flagellum shape were sufficient to infer differences in the spermatophore.

Penis morphology shows great variation among land snails and is generally species-specific, supporting the hypothesis that it is an important factor in species recognition during copulation (Gómez, 2001). It is likely that the spermatophore plays a similar role (Gómez, 2001). In the related slug family Milacidae, spermatophores are also heavily sculptured with branching spines and hooks, and are highly speciesspecific, in some cases providing the most useful means of species discrimination (Wiktor, 1987).

Body colour and shell dimensions, which are of high value in rapid, non-expert identification, were also informative characters in species delimitation in many groups. Body colour was consistent within species, although preserved specimens were faded, making colour markings sometimes difficult to accurately assess. In particular, Mysticarion obscurior, which cooccurs with congeners $M$. porrectus and M. insuetus and was often misidentified in museum collections, could reliably be distinguished in life by its darker body colour and in faded alcohol-preserved specimens by the disjunct black markings on the right shell lappet. Even in alcohol-preserved specimens body colour could be used to distinguish species in Cucullarion and Brevisentis, but was less informative in Parmavit- rina, where colour differences are more subtle.

Characters relating to the shell, commonly used in land snail identification, are now thought to be significantly influenced by environmental factors and as a result can show high levels of both convergence and conservatism (Stankowski, 2011; Criscione and Köhler, 2013a; Köhler and Criscione, 2015). Within the south-eastern Australian helicarionid clade there is great diversity in shell form, ranging from snails with a complete shell to semislugs with a highly reduced shell. Gross shell shape was therefore an important character in the separation of genera, although convergence was evident in (for example) the semislugs Peloparion helenae and Ubiquitarion iridis. At the species level, differences in shell size and shape (primarily height-to-diameter ratio) were informative, particularly in Brevisentis, Mysticarion and Parmavitrina, although differences were slight and in many cases could not reliably be used as a sole means of identification. Protoconch microsculpture has been used to delimit genera in many Australian land snails including the Helicarionidae (Stanisic et al., 2010); however, we did not find significant differences in shell microsculpture, with the exception of a unique sculpture of notched spiral grooves on the protoconch of Mysticarion.

Species delimited by their morphology were consistently found to form monophyletic clusters in the mitochondrial trees, which usually were well separated from each other by long basal branches. The amounts of interspecific genetic differentiation observed here were at the lower end of the rather wide spectrum of average interspecific differences among stylommatophoran land snails (Davison et al., 2009; Criscione et al., 2012; Köhler and Johnson, 2012; Criscione and Köhler, 2013b; Burghardt and Köhler, 2014). In addition, there has been considerable overlap between the ranges of intraspecific and interspecific distances in the southeastern Australian helicarionids, particularly in 16S (Fig. 5). This overlap is attributable primarily to the high intraspecific variation in the widespread Ubiquitarion iridis, and the comparatively low interspecific variation among $P$. megastoma, $P$. flavocarinata and P. maculosa. However, we consider the differences in the penial complex as sufficient to justify their separation as distinct species, particularly given that two of them occur in sympatry with each other. The particularly low interspecific distances among these three species are probably indicative of their rather recent origin.

The highest intraspecific differences among the 
studied species were observed in Ubiquitarion iridis (COI 2.8\%, 16S 2.2\%) and Brevisentis atratus (COI $2.8 \%, 16 \mathrm{~S} 1.6 \%$ ). In neither case was this reflected by any morphological differentiation nor were these distances remarkable when compared with other land snail groups (e.g., Davison et al., 2009). In contrast to the abovementioned species, we found that the two sympatric species of Cucullarion exhibit a high degree of genetic distinctiveness while being distinguished by rather subtle anatomical differences.

Our findings of such inconsistent amounts of morphological and mitochondrial differentiation among the examined species confirm that species are best delimited by combining the appraisals of their morphological and mitochondrial differentiation.

\section{Species distributions}

Southeastern Australian helicarionids exhibit varied distributional patterns. We have found very broad ranges of up to $500 \mathrm{~km}$ in Mysticarion and $750 \mathrm{~km}$ in Ubiquitarion (although Ubiquitarion is thought to be introduced into the southern part of its range, and its natural range is probably closer to $400 \mathrm{~km}$; Stanisic, pers. comm.). Species belonging to both genera are arboreal and when not actively crawling, sit in a resting posture on the underside of leaves. They are likely to be subjected to greater passive dispersal by wind than litter-dwelling species, such as Brevisentis. While $M$. hyalinus is allopatric with respect to its congeners, the other three species of Mysticarion are sympatric throughout much of their range. There is some evidence that $M$. porrectus inhabits higher altitude, moister areas and may not occur in micro-sympatry with the others; however, M. obscurior and $M$. insuetus have indeed been collected from the same locality. These two species are not sister taxa in the phylogenetic tree and their sympatry is probably secondary.

In contrast, the semi-arboreal taxa Peloparion and Cucullarion have relatively narrow ranges of around $30-50 \mathrm{~km}$ in diameter. Peloparion helenae lives under bark on trees or under grass (Stanisic et al., 2010). Cucullarion generally rests in the base of palm fronds or in leaf litter, only crawling on palm fronds and trunks during rain. Both are less prone to passive dispersal by wind than fully arboreal species. In addition, both groups have a high degree of shell reduction and may be more susceptible to desiccation, rendering them rather poor dispersers.

The litter-dwelling taxa Brevisentis and Parmavit- rina also exhibit restricted distributions, with ranges of about $30 \mathrm{~km}$ (B. kaputarensis) up to about $300 \mathrm{~km}$ (B. atratus, $P$. planilabris, $P$. rubrica).

\section{Acknowledgements}

This work has been made possible through financial support from the Australian Government (ABRS grant RF215-49), which is thankfully acknowledged. Furthermore, we extend our thanks to Adnan Moussalli, Alison Miller, Chris Rowley, Daryl Potter, Francesco Criscione, John Stanisic, Luisa Teasdale, Mandy Reid, and Michael Shea for providing material, for assistance with loans, and for helping with field work. We are also grateful to Michael Shea for carrying out the anatomical drawings. Finally, we would like to thank two reviewers, John Stanisic and Bernhard Hausdorf, for carefully reading and constructively commenting on an earlier version of this manuscript. Their reviews have helped to improve the quality of this work.

\section{References}

Brazier J. 1875a. Description of fourteen new species of terrestrial, fluviatile and marine shells from Australia and the Solomon Islands. Proceedings of the Linnaean Society of New South Wales 1: 1-9.

Brazier J. 1875b. Descriptions of eleven new species of terrestrial and marine shells from north-east Australia. Proceedings of the Zoological Society of London 1874: 668-672.

Brazier J. 1876a. List of land shells collected during the Chevert Expedition. Proceedings of the Linnean Society of New South Wales 1: 117-133.

Brazier J. 1876b. Descriptions of thirty-five new species of land shells from New Guinea, Australia, and islands in the Torres Straits, collected during the Chevert Expedition. Proceedings of the Linnean Society of New South Wales 1: 98-113.

Burghardt I, Köhler F. 2014. Rhagada revisited: on the taxonomy of species from the Kimberley and Dampierland, Western Australia (Pulmonata, Camaenidae). Molluscan Research 35: 37-50. http://dx.doi.org/10.1080/13235818.2014.940637

Castresana J. 2000. Selection of conserved blocks from multiple alignments for their use in phylogenetic analysis. Molecular Biology and Evolution 17: 540-552.

Cox JC. 1864. Catalogue of the specimens of the Australian land-shells in the collection of James C. Cox.

Cox JC. 1866. Description d'espèces nouvelles provenant d'Australie et des îles Solomon et Norfolk. Journal de Conchyliologie 14: 45-48.

Cox JC. 1868. A monograph of Australian land shells. Sydney: Maddock.

Cox JC. 1871. Descriptions of seven new species of Australian land shells. Proceedings of the Zoological Society of London 1871: 53-55.

Cox JC. 1873. Descriptions of new land-shells from Australia and the Solomon Islands. Proceedings of the Zoological Society of London 1873: 146-152.

Cox JC. 1909. A list of the subclass Pulmonata found in Australia, Part I., not including Tasmania, Lord Howe's Island 
(under the NSW Government), or the New Guinea Mainland and adjacent islands. Sydney: Frederick W. White.

Criscione F, Law ML, Köhler F. 2012. Land snail diversity in the monsoon tropics of Northern Australia: revision of the genus Exiligada Iredale, 1939 (Mollusca: Pulmonata: Camaenidae), with description of 13 new species. Zoological Journal of the Linnean Society 166: 689-722. http://dx.doi. org/10.1111/j.1096-3642.2012.00863.x

Criscione F, Köhler F. 2013a. Conserved shell disguises diversity in Mesodontrachia land snails from the Australian Monsoon Tropics (Gastropoda: Camaenidae). Zoologica Scripta 42: 389-405. http://dx.doi.org/10.1111/zsc.12011

Criscione F, Köhler F. 2013b. More on snails and islands: molecular systematics and taxonomic revision of Setobaudinia Iredale (Gastropoda: Camaenidae) from the Kimberley, Western Australia, with description of new taxa. Invertebrate Systematics 27: 634-654. http://dx.doi.org/10.1071/ IS13027

Dartnall AJ, Kershaw RC. 1978. Description of a new species of Helicarion (Stylommatophora: Helicarionidae) in Tasmania. Records of the Queen Victoria Museum 62: 1-18.

Dasen DD. 1933. Structure and function of the reproductive system in Ariophanta ligulata. Proceedings of the Zoological Society of London 1933: 97-118.

Davison A, Blackie RLE, Scothern GP. 2009. DNA barcoding of stylommatophoran land snails: a test of existing sequences. Molecular Ecology Resources 9: 1092-1101. http:// doi.org/10.1111/j.1755-0998.2009.02559.x

Folmer O, Black M, Hoeh W, Lutz R, Vrijenhoek R. 1994. DNA primers for amplification of mitochondrial cytochrome $\mathrm{c}$ oxidase subunit I from diverse metazoan invertebrates. Molecular Marine Biology and Biotechnology 3: 294-299.

Godwin-Austen HH. 1883. Land and Freshwater Mollusca of India, Including South Arabia, Baluchistan, Afghanistan, Kashmir, Nepal, Burmah, Pegu, Tenasserim, Malay Peninsula, Ceylon, and Other Islands of the Indian Ocean. Part IV. Supplementary to Messrs. Theobald and Hanley's Conchologica Indica. London: Taylor and Francis.

Gómez BJ. 2001. Structure and functioning of the reproductive system. Pp. 307-330 in: GM Barker, ed, The biology of terrestrial molluscs. Wallingford: CABI Publishing.

Gray JE. 1834. Characters of new species of shells. Proceedings of the Zoological Society of London 1834: 63-68.

Hausdorf B. 1998. Phylogeny of the Limacoidea sensu lato (Gastropoda: Stylommatophora). Journal of Molluscan Studies 64: 35-66.

Hedley C. 1888. A list of the land shells recorded from Queensland. Royal Society of Queensland 5: 45-70.

Hyman IT. 2007. Three new genera and five new species of Helicarionidae from southeastern Australia (Pulmonata: Stylommatophora: Helicarionoidea). Molluscan Research 27: 89-104.

Hyman IT, Ho YWS, Jermiin LS. 2007. Molecular phylogeny of Australian Helicarionidae, Euconulidae and related groups (Gastropoda: Pulmonata: Stylommatophora) based on mitochondrial DNA. Molecular Phylogenetics and Evolution 45: 792-812. http://doi.org/10.1016/j.ympev.2007.08.018

Hyman IT, Ponder WF. 2010. A morphological phylogenetic analysis and generic revision of Australian Helicarionidae (Gastropoda: Pulmonata: Stylommatophora), and an assessment of the relationships of the family. Zootaxa 2462: 1-148.
Hyman IT, Ponder WF. 2016. Helicarionidae (Gastropoda: Heterobranchia: Stylommatophora) of Lord Howe Island. Molluscan Research 36: 84-107. http://dx.doi.org/10.1080/13235 818.2015.1128568

Iredale T. 1933. Systematic notes on Australian land shells. Records of the Australian Museum 19: 37-59.

Iredale T. 1937a. A basic list of the land Mollusca of Australia. Part II. Australian Zoologist 9: 1-39.

Iredale T. 1937b. A basic list of the land Mollusca of Australia. Australian Zoologist 8: 287-333.

Iredale T. 1941. Guide to the land shells of New South Wales part III. The Australian Naturalist 11: 1-8.

Iredale T. 1942. Guide to the land shells of New South Wales part IV. The Australian Naturalist 11: 33-40.

Katoh K, Misawa K, Kuma K, Miyata T. 2002. MAFFT: a novel method for rapid multiple sequence alignment based on fast Fourier transform. Nucleic Acids Research 30: 30593066.

Kershaw RC. 1979. Redescription of Helicarion cuvieri from southern Tasmania and Helicarion freycineti from New South Wales (Pulmonata: Helicarionidae). Journal of the Malacological Society of Australia 4: 145-156.

Kershaw RC. 1981. Redescription of the genus Helicarion and of Helicarion niger (Quoy \& Gaimard, 1832) from Victoria (Stylommatophora: Helicarionidae). Journal of the Malacological Society of Australia 5: 17-31.

Köhler F. 2011. The camaenid species of the Kimberley Islands, Western Australia (Stylommatophora: Helicoidea). Malacologia 54: 203-406. http://dx.doi.org/10.4002/040.054.0108

Köhler F, Johnson MS. 2012. Species limits in molecular phylogenies: A cautionary tale from Australian land snails (Camaenidae: Amplirhagada). Zoological Journal of the Linnean Society 165: 337-362. http://dx.doi.org/10.1111/j.10 96-3642.2011.00810.x

Köhler F, Criscione F. 2015. A molecular phylogeny of camaenid land snails from north-western Australia unravels widespread homoplasy in morphological characters (Gastropoda, Helicoidea). Molecular Phylogenetics and Evolution 83: 4455. http://dx.doi.org/10.1016/j.ympev.2014.11.009

Kumar S, Stecher G, Tamura K. 2016. MEGA7: Molecular Evolutionary Genetics Analysis version 7.0 for bigger datasets. Molecular Biology and Evolution 33: 1870-1874. https://doi. org/10.1093/molbev/msw054

Pfeiffer L. 1849. Description of a new Helix and Streptaxis, from the collection of $\mathrm{H}$. Cuming, Esq. Proceedings of the Zoological Society of London 1848: 108-109.

Pfeiffer L. 1850. Descriptions of twelve new species of Vitrina and Succinea from the collection of H. Cuming, Esq. Proceedings of the Zoological Society of London 1849: 132-134.

Pfeiffer L. 1852. Descriptions of eighteen new species of land shells, from the collection of H. Cuming, Esq Proceedings of the Zoological Society of London 20: 83-87.

Pfeiffer L. 1853. Monographia heliceorum viventium: sistens descriptiones systematicas et criticas omnium hujus familiae generum et specierum hodie cognitarum. Lipsiae [Leipzig]: F.A. Brockhaus.

Pfeiffer L. 1855. Descriptions of thirty-eight new species of land shells, from the collection of H. Cuming, Esq Proceedings of the Zoological Society of London 23: 111-119.

Pfeiffer L. 1876. Monographia heliceorum viventium: sistens descriptiones systematicas et criticas omnium huius familiae 
generum et specierum hodie cognitarum. Lipsiae [Leipzig]: Brockhaus.

Pfeiffer L, Clessin S. 1881. Nomenclator heliceorum viventium Kassel.

Reeve LA. 1854. Monograph of the genus Helix, part II. In: LA Reeve, ed, Conchologia Iconica: or, illustrations of the shells of molluscous animals. London: Lovell Reeve.

Reeve LA. 1862. Monograph of the genus Vitrina. In: LA Reeve, ed, Conchologia Iconica: or, illustrations of the shells of molluscous animals. London: Lovell Reeve.

Scott B. 1995. Redescription of Fastosarion superba (Cox, 1871) with descriptions of two new species of Fastosarion from northern Queensland (Pulmonata: Helicarionidae). Molluscan Research 16: 69-80.

Silvestro D, Michalak I. 2012. A userfriendly graphical frontend for phylogenetic analyses using RAxML (Stamatakis, 2006). Organisms Diversity \& Evolution 12: 335-337.

Sites JW, Marshall JC. 2004. Operational criteria for delimiting species. Annual Review of Ecology Evolution and Systematics 35: 199-227. http://dx.doi.org/10.1007/s13127-011-0056-0

Smith BJ. 1992. Non-marine Mollusca. Pp. 1-408 in: WWK Houston, ed, Zoological Catalogue of Australia. Canberra: Australian Government Publishing Service.

Smith BJ, Reid S, Ponder WF 2002. Pulmonata. Australian Faunal Directory. Australian Biological Resources Study, Canberra. Available online at http://www.environment.gov. au/biodiversity/abrs/online-resources/fauna/afd/taxa/pulmonata [viewed on 29 October 2009]: ABRS.

Solem A. 1982. Small land snails from Northern Australia, II. Species of Westracystis Iredale, 1939 (Mollusca: Pulmonata, Helicarionidae). Journal of the Malacological Society of Australia 5: 175-193.

Solem A. 1988. Non-camaenid land snails of the Kimberley and Northern Territory, Australia. I. Affinities and ranges. Invertebrate Taxonomy 2: 455-604.

Stanisic J. 1993a. Eungarion mcdonaldi gen. et sp. nov., a montane semi-slug from mideastern Queensland rainforests (Pulmonata: Helicarionidae). Memoirs of the Queensland Museum 34: 27-34.

Stanisic J. 1993b. The identity of Helicarion semoni Martens, 1894: a large semi-slug from the Wet Tropics, northeastern Queensland (Pulmonata: Helicarionidae). Memoirs of the Queensland Museum 34: 1-9.

Stanisic J. 1998. A new semi-slug from Tamborine Mountain, Southeastern Queensland (Mollusca: Eupulmonata: Helicarionidae). Memoirs of the Queensland Museum 42: 597-603.
Stanisic J, Shea M, Potter D, Griffiths O. 2010. Australian land snails. 1. A field guide to eastern Australian species. Riviere des Anguilles, Mauritius: Bioculture Press.

Stankowski S. 2011. Extreme, continuous variation in an island snail: local diversification and association of shell form with the current environment. Biological Journal of the Linnean Society 104: 756-769. http://dx.doi.org/10.1111/j.1095-8312. 2011.01748.x

Tavaré S. 1986. Some probabilistic and statistical problems in the analysis of DNA sequences. Lectures on Mathematics in the Life Sciences 17: 57-86.

Tillier S. 1984. Patterns of digestive tract morphology in the limacisation of helicarionid, succineid and athoracophorid snails (Mollusca: Pulmonata). Malacologia 25: 173-192.

Tryon GW. 1885. Testacellidae, Oleacinidae, Streptaxidae, Helicoidea, Vitrinidae, Limacidae, Arionidae. Pp. 1-364, 60 pl. In: GW Tryon, ed, Manual of Conchology, structural and systematic, with illustrations of the species. Second series. Philadelphia: Conchological Section of the Academy of Natural Sciences of Philadelphia.

Tryon GW. 1886. Zonitidae. Pp. 1-259, 64 pl. In: GW Tryon, ed, Manual of Conchology, structural and systematic, with illustrations of the species. Second series. Philadelphia: Conchological Section of the Academy of Natural Sciences of Philadelphia.

Van Mol, J-J 1970. Anatomical studies in the families Urocyclidae and Helicarionidae: Pulmonata, Stylommatophora. American Malacological Union - Annual Reports for 1970: 57-58.

Wiktor A. 1987. Spermatophores in Milacidae and their significance for classification (Gastropoda, Pulmonata). Staatliches Museum für Tierkunde Dresden 12: 85-100.

Xia X, Xie Z, Salemi M, Chen L, Wang Y. 2003. An index of substitution saturation and its application. Molecular Phylogenetics and Evolution 26: 1-7.

Xia X, Lemey P. 2009. Assessing substitution saturation with DAMBE. Pp. 615-630 in: P Lemey, M Salemi, AM Vandamme, eds, The phylogenetic handbook: A practical approach to DNA and protein phylogeny. 2nd Edition. Cambridge: Cambridge University Press.

Received: 24 November 2016

Revised and accepted: 9 March 2017

Published online: 20 April 2017

Editor: S.E.T. van der Meij

\title{
Online supplementary material
}

\author{
S1. Examined materials.
}




\section{Appendix}

Zoobank Registration: 1sid:zoobank.org:pub:0CEB38 99-B108-48FD-96D5-0076A3966DB1

\section{Taxonomic account and descriptions}

Helicarionidae Bourguignat, 1877

Diagnosis. Shell present, complete or reduced, $5-35 \mathrm{~mm}$ in diameter; usually thin-walled, glossy; spiral grooves present on protoconch and teleoconch. Mantle with accessory lobes lying over body and shell lappets of variable size lying over shell. Sole of foot tripartite; caudal apparatus present, formed from curled up sole. Kidney unilobed; minor venation on roof of mantle cavity absent or present; mantle gland absent. Genital system oviparous; oviduct glandular. Bursa copulatrix variable in length; inserted on vagina or, if vagina absent, at junction of free oviduct and penis. Stimulator absent. Epiphallus enters penis through simple pore, fleshy lips or verge; interior of penis variable. Penial tunica present, open at proximal end, attached by muscle fibres to epiphallus. Epiphallic retractor caecum absent or present; epiphallic flagellum absent or present; where present, flagellum contains an axial filament. Spermatophore a soft capsule with hard-walled tail-pipe.

Remarks. Belongs to Helicarionoidea along with Ariophantidae and Urocyclidae; a superfamily unified by the presence of a flagellum with an axial filament, an epiphallic caecum, and mantle lobes (Hausdorf, 1998; Hyman and Ponder, 2010). However, flagellum and caecum are absent, presumably secondarily lost, in some members of all three families (e.g. Tarocystis, Sheaia, Levidens; Hausdorf, 1998; Hyman and Ponder, 2010). The boundaries of the three families are poorly defined; one character, presence of a proximally open penial tunica, distinguishes Helicarionidae from the other two families (Hausdorf, 1998; Hyman and Ponder, 2010).
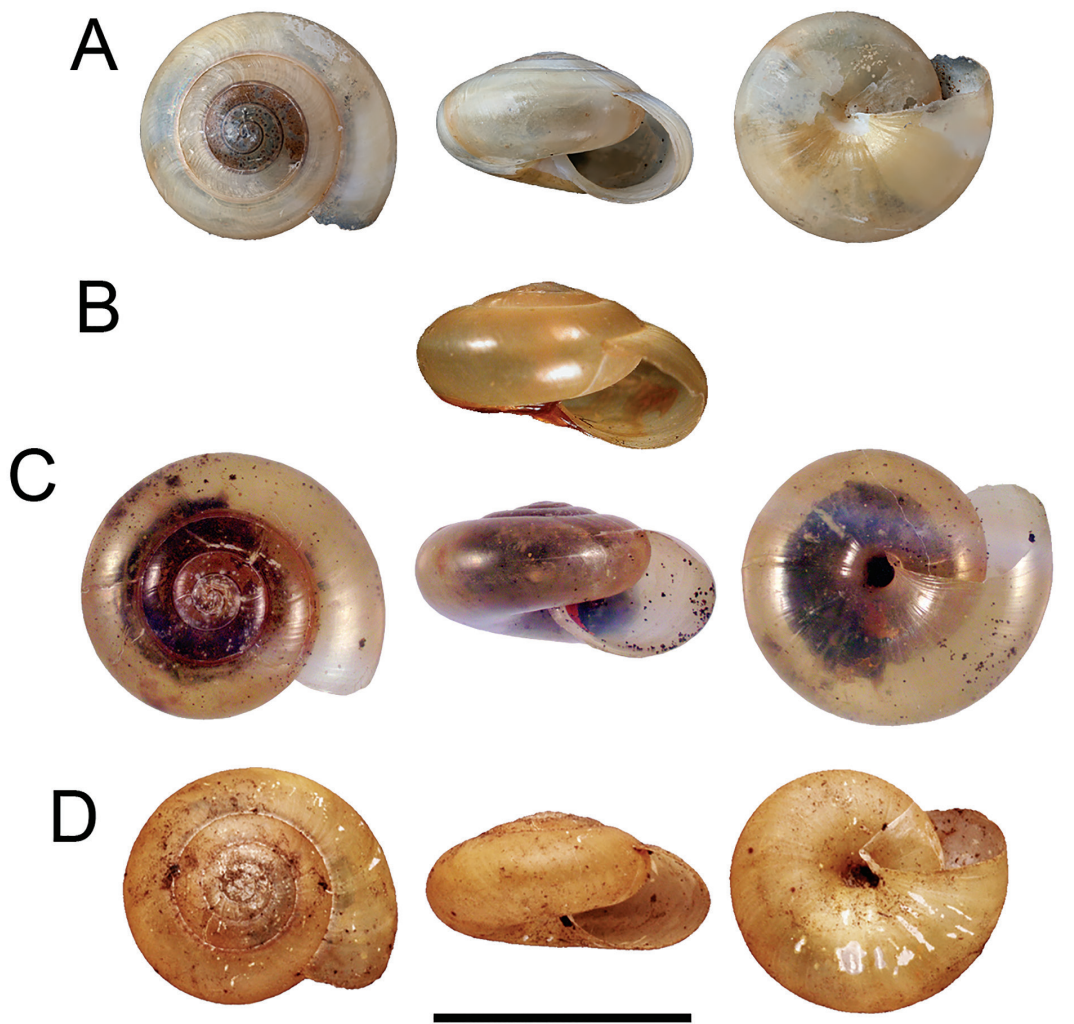

Fig. 7. Shells of Brevisentis. A-B. B. jacksoniensis: A. Syntype of Helix jacksoniensis NHMUK 20160421 (photographer: NHMUK). B. Holotype of Expocystis exclusus AM C.101143 (size indicative; photographer: AM). C. B. atratus AM C.455107. D. B. kaputarensis holotype QM MO49155 (size indicative; photographer: Michael Murphy). Scale bar $=10 \mathrm{~mm}$. 

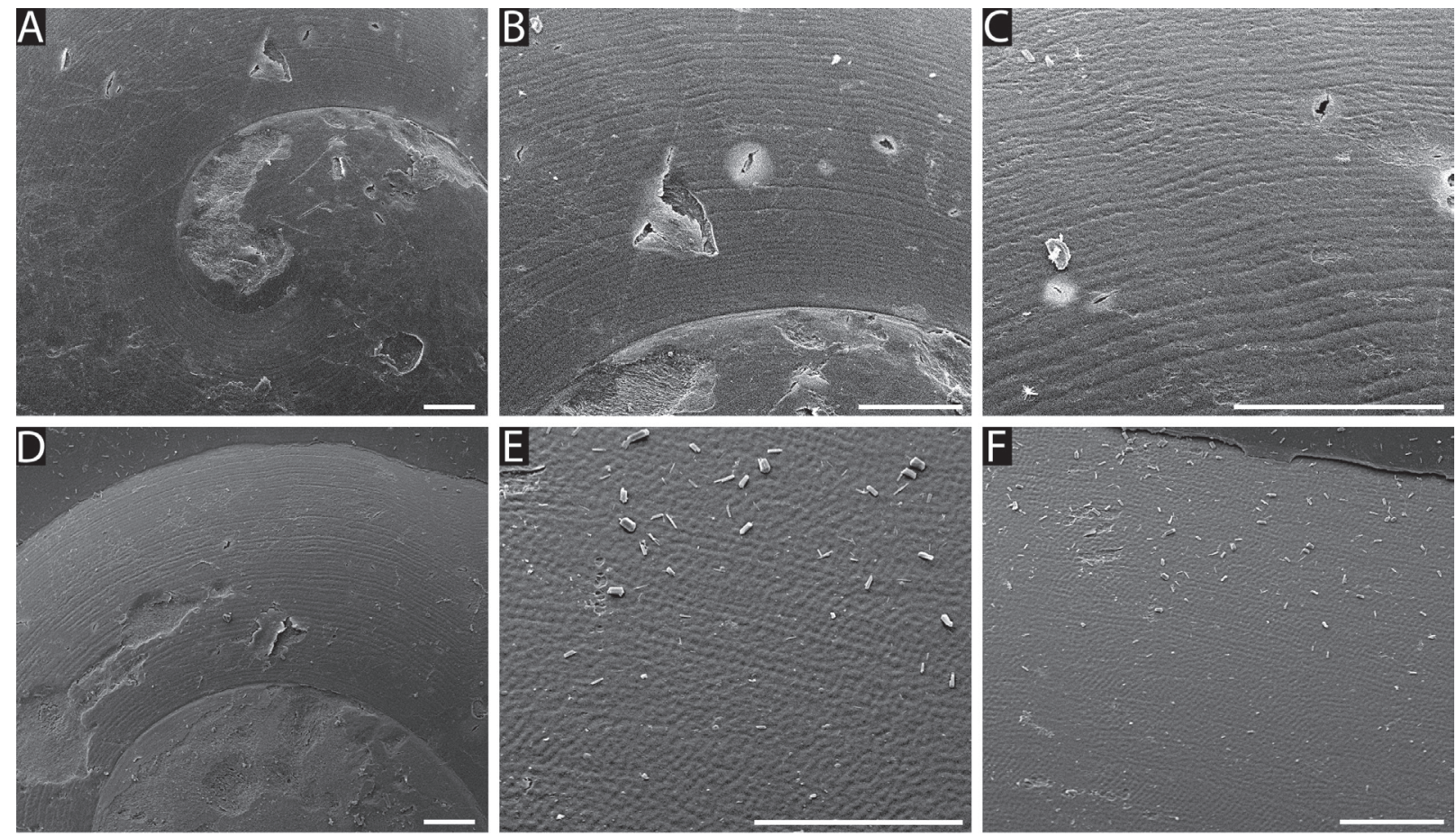

Fig. 8. Scanning electron micrographs showing shell microsculpture in Brevisentis. A-C. B. jacksoniensis AM C.205293: A. Protoconch. B. early teleoconch. C. mid-teleoconch. D-F. B. kaputarensis QM MO78909: D. Protoconch. E. early teleoconch. F. midteleoconch. Scale bars $=100 \mu \mathrm{m}$.

\section{Brevisentis Hyman, 2007}

Brevisentis Hyman, 2007: 93.

Type species: Helix jacksoniensis Gray, 1834, by original designation; masculine

Diagnosis. Shell. Medium-sized, discoidal to depressedly globose with low spire; whorls rounded; protoconch with fine, shallow spiral grooves, teleoconch with spiral rows of very fine pustules; umbilicus narrow (Fig. 7-8).

Animal. Grey to black with red mucus in at least two species. Mantle lobes moderately small; shell lappets elongate, triangular (Fig. 9).

Genitalia. Ovotestis of 4-5 lobes embedded in digestive gland. Talon usually embedded in digestive gland. Spermoviduct not folded. Distal portion of free oviduct with elongate capsular gland; free oviduct internally smooth. Bursa copulatrix relatively long, reaching half to two thirds of the way along spermoviduct, inserted on vagina, internally with longitudinal pilasters in duct; sac oval to tear-shaped. Vagina short, internally with longitudinal pilasters.
Epiphallus enters penis through verge; epiphallic caecum absent; epiphallic flagellum with axial filament present, containing small internal cryptae. Spermatophore is a soft-walled capsule with hard tail-pipe, with short branching spines in spiraling pattern on tail-pipe.

Remarks. Brevisentis originally contained two species that were previously included in Melocystis Iredale, 1937, a genus now considered as a synonym of Nitor Gude, 1911 (Hyman, 2007). A third species, B. kaputarensis, was subsequently included for strong similarity in shell features (Stanisic et al., 2010). The monophyly of Brevisentis as so delineated is confirmed herein. The three allopatric species have very similar shells, but differ in body colouration and genital anatomy. Samples from Wollemi National Park, Great Dividing Range, do not group with any described Brevisentis species in mtDNA phylogeny but form the sister group of (B.atratus + B. kaputarensis), probably representing an undescribed species. However, because the single lot consists of immature specimens only, we delay description of this species pending collection of suitable material. 


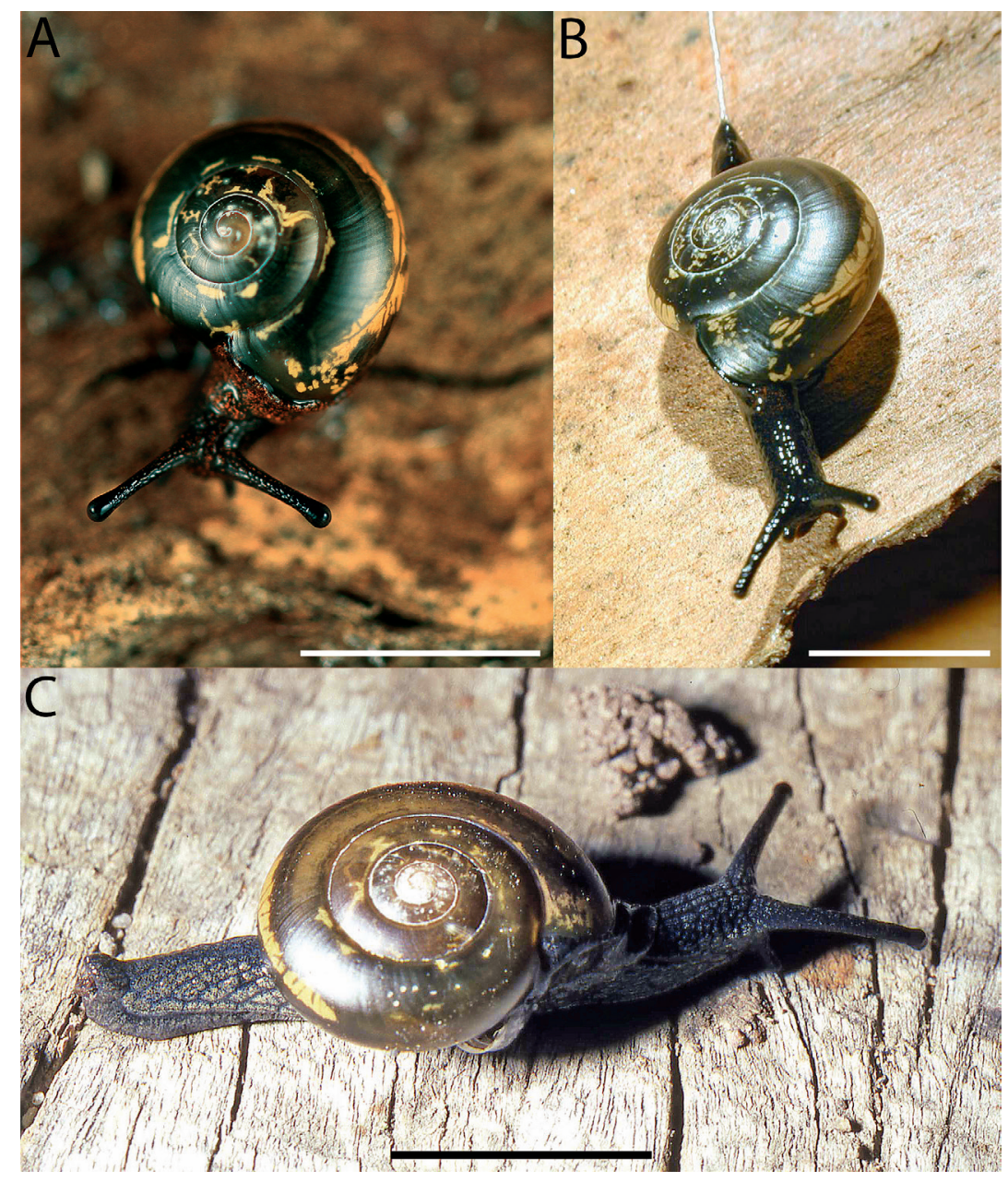

Fig. 9. Live specimens of Brevisentis. A-B. B. atratus: A. AM C.517469, Camden. B. AM C.403813, Coolah Tops National Park. C. B. kaputarensis, QM MO78908, Mt Kaputar. Scale bars = approx. $10 \mathrm{~mm}$.
Brevisentis jacksoniensis (Gray, 1834)

Figs 7A-B, 8A-C, 9A-B, 10

Helix jacksoniensis Gray, 1834: 65; Reeve, 1854: pl. 207, sp. 1462.

Helix (Microcystis) jacksoniensis: Cox, 1868: 7, pl. 9, fig. 6.

Nanina (Microcystis) jacksoniensis: Pfeiffer and Clessin, 1881: 36.

Nanina (Subg. Xesta Sect. Microcystis) jacksoniensis: Tryon, 1886: 113, pl. 37, fig. 21.

Nanina (Microchlamys) jacksoniensis: Cox, 1909: 7. Melocystis jacksoniensis: Iredale, 1937a: 5.

Expocystis exclusus Iredale, 1941: 4, fig. 7.

Melocystis exclusus: Smith, 1992: 238.

Brevisentis jacksoniensis: Hyman and Ponder, 2010: 44-45, figs 7J-K, 8J-K, 9J-K, 10B, 11B, 12G-H, 13G, 14D, 15P-R; Stanisic et al., 2010: 280-281.
Material examined. Types. 2 syntypes of Helix jacksoniensis Gray, 1834 (NHMUK 20160421, Port Jackson, leg. Lamb; Fig. 7A), holotype of Expocystis exclusus Iredale, 1937 AM C.101143, Broken Bay, N of Sydney; Fig. 7B).

Non-type material. See Table S1. Additional material: AM C.319501, AM C.348670, AM C.356645, AM C.162857, AM C.320010.

Diagnosis. Shell. Medium-sized, 4.65-5.25 whorls, amber to golden brown, depressedly subglogose with a low spire; whorls rounded, sutures impressed; protoconch with fine spiral grooves, teleoconch with fine spiral grooves becoming pustulose towards the last whorl. Umbilicus narrow (Table 3, Figs 7A-B, 8A-C).

Animal. Grey with red mucus (staining body red); sole with a slightly paler mid field; caudal gland small. Mantle lobes moderately small, not fused; shell lappets 
Table 3. Shell dimensions. Abbreviations: $\mathrm{n}=$ number of measured specimens, $\mathrm{SH}=$ shell height, $\mathrm{SD}=$ shell diameter, $\mathrm{NW}=$ number of whorls, $\mathrm{AH}=$ aperture height, $\mathrm{AW}=$ aperture width.

\begin{tabular}{|c|c|c|c|c|c|c|}
\hline Species & $\mathrm{n}$ & $\mathrm{SH}(\mathrm{mm})$ & $\mathrm{SD}(\mathrm{mm})$ & NW & $\mathrm{AH}(\mathrm{mm})$ & AW (mm) \\
\hline Brevisentis jacksoniensis & 15 & $\begin{array}{c}4.80-7.26 \\
(5.76 \pm 0.66)\end{array}$ & $\begin{array}{c}9.10-12.00 \\
(10.00 \pm 0.73)\end{array}$ & $\begin{array}{c}4.65-5.25 \\
(4.88 \pm 0.19)\end{array}$ & $\begin{array}{c}4.45-5.90 \\
(4.93 \pm 0.39)\end{array}$ & $\begin{array}{c}4.87-6.72 \\
(5.60 \pm 0.46)\end{array}$ \\
\hline Brevisentis atratus & 25 & $\begin{array}{c}4.63-6.18 \\
(5.40 \pm 0.38)\end{array}$ & $\begin{array}{l}9.50-11.51 \\
(5.00 \pm 0.26\end{array}$ & $\begin{array}{c}4.65-5.50 \\
(4.50 \pm 0.31)\end{array}$ & $\begin{array}{c}3.82-4.99 \\
(5.47 \pm 0.30)\end{array}$ & $\begin{array}{c}4.97-6.07 \\
(10.41 \pm 0.50\end{array}$ \\
\hline Brevisentis kaputarensis & 18 & $\begin{array}{c}3.37-4.75 \\
(4.19 \pm 0.47)\end{array}$ & $\begin{array}{c}6.79-10.05 \\
(8.36 \pm 0.89)\end{array}$ & $\begin{array}{c}4.20-4.90 \\
(4.58 \pm 0.23\end{array}$ & $\begin{array}{c}2.96-4.68 \\
(3.91 \pm 0.48)\end{array}$ & $\begin{array}{c}3.58-5.82 \\
(4.50 \pm 0.59)\end{array}$ \\
\hline Mysticarion porrectus & 20 & $\begin{array}{c}4.73-7.24 \\
(5.81 \pm 0.69)\end{array}$ & $\begin{array}{c}8.81-13.38 \\
(10.58 \pm 1.34)\end{array}$ & $\begin{array}{c}3.00-4.10 \\
(3.44 \pm 0.32)\end{array}$ & $\begin{array}{c}3.67-6.26 \\
(4.78 \pm 0.71)\end{array}$ & $\begin{array}{c}5.24-9.25 \\
(6.95 \pm 1.10)\end{array}$ \\
\hline Mysticarion insuetus & 20 & $\begin{array}{c}3.13-6.1 \\
(4.76 \pm 0.72)\end{array}$ & $\begin{array}{c}4.82-9.83 \\
(7.44 \pm 1.32)\end{array}$ & $\begin{array}{c}3.15-4.50 \\
(3.80 \pm 0.36)\end{array}$ & $\begin{array}{c}2.94-4.45 \\
(3.65 \pm 0.38)\end{array}$ & $\begin{array}{c}2.67-5.93 \\
(4.19 \pm 0.77)\end{array}$ \\
\hline Mysticarion hyalinus & 11 & $\begin{array}{c}4.63-8.57 \\
(6.75 \pm 1.40)\end{array}$ & $\begin{array}{c}7.28-11.89 \\
(9.48 \pm 1.43)\end{array}$ & $\begin{array}{c}3.90-4.60 \\
(4.26 \pm 0.23\end{array}$ & $\begin{array}{c}2.49-5.84 \\
(4.57 \pm 1.17)\end{array}$ & $\begin{array}{c}3.91-6.94 \\
(5.55 \pm 1.218)\end{array}$ \\
\hline Parmavitrina planilabris & 15 & $\begin{array}{c}7.51-12.96 \\
(10.2 \pm 1.48)\end{array}$ & $\begin{array}{l}16.62-23.99 \\
(20.71 \pm 2.1)\end{array}$ & $\begin{array}{c}3.40-3.75 \\
(3.55 \pm 0.12\end{array}$ & $\begin{array}{c}6.3-12.05 \\
(8.24 \pm 1.52)\end{array}$ & $\begin{array}{c}10.60-17.07 \\
(14.03 \pm 1.82)\end{array}$ \\
\hline Parmavitrina disposita & 20 & $\begin{array}{c}5.90-10.46 \\
(6.96 \pm 1.09)\end{array}$ & $\begin{array}{c}16.88-24.74 \\
(19.77 \pm 2.13)\end{array}$ & $\begin{array}{c}3.50-4.40 \\
(3.94 \pm 0.31\end{array}$ & $\begin{array}{c}5.60-9.13 \\
(7.08 \pm 0.93\end{array}$ & $\begin{array}{c}10.35-15.63 \\
(11.93 \pm 1.30)\end{array}$ \\
\hline Parmavitrina rubrica & 20 & $\begin{array}{c}5.44-9.01 \\
(6.71 \pm 0.74)\end{array}$ & $\begin{array}{c}15.52-21.22 \\
(18.17 \pm 1.49)\end{array}$ & $\begin{array}{l}3.40-3.60 \\
(3.5 \pm 0.06\end{array}$ & $\begin{array}{c}6.00-9.27 \\
(7.29 \pm 0.94)\end{array}$ & $\begin{array}{c}11.04-15.92 \\
(13.05 \pm 1.43)\end{array}$ \\
\hline Parmavitrina megastoma & 20 & $\begin{array}{l}4.47-8.43 \\
(5.94 \pm 1.2)\end{array}$ & $\begin{array}{c}9.46-18.15 \\
(12.56 \pm 2.63)\end{array}$ & $\begin{array}{c}2.50-3.00 \\
(2.74 \pm 0.14\end{array}$ & $\begin{array}{c}3.15-6.44 \\
(4.47 \pm 0.87)\end{array}$ & $\begin{array}{c}6.47-13.14 \\
(9.03 \pm 2.19)\end{array}$ \\
\hline Cucullarion albimaculosum & 10 & n.a. & $\begin{array}{c}10.33-16.76 \\
(14.28 \pm 1.91)\end{array}$ & $\begin{array}{c}2.80-3.40 \\
(3.22 \pm 0.16\end{array}$ & n.a. & n.a. \\
\hline Peloparion helenae & 20 & $\begin{array}{c}4.12-6.76 \\
(4.97 \pm 0.67)\end{array}$ & $\begin{array}{c}9.87-13.7 \\
(11.65 \pm 0.84)\end{array}$ & $\begin{array}{c}3.00-3.55 \\
(3.27 \pm 0.15\end{array}$ & $\begin{array}{c}4.16-6.22 \\
(5.20 \pm 0.71)\end{array}$ & $\begin{array}{c}6.75-11.28 \\
(8.47 \pm 1.20)\end{array}$ \\
\hline Ubiquitarion iridis & 20 & $\begin{array}{c}2.66-4.2 \\
(3.40 \pm 0.36)\end{array}$ & $\begin{array}{c}6.46-8.98 \\
(7.67 \pm 0.72)\end{array}$ & $\begin{array}{c}2.20-2.80 \\
(2.45 \pm 0.15\end{array}$ & $\begin{array}{c}1.89-3.69 \\
(2.76 \pm 0.57)\end{array}$ & $\begin{array}{c}4.22-7.03 \\
(5.42 \pm 0.75)\end{array}$ \\
\hline
\end{tabular}

narrow, triangular, right lappet moderately long, left lappet moderately short (Fig. 9A-B).

Genitalia. Penis moderately short, enclosed in penial tunica, slightly swollen at proximal end. Penis interior with longitudinal pilasters at distal end, breaking up into pustules at proximal end. Epiphallus relatively short, approximately 1.5 times penis length, entering penis apically or slightly to one side through rounded, pustulose verge of variable length, ranging from one third to three quarters penis length. Epiphallic flagellum with small internal cryptae near epiphallus, tail of flagellum without visible cryptae. Spermatophore with smooth capsule; one complex branching spine on tailpipe near capsule; opposite, eight increasingly smaller and simpler short branching spines spiraling around tail-pipe only (Fig. 10).

Remarks. This species was considered to be a synonym of Nitor circumcinctus for some years (Cox, 1909; Iredale, 1937a). Subsequently, its type locality was treated as doubtful and it was placed in incertae sedis (Iredale, 1941; Smith, 1992; Smith et al., 2002). After examination of the holotype the species was resur- rected by Hyman (2007) with Expocystis exclusus as a synonym; this treatment is followed here.

Brevisentis jacksoniensis is found from Kiama to the Hawkesbury Valley in dry vine thicket, sclerophyll forest and woodland, living in litter and under logs and rocks (Fig. 11). It was recorded by Hyman and Ponder (2010) as ranging to the Warrumbungle National Park in the north, and in the west to Bathurst and the Blue Mountains, but this appears to be in error: specimens from all three localities have been identified herein as belonging to B. atratus. Specimens from Mulgoa and Richmond (W of Sydney), Palm Beach and Hornsby (N Sydney), Berowra Waters and Berowra Creek ( $N$ of Sydney) and Kurrajong (Hawkesbury Valley) have all been confirmed by sequencing or dissection to belong to $B$.jacksoniensis.

While the three Brevisentis species all have very similar shells, the shell of B. jacksoniensis is slightly larger than B. kaputarensis, with more impressed sutures, and B.jacksoniensis has a higher spire than either of its congeners (Fig. 1A). This species can also be identified by its paler body colouration stained with 


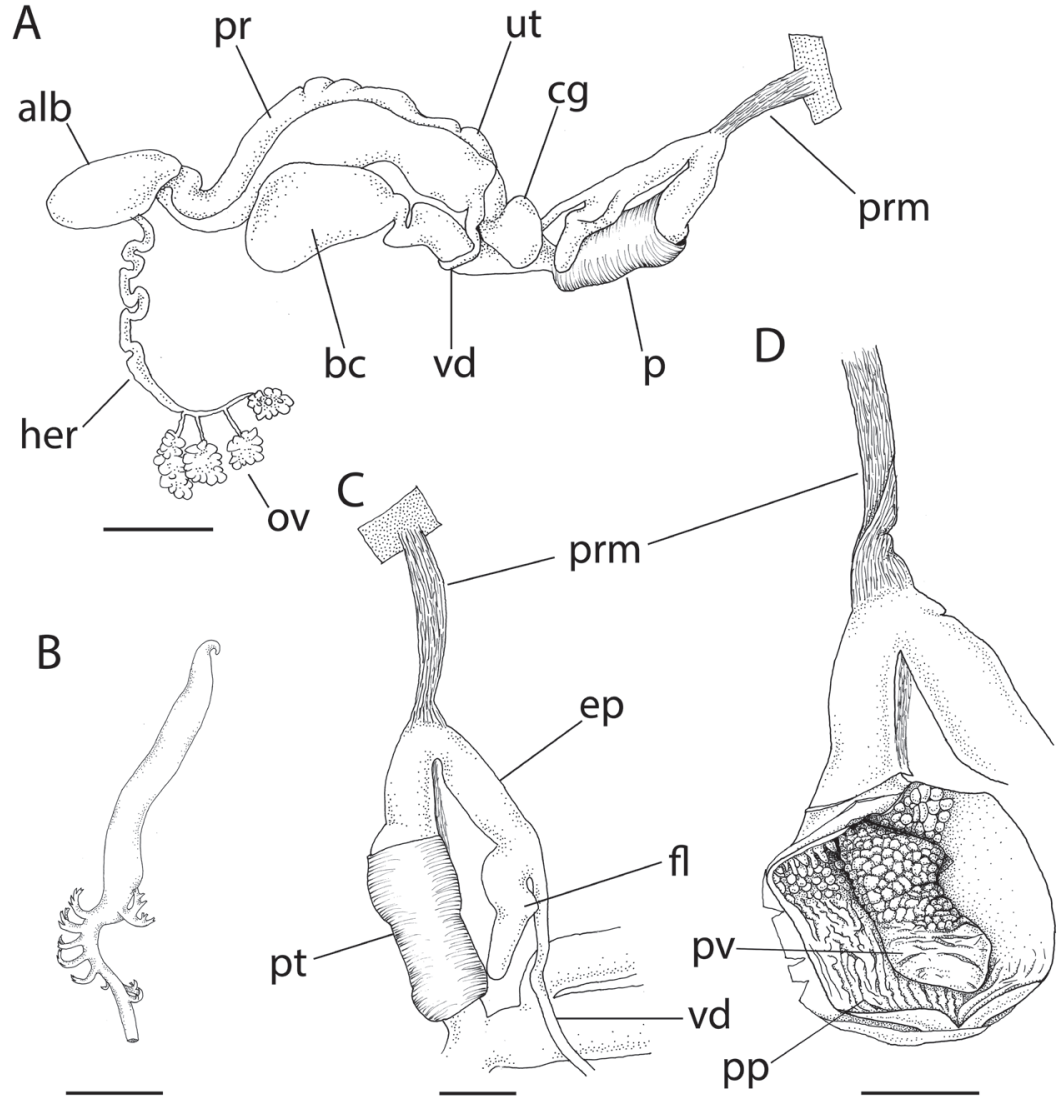

Fig. 10. Reproductive anatomy of Brevisentis jacksoniensis, AM C.205293. A. Genitalia. B. Spermatophore. C. Penial complex. D. Penial interior. Abbreviations: alb, albumen gland; bc, bursa copulatrix; cg, capsule gland; ep, epiphallus; fl, flagellum; her, hermaphroditic duct; ov, ovotestis; p, penis; pp, penial pilasters; pr, prostate; prm, penial retractor muscle; pt, penial tunica; pv, penial verge; ut, uterus; vd, vas deferens. Scale bars: A $=2 \mathrm{~mm}, \mathrm{~B}-\mathrm{D}=1 \mathrm{~mm}$. red mucus. Brevisentis atratus also produces red mucus, but its black body colour renders it less visible. Anatomically, the species are easily distinguished by the longer penis with a blind tip seen in B. atratus and the absence of pustules in the penis interior of B. kaputarensis.

Brevisentis atratus Hyman, 2007

Figs 7C, 12

Brevisentis atratus Hyman, 2007: 94-95, fig. 2; Stanisic et al., 2010: 280-282, 324.

Material examined. Holotype. AM C.446473 (Coolah Tops NP, at lookout $1 \mathrm{~km} \mathrm{~S}$ of Pinnacle Lookout, end of Pinnacle Rd, NSW, $31^{\circ} 41.8^{\prime} \mathrm{S}, 150^{\circ} 1.1^{\prime} \mathrm{E}$, basalt rock pile at edge of escarpment, leg. Shea, 26/5/2000).

Paratypes. AM C.44645 (same data as holotype).

Non-type material. See Table S1. Additional material:

AM C.446477, AM C.360695, AM C.164160, AM

C.135218, AM C.446459, AM C.517469.
Diagnosis. Shell. Medium size, 4.65-5.5 whorls, pale amber, depressedly globose to discoidal; whorls rounded; protoconch with very fine spiral grooves; teleoconch with spiral rows of tiny pustules; umbilicus narrow (Table 3, Fig. 7C).

Animal. Body dark grey to black with red mucus; tiny specks of red pigment visible in living animal; sole pale grey with a paler mid field; caudal horn small. Mantle lobes moderately small, not fused; shell lappets narrow, triangular, right lappet moderately long, left lappet moderately short.

Genitalia. Penis relatively long, sometimes not fully enclosed in penial tunica, not swollen proximally. Penis interior with primarily longitudinal pilasters at distal end, breaking into wavy pilasters then into pustules at proximal end; interior with a sharp narrowing near proximal end that is not visible externally, effectively dividing penis into two separate chambers. Epiphallus relatively short, approximately 1.5 times penis length, entering penis to one side through short verge (about $1 / 4$ penis length), leaving a small blind penis tip. Epiphallic flagellum with small internal 


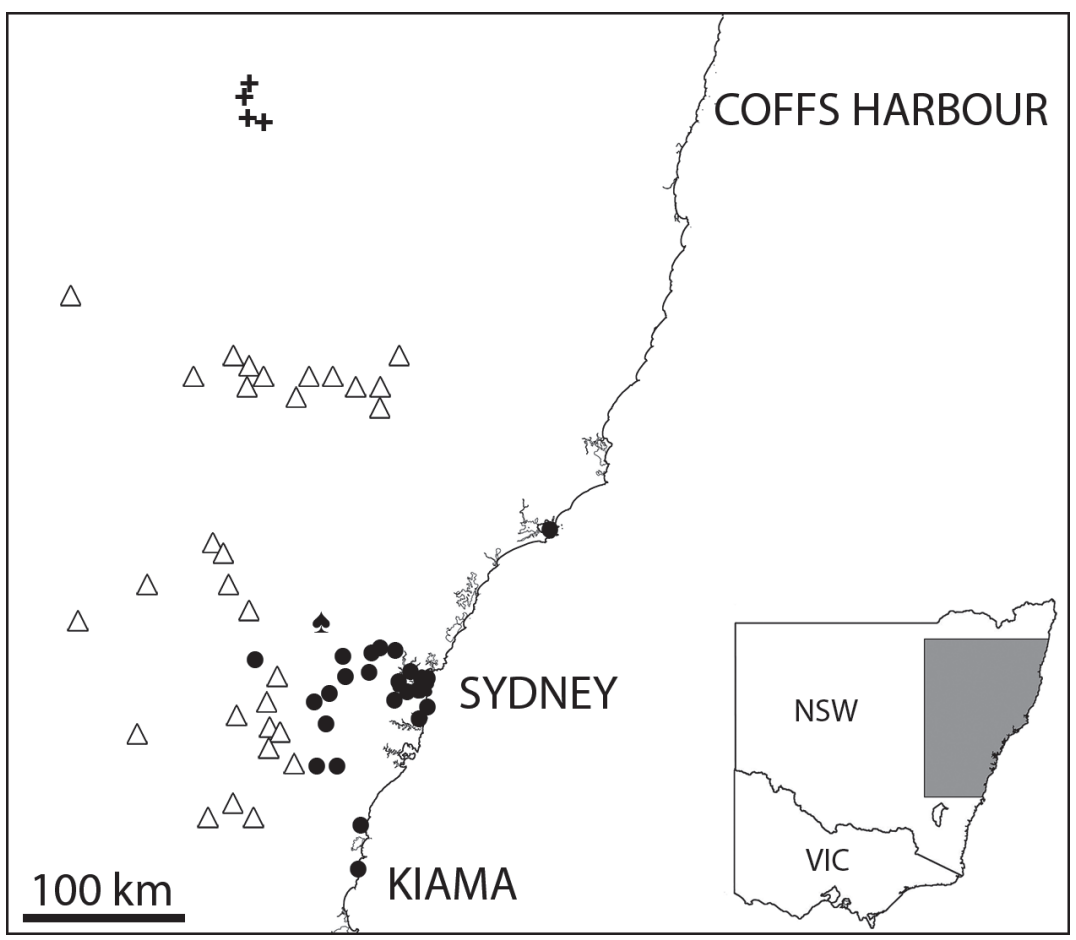

Fig. 11. Occurrence records of Brevisentis from the malacological collection of the Australian Museum, Sydney. Symbols: $\bullet=B$. jacksoniensis, $\triangle=B$. atratus,$+=B$. kaputarensis, $\boldsymbol{A}=B$. n. sp. Wollemi NP. cryptae near epiphallus, tail of flagellum without visible cryptae. Spermatophore not observed (Fig. 12).

Remarks. When first described, B. atratus was recorded from Mt Gibraltar (Bowral, SE NSW) to Coolah Tops National Park in the Hunter region (Hyman, 2007). Specimens from the Blue Mountains, Bathurst and Warrumbungle National Park, mistakenly attributed to $B$.jacksoniensis, are here shown to belong to $B$. atratus (Fig. 11). This species is found in rocky outcrops in vine thicket, sclerophyll forest and open woodland, living under rocks, logs and litter.

Brevisentis atratus can be distinguished from $B$. jacksoniensis by its black body colouration and lowerspired shell, and from B. kaputarensis by its larger and paler shell with a flatter spire. It has a very distinctive penial anatomy, with a longer penis than its congeners, distinguished by a narrowing near the proximal end that gives the impression of two separate chambers and a small blind tip.

Brevisentis kaputarensis Shea and Griffiths, 2010 Figs 7D, 8D-F, 9C, 13

Brevisentis kaputarensis Shea and Griffiths, 2010 in Stanisic et al., 2010: 280-281.
Material examined. Holotype. QMMO32629 (Dawsons Spring, Mt Kaputar, NE NSW, 30¹6'S, 150¹0'E, fern gully/remnant rainforest, under logs, in litter, leg. Stanisic et al., 8/11/1983; Fig. 7D).

Paratypes. QMMO49155, QMMO78908.

Non-type material. See Table S1.

Diagnosis. Shell. Medium size, 4.6-5.2 whorls, pale amber, discoidal with a low spire; whorls rounded; protoconch with very fine spiral grooves, teleoconch with spiral rows of very fine pustules; umbilicus narrow (Table 3, Figs 7D, 8D-F).

Animal. Body dark grey; sole with a paler mid field; caudal horn moderately small. Mantle lobes moderately small, not fused; Shell lappets narrow, triangular, right lappet moderately long, left lappet moderately short (Fig. 9C).

Genitalia. Penis relatively short, thick, tubular; penis and sometimes part of epiphallus enclosed in penial tunica. Penis interior with anastomosing ridges, primarily longitudinal. Epiphallus relatively short, approximately twice penis length, entering penis apically through a verge of variable length (1/3 to nearly complete penis length). Epiphallic flagellum with small internal cryptae near epiphallus, tail of flagellum without visible cryptae. Spermatophore with smooth capsule; one complex 
A

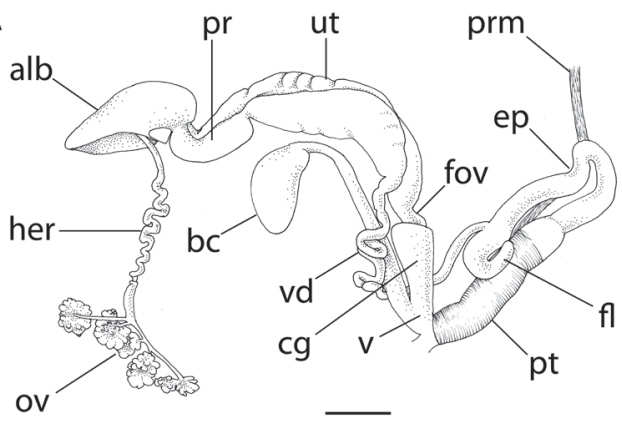

B

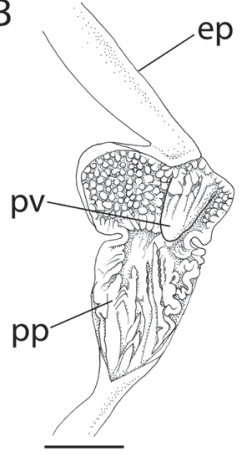

A

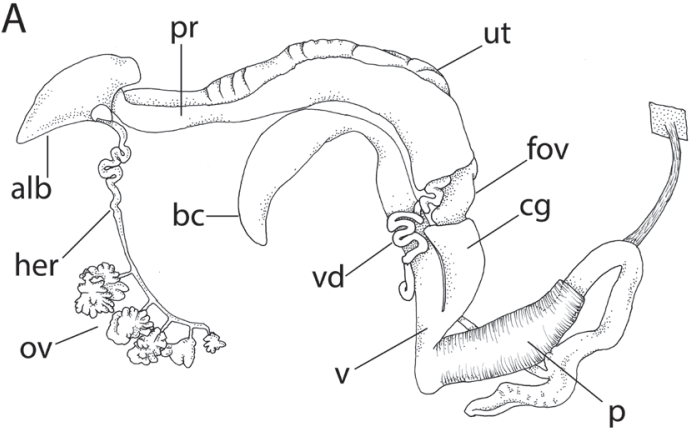

C

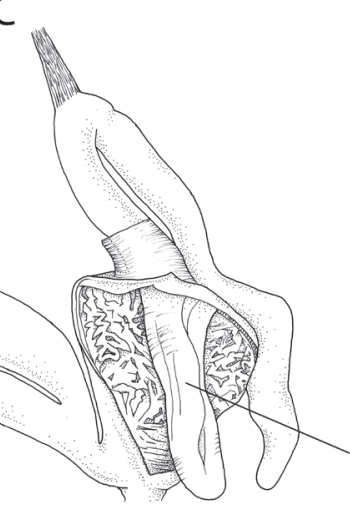

B

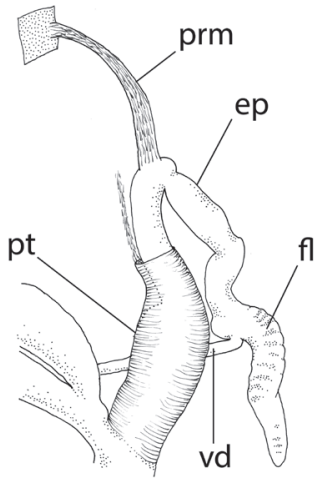

E

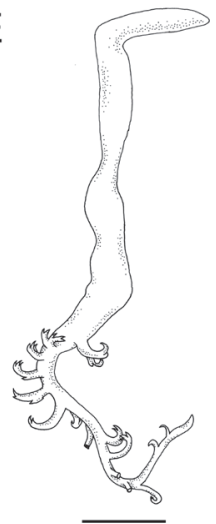

Fig. 12. Reproductive anatomy of Brevisentis atratus, AM C.360695. A. Genitalia. B. Spermatophore. B. Penial interior. Abbreviations: alb, albumen gland; bc, bursa copulatrix; cg, capsule gland; ep, epiphallus; fl, flagellum; her, hermaphroditic duct; ov, ovotestis; $p$, penis; $\mathrm{pp}$, penial pilasters; pr, prostate; prm, penial retractor muscle; pt, penial tunica; pv, penial verge; ut, uterus; vd, vas deferens. Scale bars: $A=2 \mathrm{~mm}, \mathrm{~B}=1 \mathrm{~mm}$.
Fig. 13. Reproductive anatomy of Brevisentis kaputarensis, QM MO78908. A. Genitalia. B. Penial complex. C-D. Penial interior. E. Spermatophore. Abbreviations: alb, albumen gland; bc, bursa copulatrix; cg, capsule gland; ep, epiphallus; fl, flagellum; her, hermaphroditic duct; ov, ovotestis; p, penis; pp, penial pilasters; pr, prostate; prm, penial retractor muscle; $\mathrm{pt}$, penial tunica; pv, penial verge; ut, uterus; $\mathrm{vd}$, vas deferens. Scale bars $=1 \mathrm{~mm}$.

branching spine on tail-pipe near capsule; opposite, fourteen increasingly smaller and simpler short branching spines spiraling around tail-pipe only (Fig. 13).

Remarks. Known only from Nandewar Range, northeastern NSW (Fig. 11), B. kaputarensis is the smallest species of this genus, found in dry woodland, in rock piles and leaf litter. This species has a larger penial verge than its congeners, and the penis interior has anastomosing ridges rather than pustules.

Mysticarion Iredale, 1941

Mysticarion Iredale, 1941: 7.

Type species: Mysticarion leucospira insuetus Iredale, 1941, by original designation; masculine

Diagnosis. Shell. Small to medium-sized, thin, pale golden to golden amber, glossy, globose with a low spire, whorls rounded. Protoconch with notched spiral 


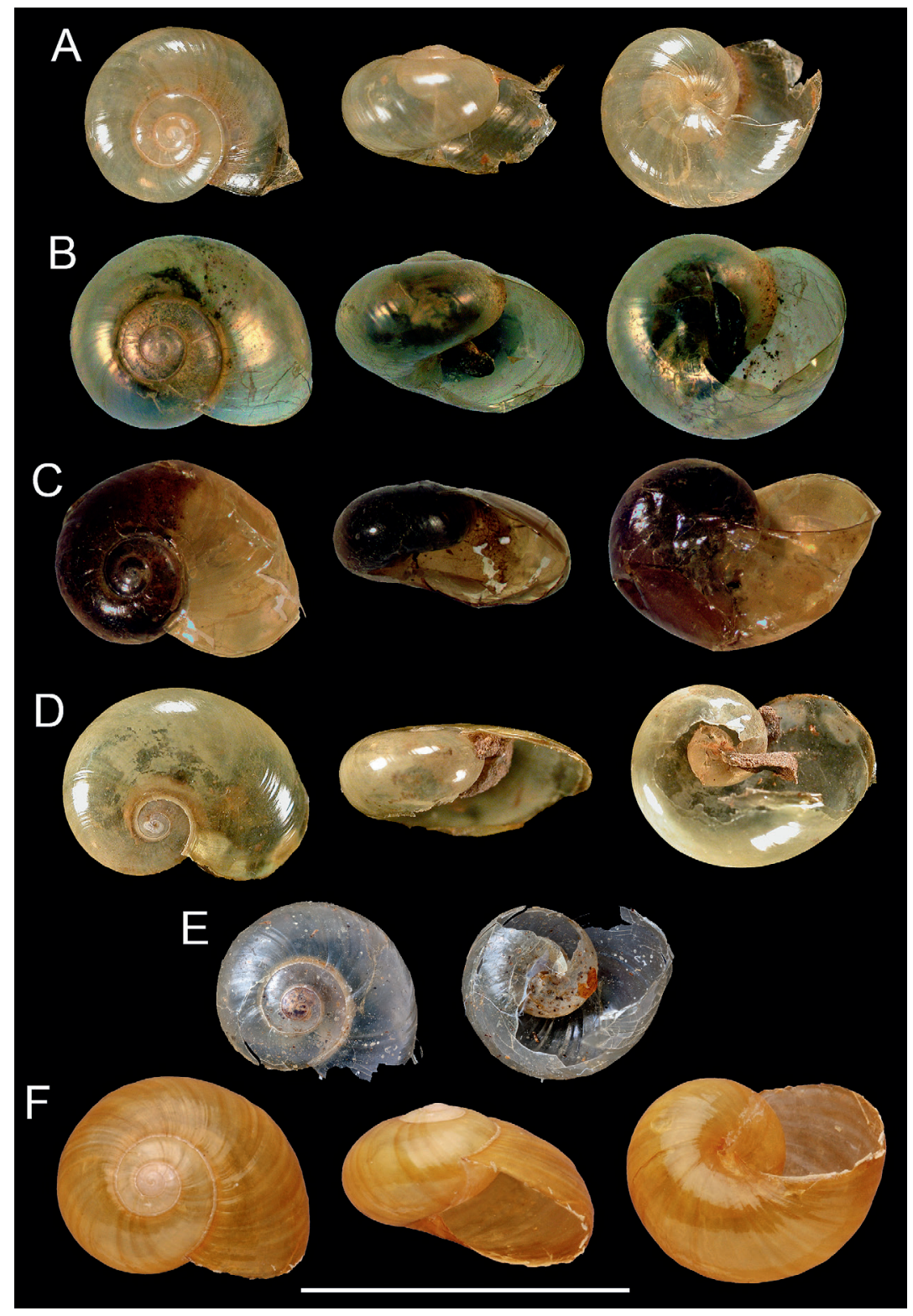

Fig. 14. Shells of Mysticarion. A-B. M. insuetus: A. Syntype of Mysticarion leucospira insuetus AM C113776 (size indicative; photographer: AM). B. M. insuetus AM C.517468. C. Paratype of Mysticarion obscurior sp. nov. AM C.524914. D. M. porrectus (probable holotype of Helicarion porrectus Iredale, 1941 AM C.101136 (size indicative, photographer: AM). E-F. M. hyalinus: E. Syntype of Vitrina hyalina Pfeiffer, 1855 NHMUK 1983075 (photographer: NHMUK). F. Holotype of Fastosarion staffordarum Stanisic, 2010, QM MO62372 (size indicative, photographer: QM). Scale bar $=10 \mathrm{~mm}$.

grooves, teleoconch with very fine spiral grooves or smooth (Figs 14-15).

Animal. Pale cream with minimal markings. Mantle lobes usually small, not fused; shell lappets wide at base, rapidly tapering, triangular (Fig. 16).

Genitalia. Spermoviduct of 2-4 lobes, embedded in digestive gland. Talon and carrefour embedded in albumen gland. Spermoviduct not folded into foot but with 1-2 small folds in proximal half. Free oviduct with spherical capsular gland in distal portion; internal walls of capsular gland smooth, remainder of free oviduct with weak longitudinal pilasters (absent in one species). Bursa copulatrix moderately long, approximately half spermoviduct length; sac portion oval; inserted at junction of penis and free oviduct. Vagina absent. Penis tunica attached tightly by muscle fibres to middle of epiphallus; epiphallus enters penis through verge; epiphallic caecum absent; near flagellum, epiphallus containing internal cryptae; epiphallic flagellum with axial filament present, containing spiraling rows of internal cryptae with a long slender tail. Spermatophore a soft-walled capsule with hard tail-pipe; 

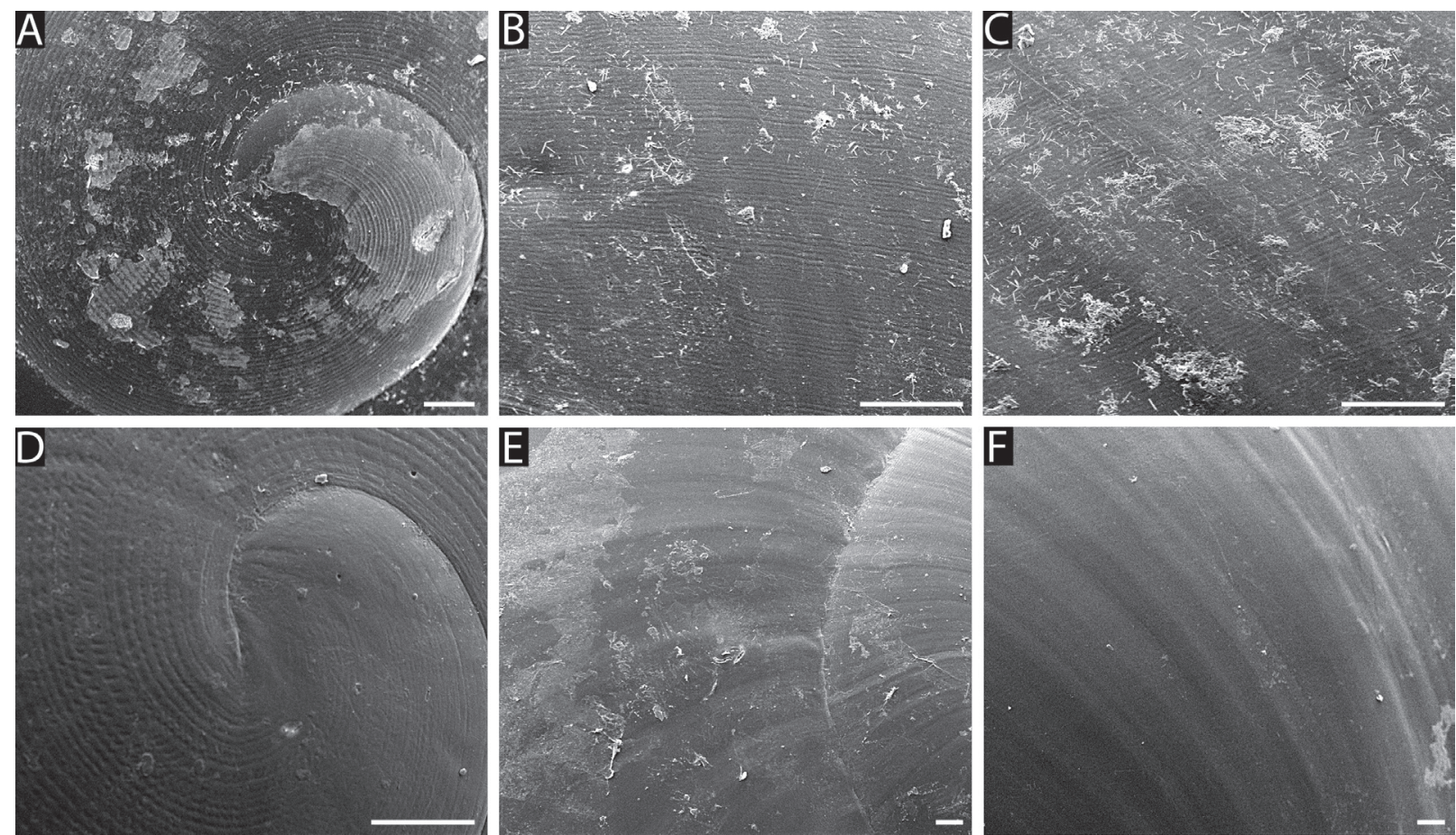

Fig. 15. Scanning electron micrographs showing shell microsculpture in Mysticarion. A-C. M. insuetus, QM MO49377: A. Protoconch. B. early teleoconch. C. mid-teleoconch. D-F. M. hyalinus, AM C.512424: D. Protoconch. E. early teleoconch. F. mid-teleoconch. Scale bars $=100 \mu \mathrm{m}$.

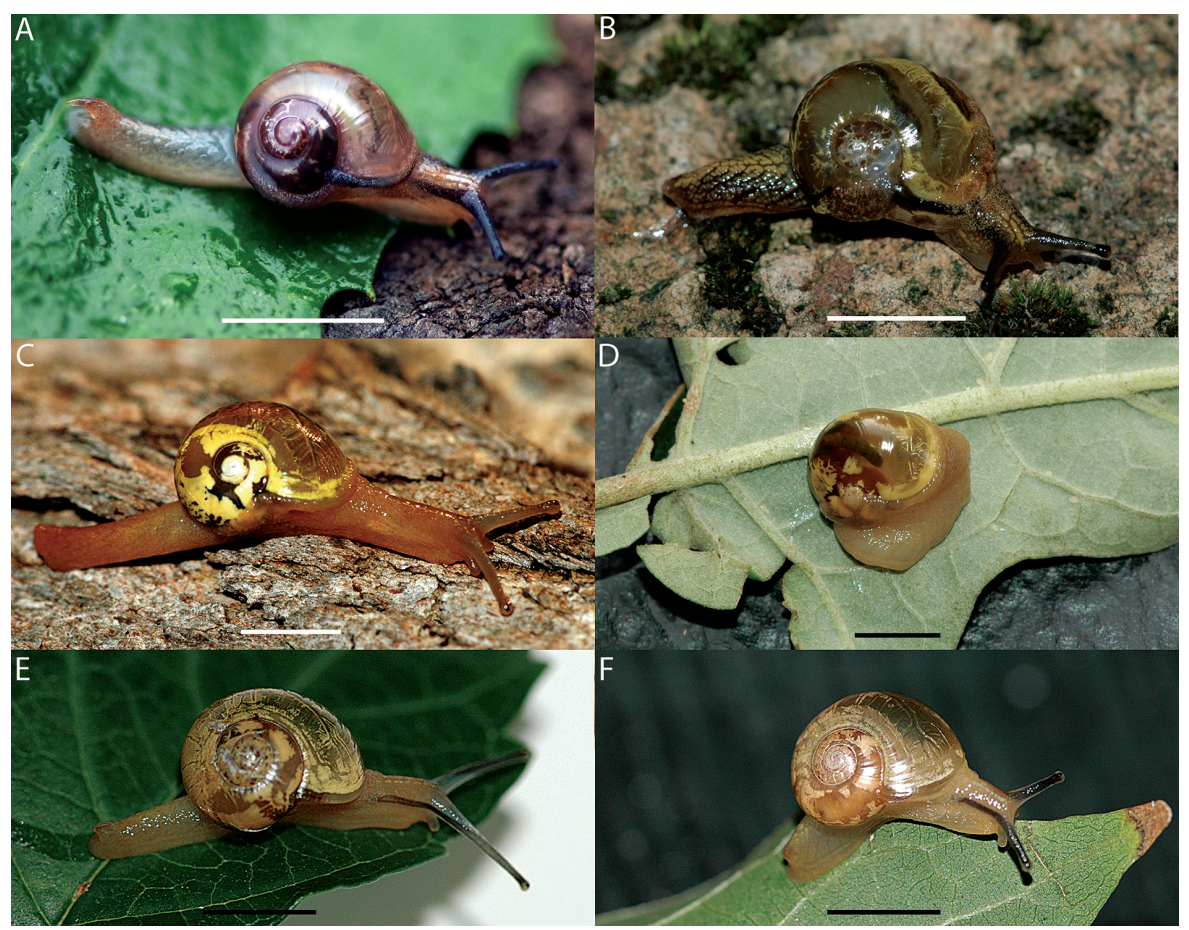

Fig. 16. Live specimens of Mysticarion. A. M. insuetus, AM C.506269, Oxley Wild Rivers NP. B. M. obscurior, AM C.524913, Wambina NR. C. M. porrectus, AM C.5000935, Mt Tomah. D. M. porrectus, resting pose, AM C.517188, Dorrigo. E-F. M. hyalinus: E. AM C.512424, Cunningham's Gap. F. AM C.512438, Bunya Mountains. Scale bars = approx. 5 mm. 


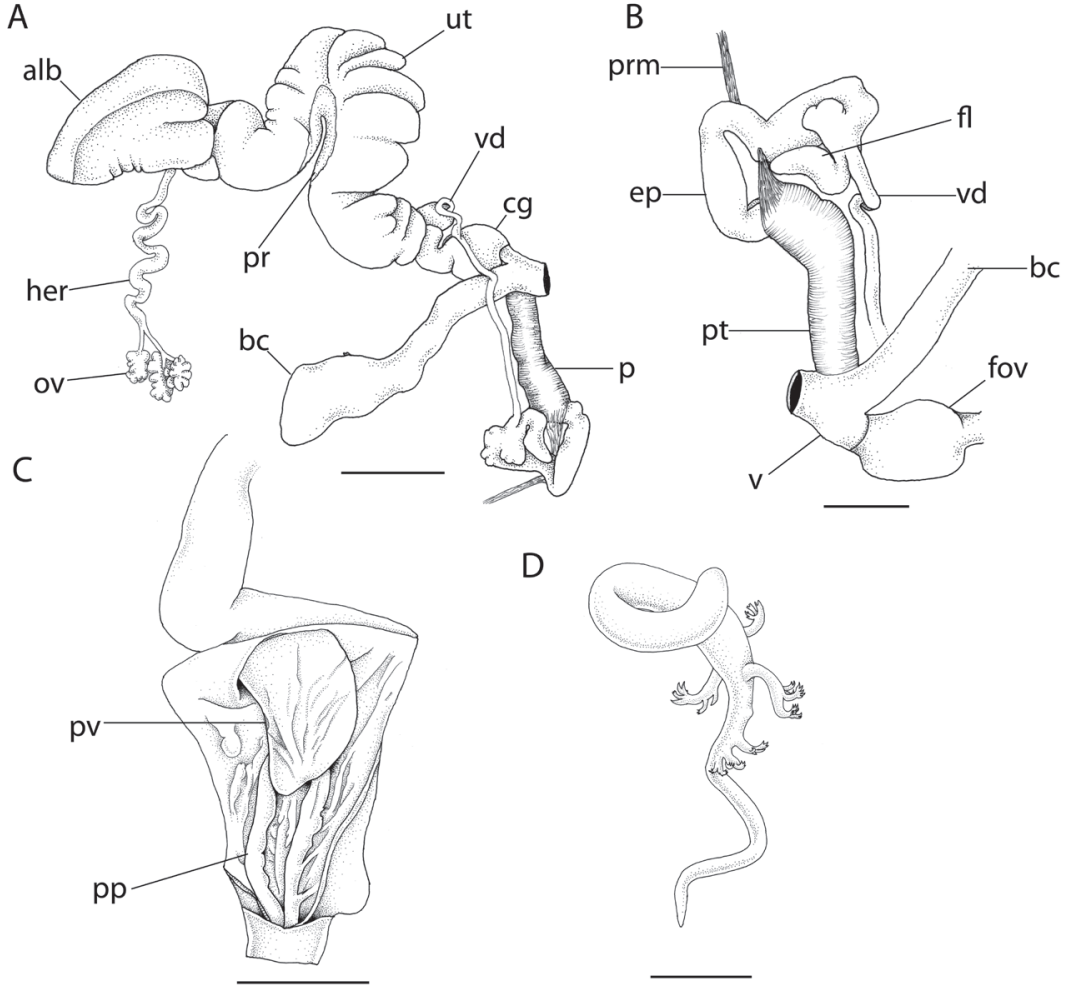

Fig. 17. Reproductive anatomy of Mysticarion insuetus, AM C.483756. A. Genitalia. B. Penial complex. C. Penial interior. D. Spermatophore. Abbreviations: alb, albumen gland; bc, bursa copulatrix; cg, capsule gland; ep, epiphallus; fl, flagellum; her, hermaphroditic duct; ov, ovotestis; $p$, penis; pp, penial pilasters; pr, prostate; prm, penial retractor muscle; pt, penial tunica; pv, penial verge; ut, uterus; vd, vas deferens. Scale bars: $\mathrm{A}=$ $2 \mathrm{~mm}, \mathrm{~B}-\mathrm{D}=1 \mathrm{~mm}$. relatively long, complex branching spines present in spiraling pattern along tail-pipe.

Remarks. Mysticarion was introduced for two globose semislugs, Vitrina leucospira Pfeiffer, 1857 and its nominal subspecies M. leucospira insuetus (Iredale, 1941). Vitrina leucospira has since been excluded from the genus based on an examination of the type material, which does not appear to be that of an Australian helicarionid; and the taxon insuetus has been elevated to a full species. Helicarion porrectus Iredale, 1941 and Vitrina hyalina Pfeiffer, 1855 were both subsequently included in Mysticarion by Hyman and Ponder (2010) and followed by Stanisic et al . (2010). This treatment is confirmed here by molecular phylogenetics.

This genus contains arboreal semislugs with a golden, globose shell with a relatively high whorl count and a pale body. The genital features unifying this group include a moderately long penis with a penial verge and longitudinal pilasters, a short epiphallus with an accessory flagellum containing internal cryptae but no epiphallic caecum, a moderately long bursa copulatrix, and the absence of a vagina. The spermatophore is spiraling with branched spines present on the base of the capsule and continuing on the tail-pipe.
Mysticarion insuetus Iredale, 1941

Figs 14A-B, 15A-C, 16A, 17

Mysticarion leucospira insuetus Iredale, 1941: 7. Mysticarion insuetus: Stanisic et al., 2010: 308-309, 330.

Material examined. Syntype. AM C.113776 (Scone, $32^{\circ} 03^{\prime} \mathrm{S}, 150^{\circ} 52^{\prime}$ E, pre-1912; Fig. 14A).

Non-type material. See Table S1. Additional specimens: AM C.164470, AM C.456541, AM C.204742, AM C.204744.

Diagnosis. Shell. Small, thin, transparent golden amber, 3.2-3.9 whorls, glossy, globose with a low spire, whorls rounded. Protoconch with slightly notched, deep spiral grooves, teleoconch with very fine, shallow spiral grooves (Table 3, Figs 14A-B, 15A-C).

Animal. Body white with pale brown speckling on sole, tail tip, neck and shell lappets; eye tentacles grey, grey stripe down each side of tail, black line along mantle edge. Caudal horn large. Right mantle lobe moderately large, other lobes small, none fused. Right shell lappet long, left lappet moderately long, both lappets wide at base, rapidly tapering, white 


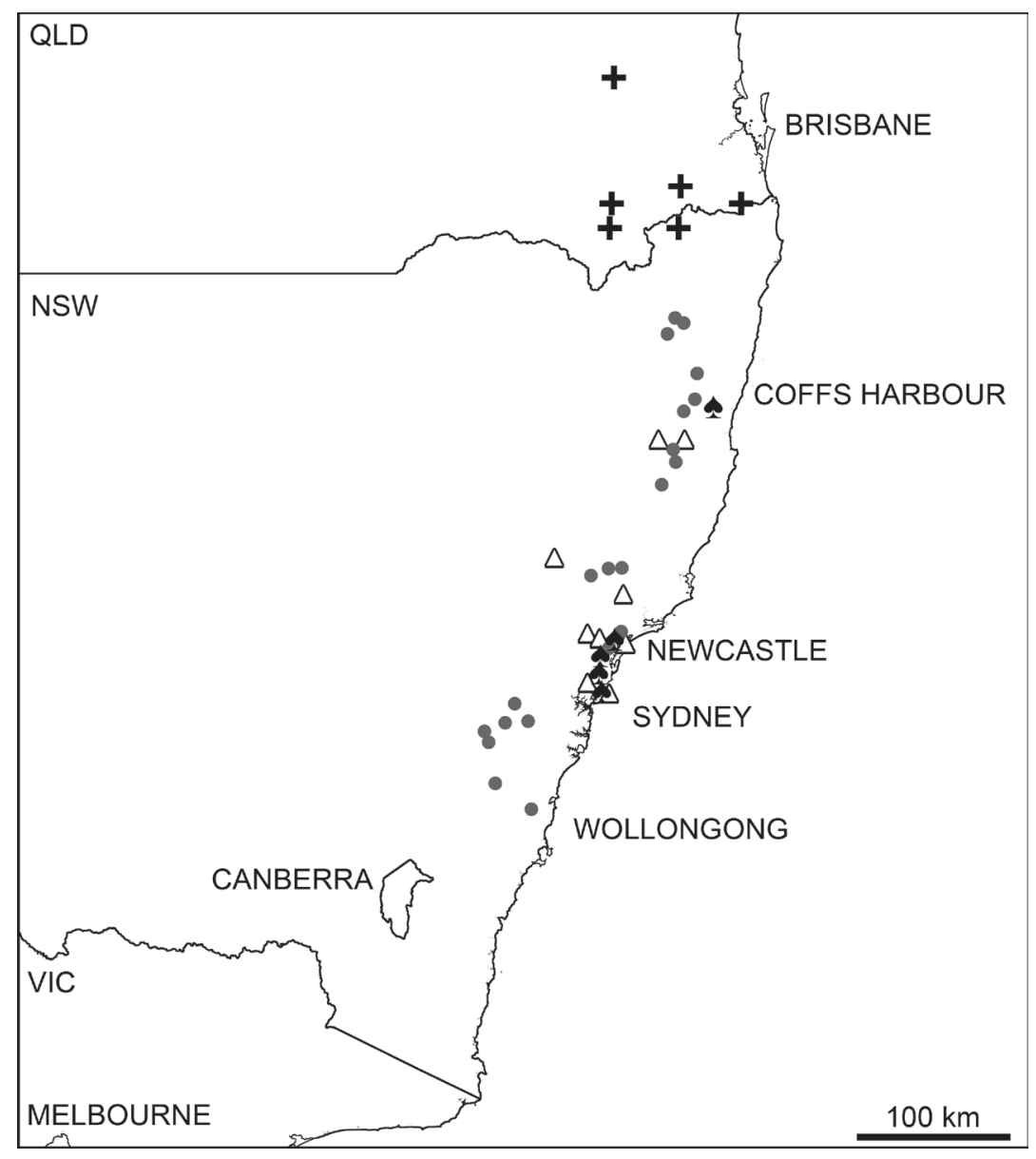

Fig. 18. Occurrence records of Mysticarion species from the malacological collection of the Australian Museum, Sydney. Symbols: $=M$. porrectus, $\triangle$ $=M$. insuetus,$+=M$. hyalinus, $\mathbf{A}=M$. obscurior. with black markings on underside (Fig. 16A).

Genitalia. Bursa copulatrix moderately short, less than half spermoviduct length, duct uniform in diameter, sac tear-shaped. Penis moderately long, slender, slightly swollen proximally, enclosed in penial tunica. Penis interior with two main longitudinal pilasters and multiple longitudinal ridges. Epiphallus short, approx. penis length, containing internal cryptae near flagellum; entering penis through rounded verge with a pointed tip of about half penis length. Epiphallic flagellum with few internal cryptae and slender tail. Spermatophore with 7 branched spines in a spiraling pattern: three widely spaced, complex branched spines at base of capsule, followed by four closely spaced, increasingly short and simple spines on tail-pipe (Fig. 17).

Remarks. Mysticarion insuetus has a wide, disjunct range that stretches over $400 \mathrm{~km}$, from Razorback, south of Sydney to the Macleay Valley in northern NSW (Fig. 18). Throughout much of its range, $M$. insuetus is sympatric with both M.porrectus and M.ob- scurior sp. nov. However, M. insuetus is generally found at lower altitudes, in drier habitats, such as vine thickets, while M.porrectus and M.obscurior are present in rainforest or wet sclerophyll forests, and in the case of $M$. porrectus, usually at higher altitudes.

The type locality for M. insuetus was given simply as 'Scone' (Iredale, 1941). The material closest to this locality in the research collections of the AM and the QM comes from Barrington Tops National Park, where three Mysticarion species are present: $M$. insuetus, M. porrectus, and M. obscurior. Mysticarion porrectus can easily be distinguished from its congeners by its larger size and less globose shell with a flatter spire and fewer whorls. Mysticarion insuetus and $M$. obscurior have much more similar shells, but the shell of $M$. insuetus is slightly higher-spired and the last whorl descends more rapidly. The two species can be distinguished much more readily alive, since the body of M. obscurior is considerably darker with orange and brown pigmentation. The fourth species in the 
genus, M. hyalinus, is found further to the north, and while it is very similar in appearance to M. insuetus it can be distinguished by its larger size and paler body colour. $M$. insuetus has a unique genital anatomy consisting of a short epiphallus and moderately long, narrow penis with a long verge and numerous longitudinal pilasters.

\section{Mysticarion obscurior sp. nov.}

Figs 14C, 16B, 19

Material examined. Holotype. AM C.524913 (Matcham, Matcham Road, Wambina Nature Reserve, NSW, 3324'10" S, 151²6'24" E, leg. Hyman et al., 13/5/2016)

Paratype. AM C.524914 (same data as holotype; Fig. 14C).

Non-type material. See Table S1. Additional material: AM C.340671, AM C.334330, AM C.456540, AM C.500932.

Diagnosis. Shell. Small, thin, transparent, pale gold, 3.5 whorls, glossy, globose with a very low spire, whorls rounded. Protoconch with notched spiral grooves, teleoconch with very fine, shallow spiral grooves (Fig. 14C).

Animal. Body beige, pale orange along neck and middle of tail, brown on sides of tail, eye tentacles grey, black line along mantle edge, right shell lappet discontinuously edged with black. Caudal horn large. Right mantle lobe moderately large, other lobes small, none fused. Right shell lappet long, left lappet moderately long, both lappets wide at base, rapidly tapering; with black markings (Fig. 16B).

Genitalia. Bursa copulatrix moderately long, reaching half way along spermoviduct; bursa duct broad at base, then narrowing; sac small, oval-shaped. Penis moderately long, broad, slightly swollen at proximal end, enclosed in penial tunica. Penis interior with two main longitudinal pilasters and multiple wavy ridges. Epiphallus short, approx. 1-1.5 times penis length, containing very few (2-3) internal cryptae near flagellum; entering penis through pyramidal verge of about one third penis length. Epiphallic flagellum slender, with no internal cryptae. Spermatophore not observed (Fig. 19).

Remarks. Mysticarion obscurior has a very similar range to $M$. insuetus, stretching from just north of Gosford on the Central Coast to Bellingen in northern NSW, in subtropical rainforest and wet sclerophyll forest (Fig. 18). The two species co-occur in some areas

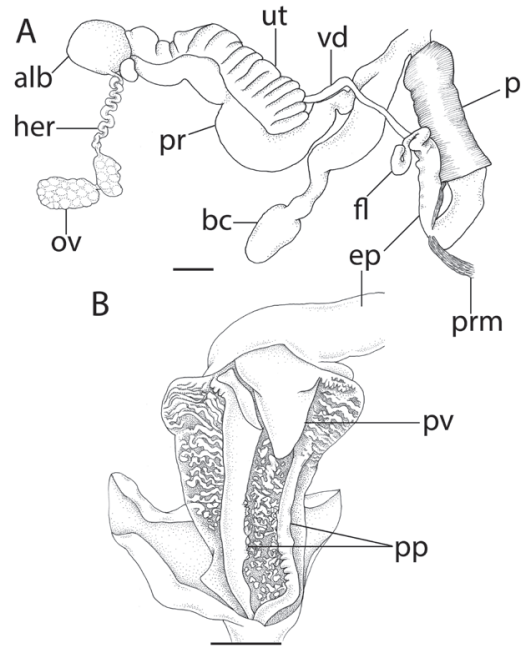

Fig. 19. Reproductive anatomy of Mysticarion obscurior sp. nov. A. Genitalia (AM C.374301). B. Penial interior (AM C.524913). Abbreviations: alb, albumen gland; bc, bursa copulatrix; cg, capsule gland; ep, epiphallus; fl, flagellum; her, hermaphroditic duct; ov, ovotestis; $p$, penis; pp, penial pilasters; pr, prostate; prm, penial retractor muscle; pt, penial tunica; pv, penial verge; ut, uterus; vd, vas deferens. Scale bars $=1 \mathrm{~mm}$.

(e.g. Little Jilliby State Conservation Preserve), although in general $M$. insuetus appears to be found in drier habitats. Mysticarion obscurior can be distinguished from its congeners by its darker body colouration of brown and pale orange pigmentation and by the discontinuous black edge on the right shell lappet, which is visible in preserved specimens even when the rest of the body pigmentation has faded. This species also has a paler shell with a slightly lower spire than $M$. insuetus. Unique features of its genital anatomy include a flagellum with no internal cryptae and only a very few cryptae in the epiphallus, indicating that the spermatophore very fewer branching spines. It also has a distinctive pyramidal penial verge and a bursa copulatrix with a long duct with broad and narrow portions and a small, distinct, rounded sac.

Etymology. From obscurior (Latin $=$ darker; adjective), referring to the darker colour of the animal relative to its congeners.

Mysticarion porrectus (Iredale, 1941)

Figs 14D, 16C-D, 20

Helicarion porrectus Iredale, 1941: 6; Smith, 1992: 234. Mysticarion porrectus: Hyman and Ponder, 2010: 36- 

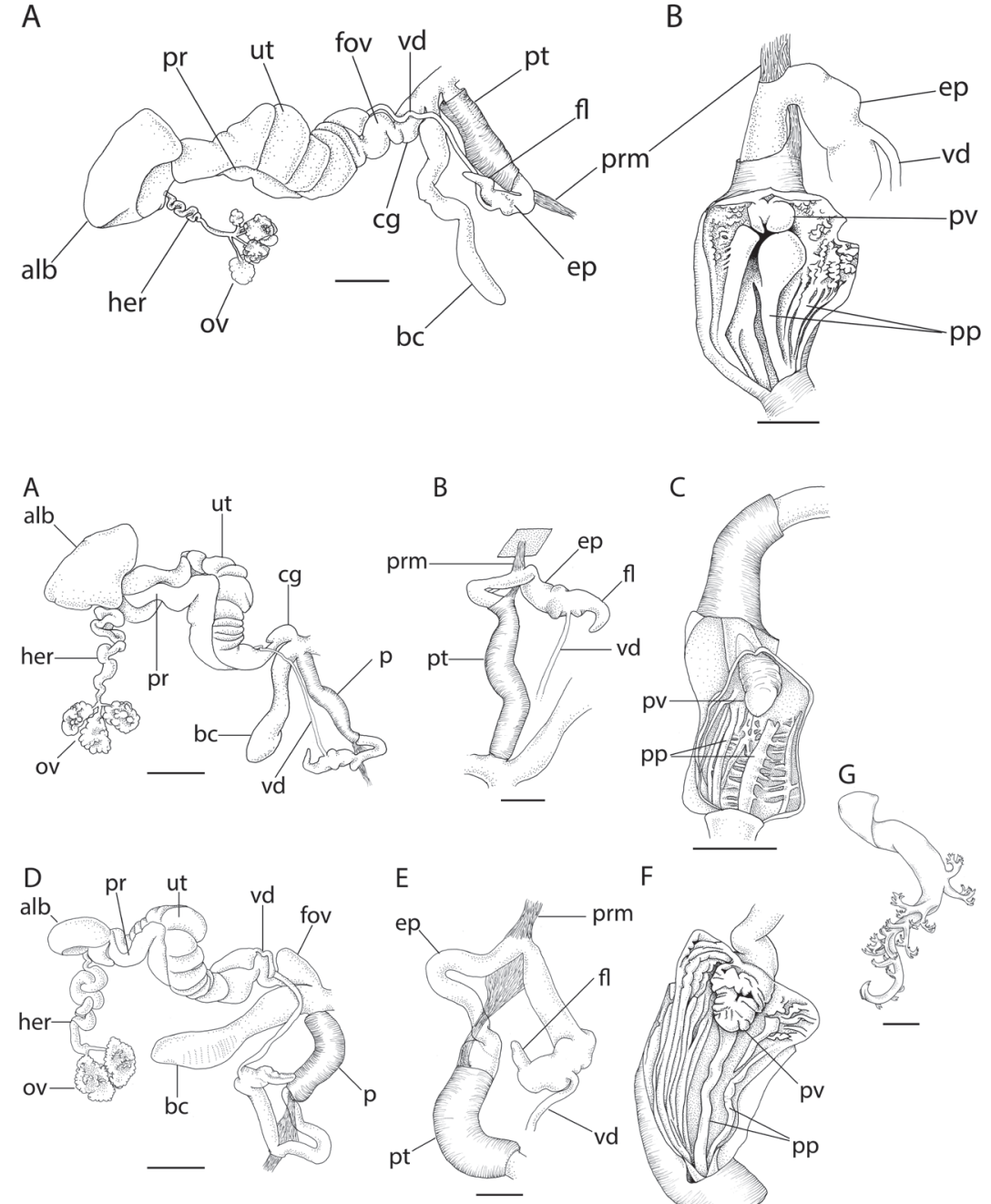

$\mathrm{F}$

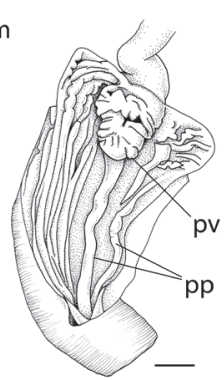

Fig. 20. Reproductive anatomy of Mysticarion porrectus, AM C.462828. A. Genitalia. B. Penial interior. Abbreviations: alb, albumen gland; bc, bursa copulatrix; cg, capsule gland; ep, epiphallus; fl, flagellum; her, hermaphroditic duct; ov, ovotestis; p, penis; pp, penial pilasters; pr, prostate; prm, penial retractor muscle; pt, penial tunica; pv, penial verge; ut, uterus; vd, vas deferens. Scale bars: $A=2 \mathrm{~mm}, \mathrm{~B}=1 \mathrm{~mm}$.
Fig. 21. Reproductive anatomy of Mysticarion hyalinus A-C. AM C.512424, Cunninghams Gap, SE Qld: A. Genitalia. B. Penial complex. C. Penial interior. D-G. AM C.512438, Bunya Moutains, SE Qld: D. Genitalia. E. Penial complex. F. Penial interior. G. Spermatophore. Abbreviations: alb, albumen gland; bc, bursa copulatrix; cg, capsule gland; ep, epiphallus; fl, flagellum; her, hermaphroditic duct; ov, ovotestis; p, penis; pp, penial pilasters; pr, prostate; prm, penial retractor muscle; pt, penial tunica; pv, penial verge; ut, uterus; vd, vas deferens. Scale bars: A, D = $2 \mathrm{~mm}, \mathrm{~B}-\mathrm{C}, \mathrm{E}-\mathrm{G}=1$ $\mathrm{mm}$.
37, Figs 5B, 6C, 7F, 8F, 9F, 12C, 13C, 15D-F, 16A; Stanisic et al., 2010: 308-309, 329.

Material examined. Probable holotype. AM C.101136 (NW of Sydney, Blue Mountains, Mt. Irvine, NSW, $33^{\circ} 29^{\prime}$ S, $150^{\circ} 28^{\prime}$ E, leg. Ward, pre-1941; Fig. 14D). Non-type material. See Table S1.

Diagnosis. Shell. Small to medium-sized, thin, glossy, pale golden to golden amber, globose with a flat spire. Protoconch with notched spiral grooves, teleoconch with fine, almost indistinct spiral grooves (Fig. 14D).

Animal. Body pale cream with no markings. Caudal horn moderately large. Sole slightly paler than body. Mantle lobes moderately small; shell lappets moder- ately small, wide at base, rapidly tapering, joined by a narrow mantle collar (Table 3; Fig. 16C-D).

Genitalia. Penis of moderate length, proximally swollen, penis and part of epiphallus enclosed in penial tunica. Penis interior with two main longitudinal pilasters, one proximally swollen, and multiple smaller longitudinal pilasters breaking up into pilasters at proximal end. Epiphallus very short, approx. equal to penis length, containing internal cryptae near flagellum; entering penis through very short verge. Epiphallic flagellum with internal cryptae and slender tail. Spermatophore not observed (Fig. 20).

Remarks. Hyman and Ponder (2010) revised this species and concluded that it had a very wide range containing several disjunct populations that were all identical anatomically (Fig. 18). Our DNA study confirms 
A
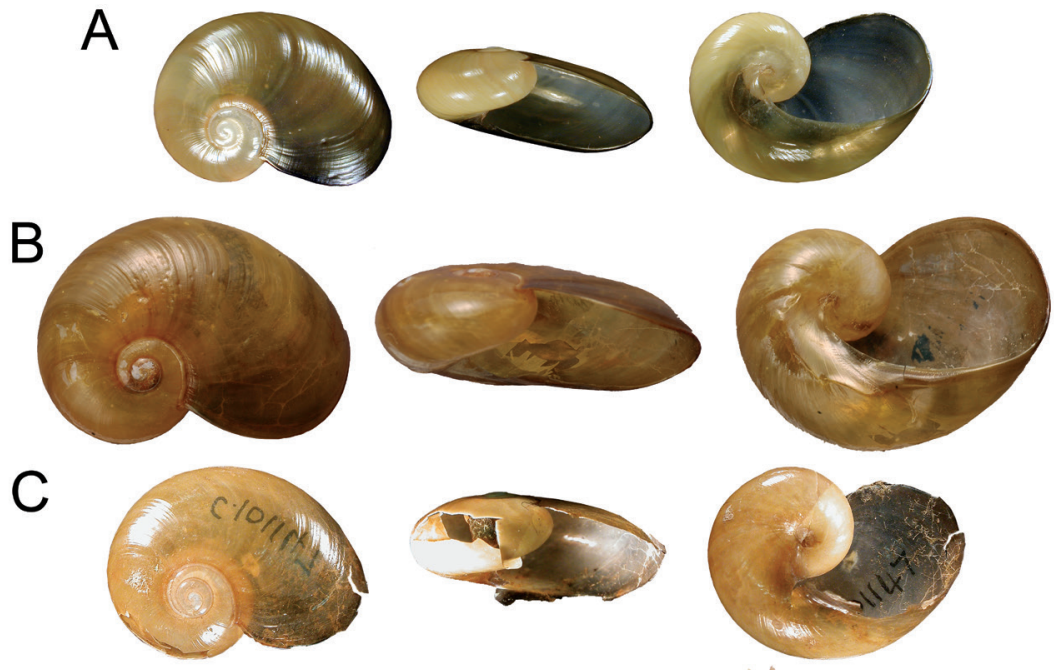

D
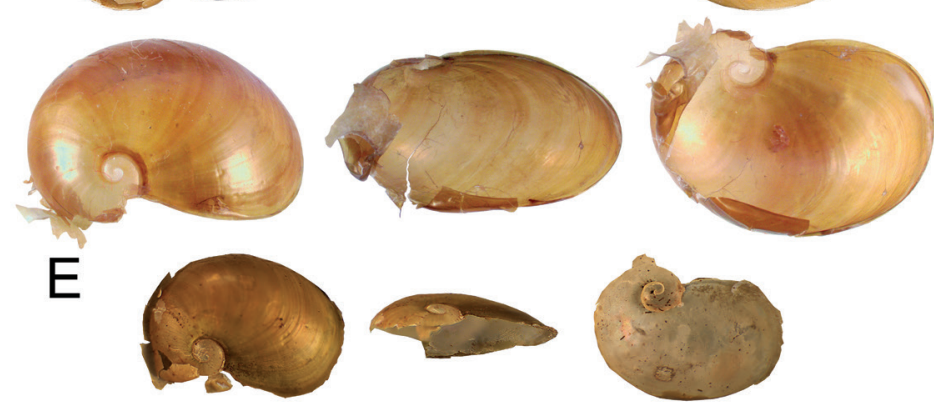

$\mathrm{F}$
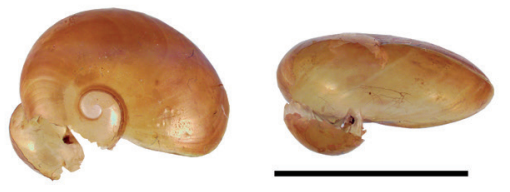

Fig. 22. Shells of Parmavitrina. A. P. planilabris, AM C.103630. B. P. rubrica AM C.376379 (size indicative; photographer; AM). C. P. disposita, probable holotype of Desidarion rubricus Iredale, 1941, AM C.101147 (size indicative; photographer: AM). D. P. megastoma, AM C.448244. E. P. maculosa, AM C.448344. F. P. flavocarinata, AM C.512373. Scale bar $-10 \mathrm{~mm}$.

that populations from Robertson, the Royal NP, the Blue Mountains, Barrington Tops, Dorrigo and the Gibraltar Range are genetically not very distinct and since they are also indistinguishable anatomically, should be treated as a single species. Material from Narooma in southeastern NSW was unable to be conclusively allocated to this species since the single specimen available was immature and proved unsuitable for DNA extraction. Even if this population is excluded, the range of this species still bridges a linear distance of over $500 \mathrm{~km}$. Mysticarion porrectus is generally found at higher altitudes than M. obscurior and $M$. insuetus, both of which are found throughout parts of its range, and occupies rainforest or wet sclerophyll forest.

Mysticarion porrectus is larger and less globose than its congeners, with a lower whorl count. It also has the shortest epiphallus of any Mysticarion species. Other distinctive features of the reproductive system include a proximally swollen penis with two main longitudinal pilasters and a very short penial verge, and very little folding present in the ovotestis.

\section{Mysticarion hyalinus (Pfeiffer, 1855)}

Figs 14E-F, 15D-F, 16E-F, 21

Vitrina hyalina Pfeiffer, 1855: 296-297; Reeve, 1862: pl. 9, sp. 68; Cox, 1868: 85, pl. 14, figs 7, 7a; Pfeiffer, 1876: 24; Smith, 1992: 244 (in Incertae Sedis).

Vitrina hyalinus: Cox, 1909: 6.

Helicarion hyalinus: Tryon, 1885: 172, pl. 39, figs 7576; Hedley, 1888: 50; Iredale, 1937a: 8.

Mysticarion hyalina: Hyman and Ponder, 2010: 38-40, figs 5C, 7G, 8G, 9G, 12D, 13D, 15G-I.

Mysticarion hyalinus: Stanisic et al., 2010: 308-309.

Fastosarion staffordorum Stanisic, 2010 (in Stanisic et al., 2010): 304-305. 

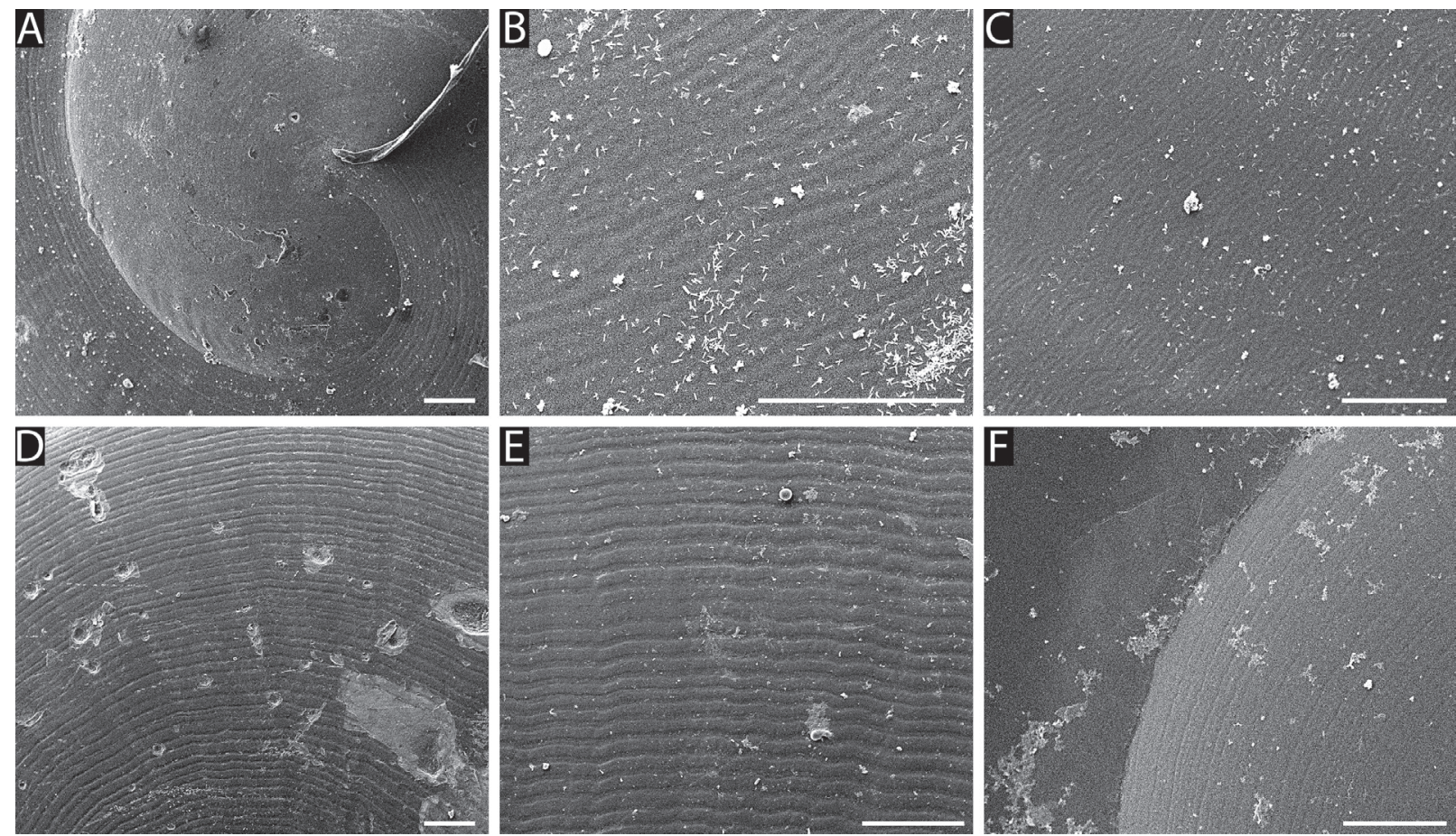

Fig. 23. Scanning electron micrographs showing shell microsculpture in Parmavitrina. A-C. P. planilabris, AM C.460262: A. Protoconch. B. early teleoconch. C. mid-teleoconch. D. P. rubrica, AM C.205515 protoconch. E. P. disposita, AM C.460261, early teleoconch. F. P. flavocarinata, AM C.512373, protoconch. Scale bars $=100 \mu \mathrm{m}$.

Material examined. Types. Syntype of Vitrina hyalina Pfeiffer, 1855 NHMUK 1983075 (Moreton Bay, leg. Strange, coll. Cuming; Fig. 14E), Holotype of Fastosarion staffordorum Stanisic, 2010 QMMO62372 (Dan-

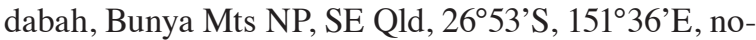
tophyll vine forest, leg. Bishop, 5/3/1976; Fig. 14F).

Non-type material. See Table S1.

Diagnosis. Shell. Medium-sized, 3.9-4.6 whorls, thin, glossy, golden amber, globose with a low spire. Protoconch with notched spiral grooves, continuing onto early teleoconch; last whorls with no sculpture (Table 3, Figs 14E-F, 15D-F).

Animal. Body very pale cream with faint brown specks of pigment on shell lappets and mantle edge. Caudal horn moderately large. Right mantle lobe moderately small, other lobes small, none fused. Shell lappets moderately small, wide at base, rapidly tapering (Fig. 16E-F).

Genitalia. Penis moderately long, tubular, slightly swollen proximally, penis and sometimes part of epiphallus enclosed in penial tunica. Penis interior with one main longitudinal pilaster and multiple smaller longitudinal pilasters. Epiphallus long, approx. twice penis length, containing internal cryptae near flagellum; entering penis through verge of about one quarter to one third penis length. Epiphallic flagellum with internal cryptae and slender tail. Spermatophore with 11-13 moderately long, complex branched spines in a spiraling pattern; initial 3-4 spines situated on base of capsule, remainder on tail-pipe; initial 5-6 spines have two major branches; remaining spines are increasingly short and simple (Fig. 21).

Remarks. This species was revised by Hyman and Ponder (2010). Here we include another species, Fastosarion staffordorum, in synonymy with Mysticarion porrectus. Three specimens from each species were sequenced, and while the two populations form monophyletic groups in the phylogenetic tree, the genetic distances between them are clearly within the range of intraspecific divergence (Table 1). Dissections revealed that the genitalia of the two taxa are identical; hence $F$. stafforodum is here considered as a younger synonym of $M$. hyalinus. This means that like $M$. porrectus and $M$. insuetus, $M$. hyalinus has a disjunct range including populations from Casino in northern NSW to Cunningham's Gap in southern QLD, and 200 $\mathrm{km}$ further north, one population in Bunya Mountains 


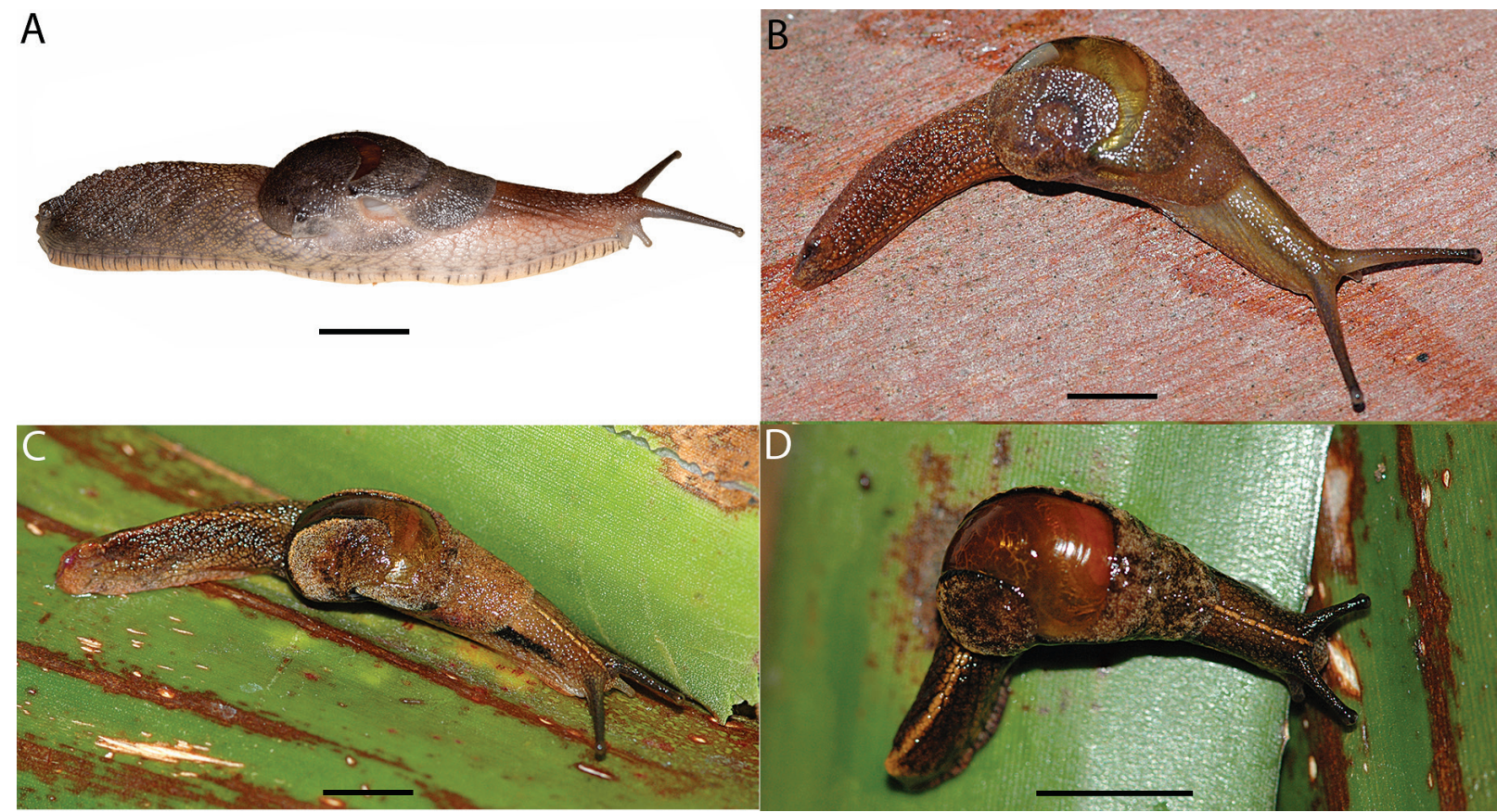

Fig. 24. Live specimens of Parmavitrina. A. P. planilabris, MV F219267, Boorganna Nature Reserve (photographer: A. Moussalli). B. P. rubrica, AM C.524922, Forest of Tranquility. C. P. megastoma, C.512383, Washpool National Park. D. P. flavocarinata, C.512374, Washpool National Park. Scale bars $=$ approx. $10 \mathrm{~mm}$.

National Park (QLD) (Fig. 18). This species is found in rainforest habitats, living on tree trunks and leaves.

Mysticarion hyalinus is larger than M. insuetus but slightly smaller than $M$. porrectus (Fig. 1B). It has a globose shell into which it can fully retract and a very pale body. Unique genital features of this species include a longer epiphallus than its congeners, a moderately long penis with a moderately small verge and one main longitudinal pilaster.

\section{Parmavitrina Iredale, 1937}

Parmavitrina Iredale, 1937c: 8.

Type species: Helicarion planilabris Cox, 1866, by monotypy; feminine

Desidarion Iredale, 1941: 8.

Type species: Desidarion dispositus Iredale, 1941, by monotypy; masculine

Diagnosis. Shell. Medium to large, ear-shaped, last whorl large and sometimes widely flared, umbilicus closed, shell glossy, protoconch and teleoconch sculptured with fine to very fine spiral grooves or smooth (Figs 22, 23).
Animal. Grey to dark brown, usually with spots or mottling on sides of tail and mantle lobes and shell lappets. Tail keeled. Mantle lobes small to moderately large, cephalic shield formed from median lobe or from fused left and median lobes, shell lappets moderately small to moderately large, connected by narrow collar; right lappet rounded (Fig. 24).

Genitalia. Ovotestis of 3-5 lobes embedded in digestive gland. Carrefour and talon usually embedded in albumen gland. Spermoviduct folded 3-4 times. Distal portion of free oviduct with elongate capsular gland with no internal sculpture, remainder of free oviduct with longitudinal pilasters internally. Bursa copulatrix relatively short, internally with longitudinal pilasters (duct) and weak transverse ridges (sac), inserted on vagina. Vagina short to moderately long, internally with longitudinal pilasters. Epiphallus enters penis through a verge or thickened ring; epiphallic caecum absent; near flagellum, epiphallus often swollen with internal cryptae; epiphallic flagellum with axial filament present, containing spiraling rows of internal cryptae with a long slender tail. Spermatophore a soft-walled capsule with hard tail-pipe; branching spines present in spiraling pattern on base of capsule and along part of tail-pipe; sometimes with 


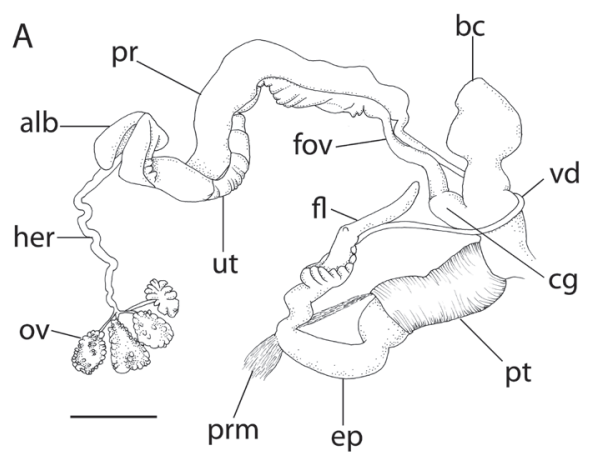

B

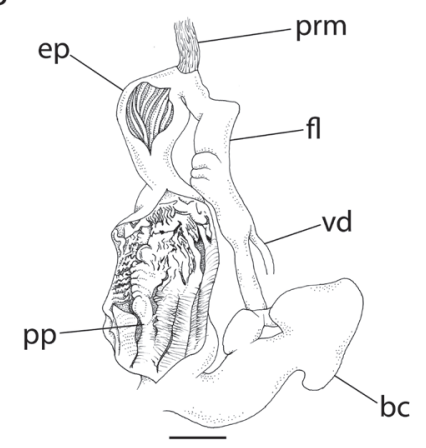

Fig. 25. Reproductive anatomy of Parmavitrina planilabris, QM MO33052: A. Genitalia. B. Penial interior. Abbreviations: alb, albumen gland; bc, bursa copulatrix; cg, capsule gland; ep, epiphallus; fl, flagellum; her, hermaphroditic duct; ov, ovotestis; p, penis; pp, penial pilasters; pr, prostate; prm, penial retractor muscle; pt, penial tunica; pv, penial verge; ut, uterus; vd, vas deferens. Scale bars: $A=4 \mathrm{~mm}, B=2 \mathrm{~mm}$.

a single long spine towards end of tail-pipe.

Remarks. Parmavitrina was introduced as a monotypic subgenus of Helicarion based on its expansive mouth, flattened upper surface and degenerate base (Iredale, 1937a). Another large semislug, Desidarion dispositus, was described a few years later as being similar to Parmavitrina, but due to its less flattened shell and complete base it was placed in a separate genus (Iredale, 1941). The anatomy of P.planilabris was described by Hyman and Ponder (2010) but no anatomical details have previously been known for $D e$ sidarion, beyond a few brief notes given to justify taking Desidarion out of synonymy with Helicarion (Hyman and Ponder, 2010). In the current study, shell shape analysis reflected the groupings shown by Stanisic et al. (2010), with D. dispositus and D. rubricus showing a significantly lower H/D ratio compared to P. planilabris and P. megastoma. However, mitochondrial phylogeny and comparative anatomy indicated that these similarities are superficial and that the two genus names are synonymous with the older Parmavitrina having priority. Anatomical comparisons show that Parmavitrina and Desidarion are unified by their large size, flattened shell with a wide aperture, and spermatophore with spines situated primarily on the capsule rather than the tail-pipe (corresponding to internal cryptae in the epiphallus and very few in the flagellum).

In the phylogenetic tree, Parmavitrina megastoma clustered with two undescribed species. Individuals from the three populations differed in shell size and aperture width: the largest species (from Bruxner Park, north of Coffs Harbour) had a very widely flared last whorl and wide aperture, the smallest species (from Gibraltar Range National Park) had a less flared last whorl and narrower aperture, and the third species was intermediate. The three species also differed anatomically. The intermediate species most closely matches the holotype of $P$. megastoma and the other two species are described below as $P$. maculosa sp. nov. and $P$. flavocarinata sp. nov. These three closely related species differ from the rest of Parmavitrina in several ways; they have a more reduced shell of fewer than 3 whorls, a more slender penis with a verge, a longer vagina and bursa copulatrix, and a more slender flagellum forming a spermatophore with short, highly branched spines. However, this clade of three species groups with the other members of Parmavitrina based on both morphology and molecular phylogeny and does not warrant recognition as a separate genus.

Parmavitrina planilabris (Cox, 1866)

Figs 22A, 23A-C, 24A, 25

Vitrina planilabris Cox, 1866: 45-46 [Holotype missing, presumed lost].

Vitrina macgillivrayi Cox, 1868: 86, pl. 14, figs 8, 8a; Pfeiffer, 1876: 23; Cox, 1909: 6 [unnecessary replacement name for Vitrina planilabris Cox, 1866].

Helicarion macgillivrayi: Tryon, 1885: 171, pl. 39, figs 67-68.

Parmavitrina planilabris: Iredale, 1937a: 8, fig.8; Smith, 1992: 240; Hyman and Ponder, 2010: 40-41, figs $5 \mathrm{D}, 7 \mathrm{H}, 8 \mathrm{H}, 9 \mathrm{H}, 12 \mathrm{E}, 13 \mathrm{E}, 15 \mathrm{~J}-\mathrm{L}$; Stanisic et al., 2010: 312-313.

Material examined. Non-type material. See Table S1.

Diagnosis. Shell. large, 3.4-3.8 whorls, amber, earshaped, flattened; last whorl large and flared with 


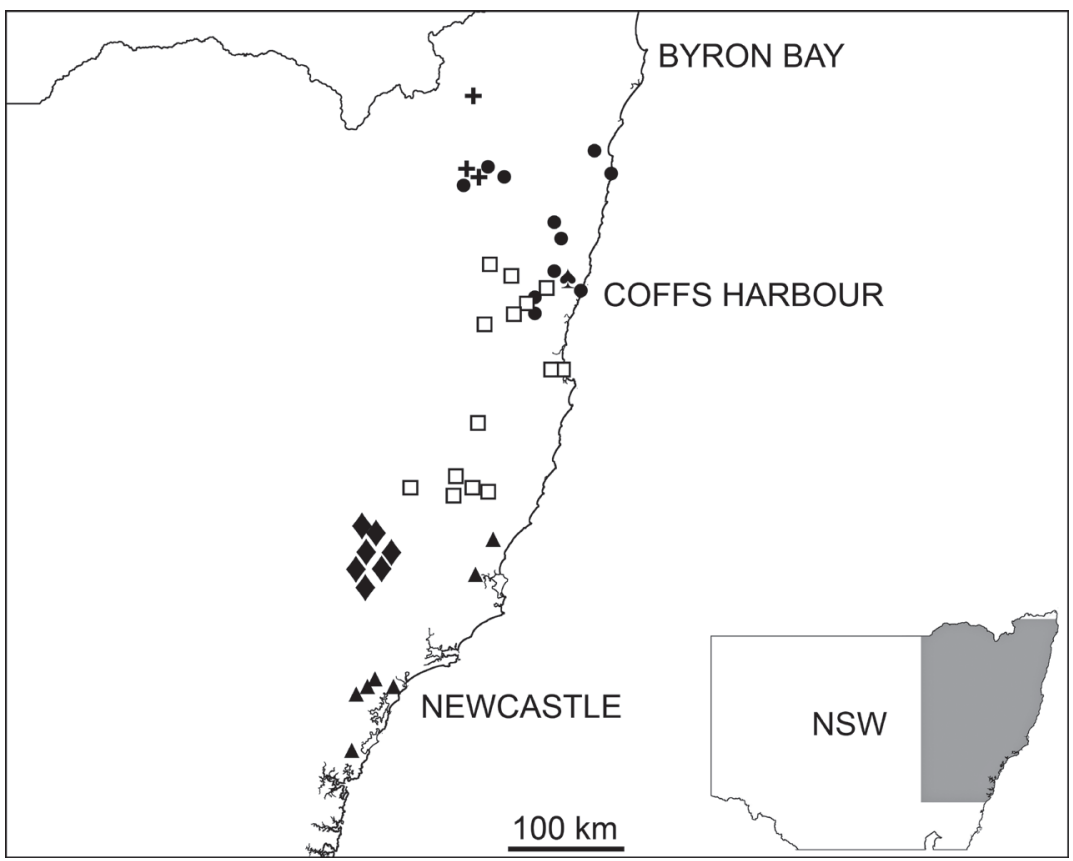

Fig. 26. Occurrence records of Parmavitrina species from the malacological collection of the Australian Museum, Sydney. Symbols: $\square=$ P. planilabris, $=P$. megastoma, $\mathbf{\Delta}=$ P. rubrica,$+=P$. flavocarinata, $\mathbf{A}=$ P. maculosa, $\diamond=P$. disposita. membraneous base; shell glossy, protoconch sculptured with fine spiral grooves, teleoconch sculptured with very fine, almost indistinct spiral grooves (Table 3, Figs 22A, 23A-C).

Animal. Grey with darker spots and orange-red mucus, mid field of sole paler than outer fields, sides of sole striped, slime network prominent, tail strongly keeled, caudal gland small. Mantle lobes moderate size, left and median lobes fused; shell lappets broad but moderately small, rounded, pustulose (Fig. 24A).

Genitalia. Bursa copulatrix short, equal in length to free oviduct, sac spherical to tear-shaped. Penis large, often very swollen at proximal end, sometimes not fully covered by penial tunica. Penis interior with irregular pilasters, ridged, primarily longitudinal at distal end, breaking up into irregular pilasters or pustules at proximal end. One pilaster often greatly swollen towards proximal end. Epiphallus relatively short, approx. 1-1.5 x penis length, containing internal cryptae near flagellum; entering penis through thickened ring. Epiphallic flagellum with internal cryptae and long, slender tail. Spermatophore not observed (Fig. 25).

Remarks. The species has been described from "Mitchell River, NSW"; the holotype is presumed lost. Parmavitrina planilabris is distributed from Buladelah in mideastern NSW to the New England Tableland in northern NSW in rainforest and wet sclerophyll for- est (Fig. 26). This species has a unique genital anatomy consisting of a large, proximally swollen penis with no penial verge and irregular penial pilasters. It can be distinguished from the similarly sized $P$. disposita, with which it is sympatric around Chichester, by its grey colouration and shell with a membraneous base. This species is phenotypically similar and phylogenetically closely related to $P$. rubrica. Both taxa differ from each other by p-distances of 2.4-3.6\% in $16 \mathrm{~S}$ and $5-6 \%$ in COI, which are near the boundary between intra- and interspecific distances. It is possible that $P$. rubrica should not be retained as a separate species and merely represents a southern range extension of $P$. planilabris. However, there are several differences between the two taxa. Parmavitrina rubrica is slightly smaller, with a more orange-brown colouration; it does not have fused mantle lobes; it has a smaller, more tubular penis with a penial verge, internally with deep, zigzagging or wavy longitudinal pilasters. In contrast, $P$. planilabris is larger, more grey in colouration, with fused mantle lobes; it has a proximally swollen penis with a short penial tunica, no penial verge, and less distinct, broad, shallow, ridged pilasters breaking up into irregular pilasters or pustules proximally. Given the small but distinct morphological differences between the two taxa we retain $P$. rubrica as separate species. 
A

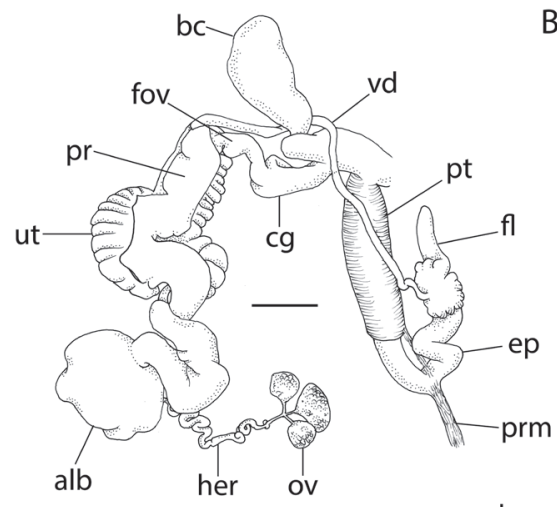

B

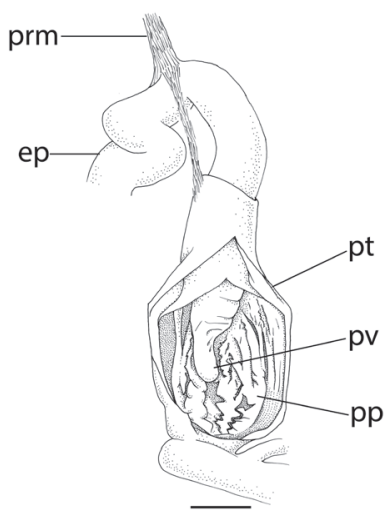

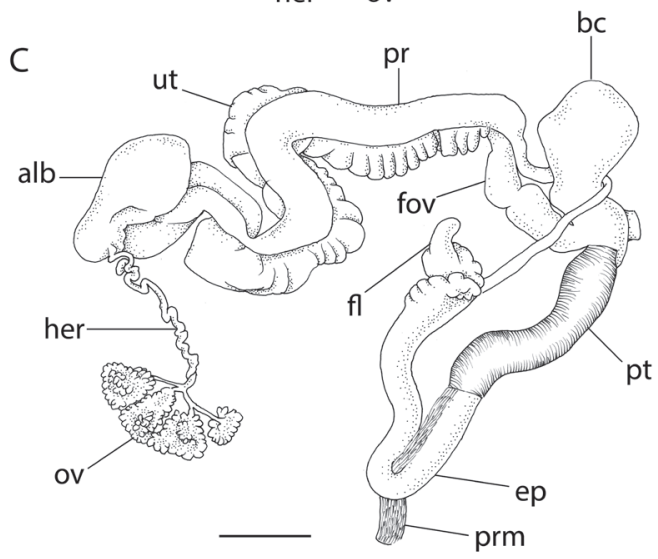

D

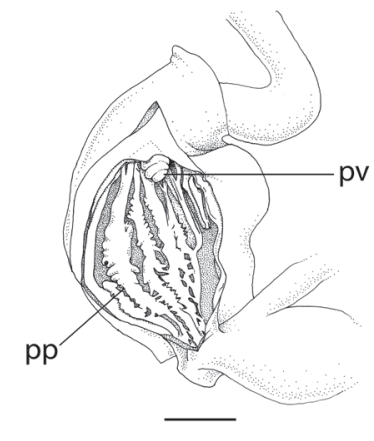

Fig. 27. Reproductive anatomy of Parmavitrina rubrica. A. Genitalia, C.364763. B. Penial interior, C.364763. C. Genitalia, AM C.334201. D. Penial interior, QM MO49406. Abbreviations: alb, albumen gland; bc, bursa copulatrix; cg, capsule gland; ep, epiphallus; fl, flagellum; her, hermaphroditic duct; ov, ovotestis; p, penis; pp, penial pilasters; pr, prostate; prm, penial retractor muscle; pt, penial tunica; pv, penial verge; ut, uterus; vd, vas deferens. Scale bars: A, C $=4 \mathrm{~mm}, \mathrm{~B}, \mathrm{D}=2 \mathrm{~mm}$.
Parmavitrina rubrica (Shea and Griffiths, 2010) comb. nov.

Figs 22B, 23D, 24B, 27

Desidarion rubricus Shea and Griffiths, 2010 in Stanisic et al., 2010: 310-311, 331.

Material examined. Holotype. AM C.376379 (W of Wyee, NW of Dooralong, Watagan road above Lowers Gully, NSW, $33^{\circ} 10.150^{\prime} S, 151^{\circ} 19.100^{\prime} \mathrm{E}$, on rock near road edge, $13 / 1 / 2000)$.

Paratypes. AM C.333639; AM C.373660; AM C.373672; AM C.373717; QMMO29727.

Non-type material. See Table S1.

Diagnosis. Shell. Large, 3.4-3.6 whorls, greenish amber, ear-shaped, flattened, protoconch slightly raised, last whorl large with membranous base; shell glossy, protoconch with fine spiral grooves, teleoconch with very fine, indistinct spiral grooves (Table 3, Fig 22B, 23D).

Animal. Orange-brown with orange-red mucus, faintly spotted on tail and shell lappets; mid field of tail paler than outer fields, slime network well-developed, tail keeled, caudal horn small. Mantle lobes moderately large, none fused, median lobe forming cephalic shield; shell lappets moderately large, connected by a narrow collar, right lappet rounded with a small point (Fig. 24B).

Genitalia. Bursa copulatrix short, slightly longer than free oviduct, sac oval-shaped. Penis thick, moderately short, cylindrical, penis and part of epiphallus enclosed in penial tunica; penis interior with approx. five longitudinal, wavy pilasters. Epiphallus moderately short, about twice penis length, with internal cryptae adjacent to flagellum; epiphallus enters penis through short to medium length verge, ranging from one sixth to half penis length. Epiphallic flagellum with spiraling rows of internal cryptae and slender tail. Spermatophore with branching spines present in spiraling pattern on base of capsule; two rows of spines present, one of thick spines with multiple branches and the second of thinner, shorter, less branched spines; tail pipe short, smooth, without branches (Fig. 27).

Remarks. Parmavitrina rubrica is found in the Hunter region, in rainforest and wet sclerophyll forest 
from Ourimbah to north of Buladelah, with a population in Gordon (northern Sydney) that may be introduced (Fig. 26; Stanisic et al., 2010). This species is slightly smaller than $P$. planilabris and $P$. disposita. This size difference and its degenerate shell edge distinguishes it from $P$. disposita, which shares its orange-brown body colour. This species can also be distinguished by the combination of a moderately short, thick penis with wavy longitudinal pilasters and a short to moderately long penial verge.

A population south of Taree is anatomically distinct from the rest of the species. It has a much longer epiphallus and a penis with a shorter verge. Only a single sequence represents this population in the tree and while it is distinct from the rest of the species, it is not highly divergent, and so we retain this population as part of $P$. rubrica.

Parmavitrina disposita (Iredale, 1941) comb. nov. Figs 22C, 23E, 28

Desidarion dispositus Iredale, 1941: 8; Stanisic et al., 2010: 310-311, 330.

Helicarion dispositus: Smith, 1992: 233.

Material examined. Probable holotype. AM C.101147 (Barrington Tops, NSW, 3201'30” S, 151 27'00” E, pre-1941; Fig. 22C).

Non-type material. See Table S1.

Diagnosis. Shell. Large, 3.7-4.4 whorls, amber, earshaped, flattened, protoconch slightly raised, last whorl large; shell glossy, protoconch with fine spiral grooves, teleoconch with very fine, indistinct spiral grooves (Table 3, Figs 22C, 23E).

Animal. Orange-brown with orange-red mucus, paler on sides of neck and along tail; sole cream, slime network well-developed, tail keeled, caudal horn small. Mantle lobes moderately large, none fused, median lobe forming small cephalic shield; shell lappets moderately large, connected by a narrow collar, right lappet rounded.

Genitalia. Bursa copulatrix short, approximately equal in length to free oviduct, sac spherical. Penis large, slightly swollen at proximal end, enclosed in penial tunica, penis interior with numerous longitudinal pilasters, becoming more irregularly shaped at proximal end with longitudinal threads between them. Epiphallus very short, less than penis length, swollen with internal cryptae; enters penis through a short verge. Epiphallic flagellum with spiraling rows of internal cryptae and slender tail. Spermatophore with branching spines on base of capsule and tail-pipe, tailpipe very short, one very long, slender spine with no accessory branches attached near the junction of capsule and tail-pipe; spermatophore golden brown, tips of branches dark brown (Fig. 28).

Remarks. This species is found from Barrington Tops and the Mt Royal Range to the Liverpool Ranges. It is also recorded from the Comboyne Plateau (Stanisic et al., 2010) (Fig. 26).

Parmavitrina disposita can be distinguished from $P$. planilabris, which is similar in size, by its orangebrown body colour and complete shell. Its genital morphology differs from that of its congeners by the presence of a very short epiphallus and a large penis with a small verge and numerous longitudinal pilasters.

Parmavitrina megastoma (Cox, 1868)

Figs 22D, 24C, 29

Vitrina megastoma Cox, 1868: 87.

Helicarion megastoma: Tryon, 1885: 170, pl. 38, figs 52-53.

Parmavitrina megastoma: Iredale, 1941: 8; Smith, 1992: 240; Stanisic et al., 2010: 312-313, 331.

Material examined. Holotype. AM C.101145 (Clarence River, NSW).

Non-type material. See Table S1.

Diagnosis. Shell. Amber, moderately large, 2.5-3.0 whorls, ear-shaped, flattened; last whorl very large and flared with membraneous base; shell glossy, protoconch with fine spiral grooves, teleoconch with very fine, indistinct spiral grooves (Table 3, Fig. 22D).

Animal. Brown with purple mucus, faintly spotted, yellow line along neck, foot border edged with orange, mid field of sole slightly darker than outer fields, slime network prominent, tail with a strong, reddish keel, caudal horn small. Mantle lobes moderately large, left and median lobes fused to form a large cephalic shield; shell lappets broad, moderate size, rounded, edged with black and with faint black markings (Fig. 24C).

Genitalia. Bursa copulatrix long, more than twice length of free oviduct, sac elongate. Penis relatively slender, cylindrical; penis and part of epipahllus enclosed in a thick penial tunica. Penis interior with one longitudinal pilaster and numerous weak longitudinal ridges. Epiphallus long, more than twice penis length; 


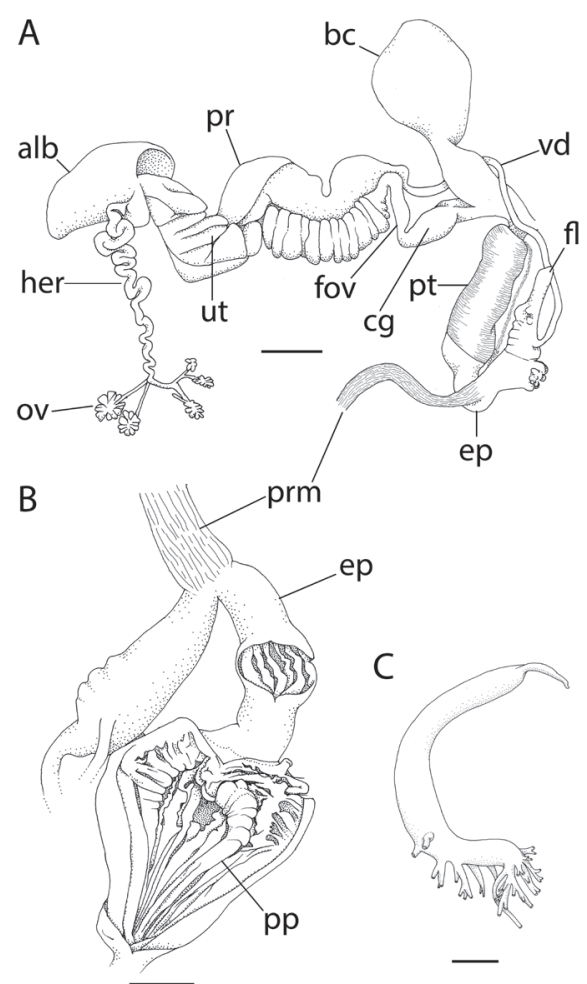

Fig. 28. Reproductive anatomy of Parmavitrina disposita. A. Genitalia, AM C.165923. B. Penial interior, AM C.460261. C. Spermatophore, AM C.165923. Abbreviations: alb, albumen gland; bc, bursa copulatrix; cg, capsule gland; ep, epiphallus; fl, flagellum; her, hermaphroditic duct; ov, ovotestis; $p$, penis; pp, penial pilasters; pr, prostate; prm, penial retractor muscle; pt, penial tunica; pv, penial verge; ut, uterus; vd, vas deferens. Scale bars: $A=4 \mathrm{~mm}, \mathrm{~B}-\mathrm{C}=2 \mathrm{~mm}$.

epiphallis enters penis through a moderately long, slender verge. Epiphallic flagellum with spiraling rows of internal cryptae and slender tail. Spermatophore not observed (Fig. 29).

Remarks. This species is listed by Stanisic et al. (2010) as ranging from Coffs Harbour to Grafton (Fig. 26). Specimens confirmed as $P$. megastoma by dissection or sequencing range from just north of Coffs Harbour to the Gibraltar Range and the Grafton area, in dry woodland to rainforest habitats. Parmavitrina megastoma is intermediate in size between $P$. тасиlosa and P. flavocarinata and is the only species known to exude bright purple mucus when disturbed (mucus colour is not known for P. maculosa). It is sympatric with $P$. flavocarinata in the Gibraltar Range National Park and Washpool National Park. It may also be sympatric with $P$. maculosa since the two species occur very close together just north of Coffs Harbour,
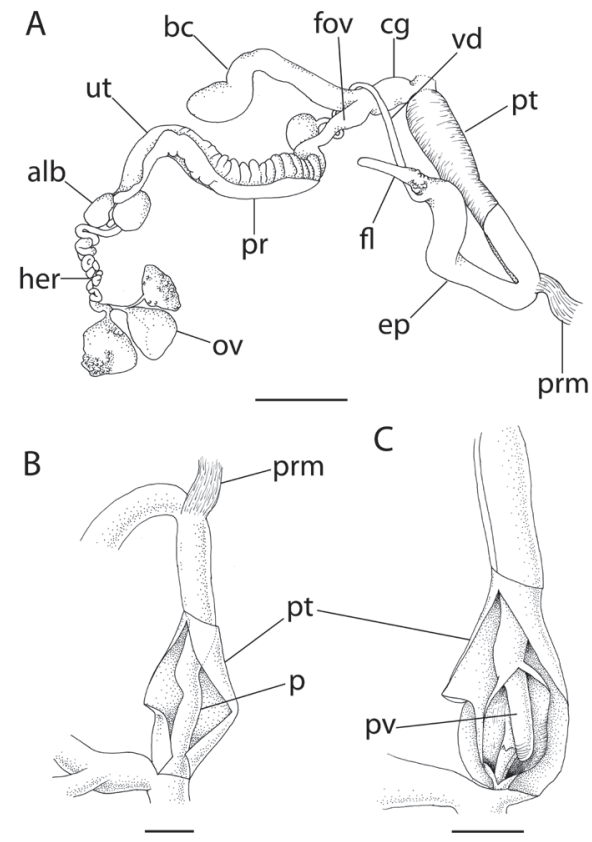

Fig. 29. Reproductive anatomy of Parmavitrina megastoma, AM C.377461. A. Genitalia. B. Penial complex. C. Penial interior. Abbreviations: alb, albumen gland; bc, bursa copulatrix; cg, capsule gland; ep, epiphallus; fl, flagellum; her, hermaphroditic duct; ov, ovotestis; p, penis; pp, penial pilasters; pr, prostate; prm, penial retractor muscle; pt, penial tunica; pv, penial verge; ut, uterus; vd, vas deferens. Scale bars: $\mathrm{A}=4 \mathrm{~mm}, \mathrm{~B}-\mathrm{C}=$ $2 \mathrm{~mm}$.

P. megastoma in Bagawa State Forest and P. maculosa in Bruxner Park Flora Reserve.

\section{Parmavitrina maculosa sp. nov.}

Figs 22E, 30

Material examined. Holotype. AM C.448344 (near Coffs Harbour, Orara East SF, Bruxner Park Flora Reserve, cnr Bruxner Park Rd and Sealy Lookout road, NSW, $30^{\circ} 15^{\prime} 02^{\prime \prime} \mathrm{S}, 153^{\circ} 06^{\prime} 30$ " E, tall open Blackbutt forest, Imperata/Themeda/Lomandra groundcover, under burnt hardwood logs, 14/9/2005).

Paratypes. AM C.532840. Same data as holotype. Non-type material. See Table S1.

Description. Shell. Large, 2.5 whorls, golden-amber, strongly ear-shaped, flattened; last whorl extremely 

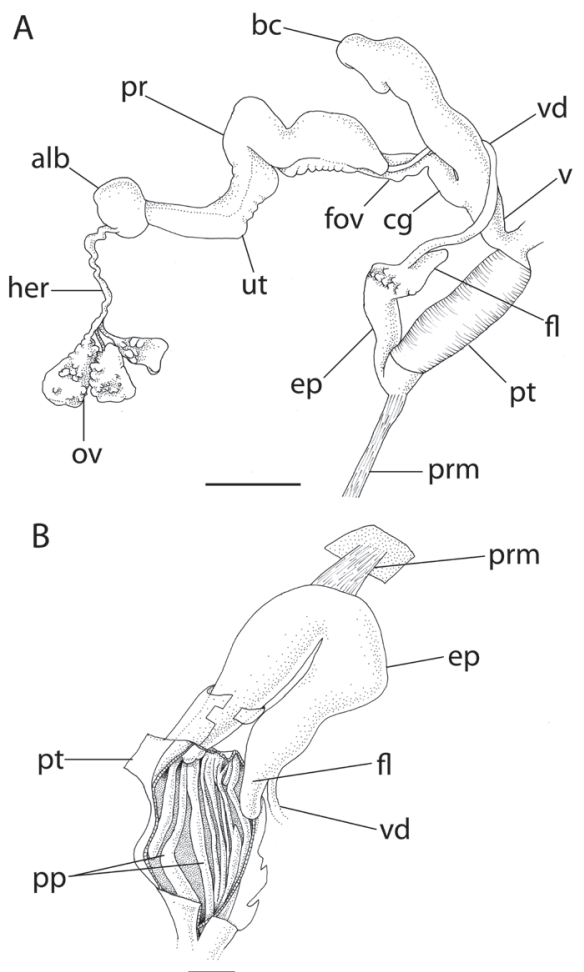

Fig. 30. Reproductive anatomy of Parmavitrina maculosa. A. Genitalia, AM C.532840. B. Penial interior, AM C.344211. Abbreviations: alb, albumen gland; bc, bursa copulatrix; cg, capsule gland; ep, epiphallus; fl, flagellum; her, hermaphroditic duct; ov, ovotestis; p, penis; pp, penial pilasters; pr, prostate; prm, penial retractor muscle; pt, penial tunica; $p v$, penial verge; ut, uterus; vd, vas deferens. Scale bars: $A=4 \mathrm{~mm}, B=1 \mathrm{~mm}$.

large and flared with membraneous base; shell glossy, very faint, indistinct spirals visible on protoconch and teleoconch (Fig. 22E).

Animal (in spirit). Grey, with prominent grey spots on tail, mantle lobes and shell lappets; mid field of sole slightly darker than outer fields, slime network prominent, tail keeled, caudal horn small. Mantle lobes large, left and median lobes fused to form a large cephalic shield; shell lappets moderate size, right lappet rounded.

Genitalia. Bursa copulatrix long, more than twice length of free oviduct, sac slender. Penis very short, penis and part of epiphallus enclosed in thin penial tunica, penis interior with longitudinal pilasters, two strong and six weaker. Epiphallus approximately 2-2.5 times penis length; enters penis through a short verge. Epiphallic flagellum with spiraling rows of internal cryptae and slender tail. Spermatophore not observed (Fig. 30).

Remarks. Parmavitrina maculosa, preliminarily identified as 'Helicarionidae sp. NN 6' through curatorial work, is only known from in or around Bruxner Park Flora Reserve, north of Coffs Harbour in northern NSW, in open blackbutt and moist sclerophyll forests. It is represented by very few specimens in the collections of the AM and the QM and has not been observed live, so comparative comments on its external appearance are based only on preserved specimens.

This species is larger than its congeners, with a more widely flared aperture and the shortest penis length relative to body size.

Etymology. From maculosa $($ Latin = spotted; adjective), referring to spots on both sides of the tail.

Parmavitrina flavocarinata sp. nov.

Figs 22F, 23F, 24D, 31

Material examined. Holotype. AM C.512373 (Washpool National Park, off Gwydir Highway, NSW, $29^{\circ}$ 29' S, $152^{\circ} 20^{\prime}$ E, 23/2/2016).

Paratypes. AM C.532841 (Same data as holotype). Non-type material. See Table S1.

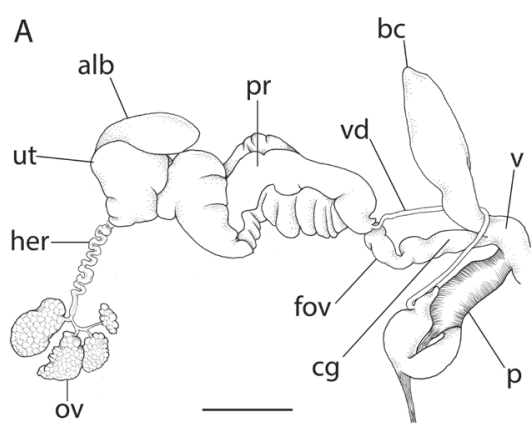

B

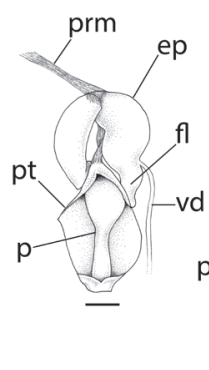

C

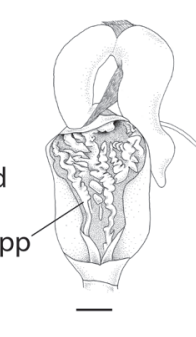

Fig. 31. Reproductive anatomy of Parmavitrina flavocarinata, AM C.532841. A. Genitalia. B. Penial complex. C. Penial interior. D. Spermatophore. Abbreviations: alb, albumen gland; bc, bursa copulatrix; cg, capsule gland; ep, epiphallus; fl, flagellum; her, hermaphroditic duct; ov, ovotestis; $p$, penis; pp, penial pilasters; pr, prostate; prm, penial retractor muscle; pt, penial tunica; pv, penial verge; ut, uterus; vd, vas deferens. Scale bars: $A=4 \mathrm{~mm}$, $\mathrm{B}-\mathrm{C}=1 \mathrm{~mm}$. 
Description. Shell. Moderately large, 2.6 whorls, orange-amber, ear-shaped, flattened; last whorl large and flared with membraneous base; shell glossy, protoconch with fine spiral grooves, not closely spaced, and teleoconch with very fine, faint spiral grooves (Figs 22F, 23F).

Animal. Dark brown, spotted, yellow line along neck, foot border edged with crimson, slime network moderately strong, tail with a strong, yellow keel, caudal horn small. Mantle lobes moderately small, none fused, median lobe forms small cephalic shield; shell lappets broad, moderate in size, right lappet rounded, edged with black and with black markings (Fig. 24D).

Genitalia. Bursa copulatrix moderately long, approximately 1.5 times length of free oviduct. Penis short, appearing cylindrical when enclosed in penial tunica, penial tunica thick at distal end and thin at proximal end; penis swollen at proximal end; penis interior with longitudinal, zig-zagging pilasters, two present at distal end and numerous present at proximal end. Epiphallus short, less than 1.5 times penis length; enters penis through thickened ring. Epiphallic flagellum with spiraling rows of internal cryptae and slender tail. Spermatophore with spiraling rows of branching spines present on base of capsule with a few continuing on to tail-pipe; spines split into multiple branches aligned longitudinally (Fig. 31).

Remarks. Parmavitrina flavocarinata, preliminar- ily identified as 'Helicarionidae sp. NN7' through curatorial work, is known from the Gibraltar Range National Park to the Girard State Forest in northern NSW (Fig. 26), living under logs in rainforest habitats, and is the smallest Parmavitrina species. It is most similar to the sympatric $P$. megastoma but can be distinguished by its smaller size, darker colouration with small but distinct spots and lack of purple mucus. Its shell is darker in colour and has a less widely flared aperture. Anatomically it is distinguished by its proximally swollen penis with a penial tunica that is thick distally and thin proximally, zig-zagging pilasters and the lack of a penial verge.

Etymology. From flavus $($ Latin $=$ yellow; adjective $)$ and carinata (Latin = keeled; adjective), referring to the strong yellow keel.

\section{Cucullarion Stanisic, 1998}

Cucullarion Stanisic, 1998: 597.

Type species: Cucullarion parkini Stanisic, 1998, by original designation; masculine

Diagnosis. Shell. Medium sized, reduced, ear-shaped, flattened; base and internal whorls completely membraneous, dorsal calcified area plate-like; shell glossy, no sculpture.
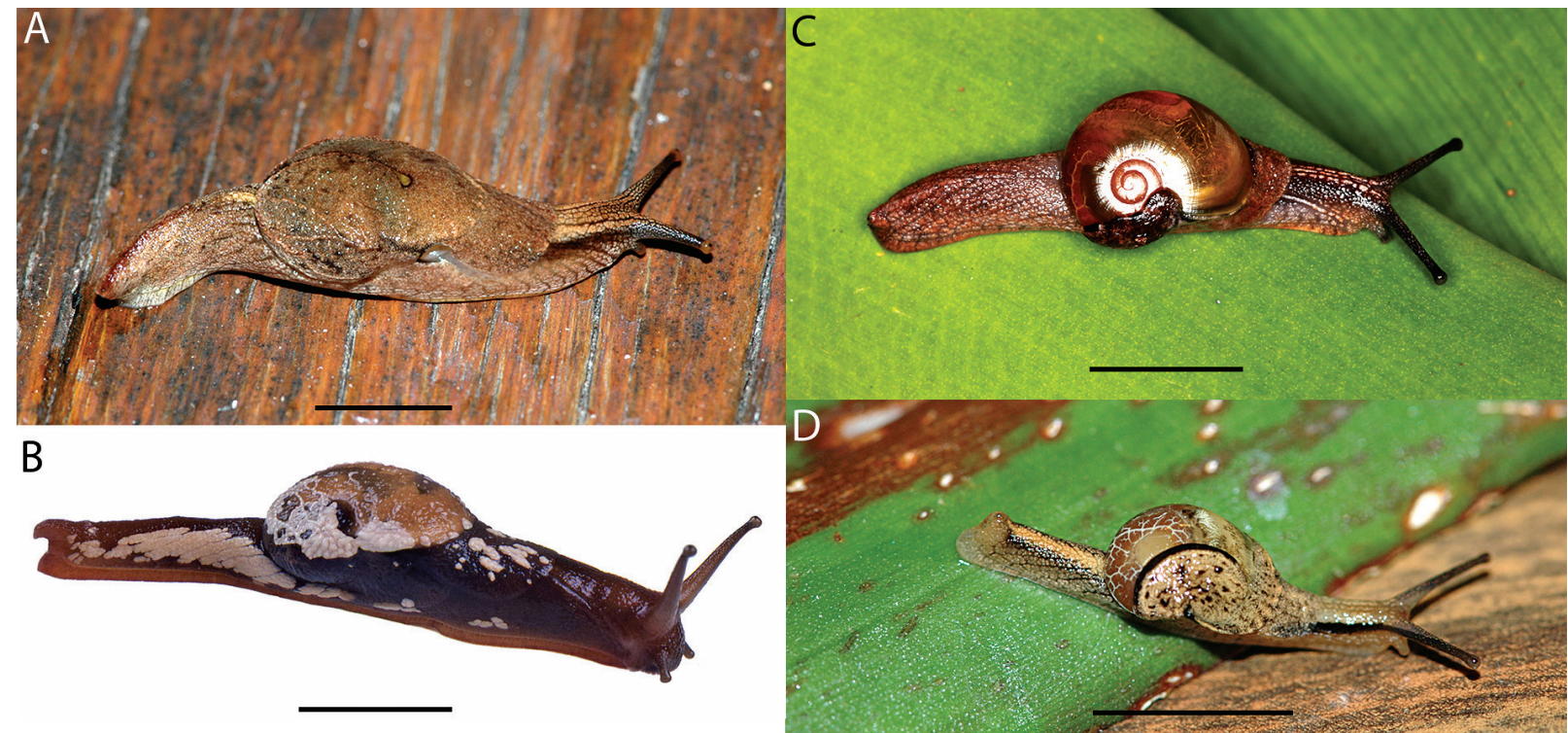

Fig. 32. Live specimens of Cucullarion, Peloparion and Ubiquitarion gen. nov. A. Cucullarion parkini, AM C.512610, Lamington National Park. B. C. albimaculosum, AM C.103209 (photographer: G. Millen). C. Peloparion helenae, MV F219249, Barrington Tops National Park (photographer: A. Moussalli). D. Ubiquitarion iridis, AM C.512394, Pikapene National Park. Scale bars = approx. 10 mm. 
Animal. Beige to orange- or red-brown; caudal horn small. Mantle lobes large, left and median lobes fused to form cephalic shield; shell lappets large, fused at both sides, covering most of shell (Fig. 32A-B).

Gentitalia. Ovotestis of 3-4 lobes grouped together and embedded in tip of digestive gland. Talon and carrefour embedded in albumen gland. Spermoviduct folded 5 times. Free oviduct long with no internal sculpture; capsular gland small, spherical. Bursa copulatrix moderately long, reaching two thirds of the way along spermoviduct, consisting of swollen base, slender duct and elongate sac; internally with longitudinal pilasters; inserted on vagina. Vagina very short. Penial tunica tightly attached to epiphallus by muscle fibres; epiphallus enters penis through verge; epiphallic caecum absent; epiphallic flagellum with axial filament present; single internal crypt present in part of epiphallus adjacent to flagellum but not in flagellum. Spermatophore a soft-walled capsule with hard tailpipe; one spine present at junction of capsule and tailpipe; tail-pipe sculptured with a spiraling row of tiny teeth.

Remarks. Cucullarion was introduced for a semislug from southern Queensland, C. parkini (Stanisic, 1998) and was later expanded to include a second species, C. albimaculosum (Stanisic et al., 2010). The two species are notable for their degenerate, plate-like shells with membranous sides, bases and internal whorls.

\section{Cucullarion parkini Stanisic, 1998}

(Figs 32A, 33A-B)

Cucullarion parkini Stanisic, 1998: 598, figs 1-4; Stanisic et al., 2010: 314-315, 332.

Material examined. Holotype. QMMO60128 (The Knoll NP, Tamborine Mtn, SE QLD, $27^{\circ} 55^{\prime} \mathrm{S}, 153^{\circ}$ 11' E, leg. Stanisic et al., 26/2/1985).

Non-type material. See Table S1.

Diagnosis. Shell. Medium sized, 2.8 whorls, yellowamber, ear-shaped, flattened; base and internal whorls completely membraneous, dorsal calcified area platelike; shell glossy, no sculpture.

Animal. Beige with reddish-brown colouring deepening on tail and neck, speckled with tiny spots of yellow pigment, faintly spotted with darker brown; sides of sole striped; tail with a strong reddish-brown keel; caudal horn small. Mantle lobes large, left and median
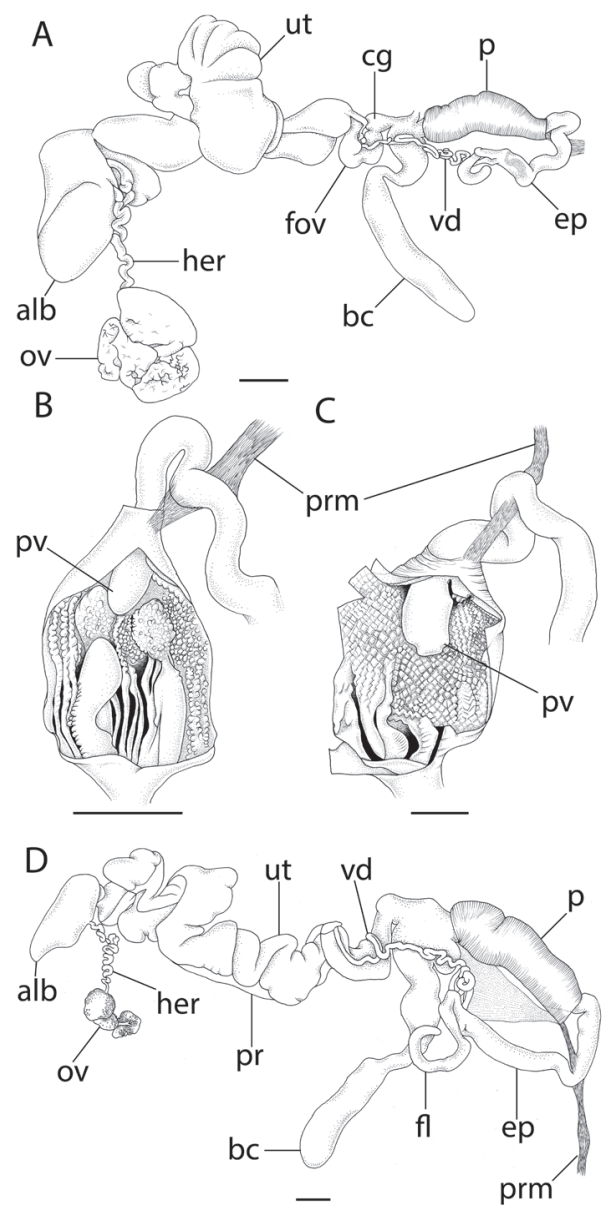

Fig. 33. Reproductive anatomy of Cucullarion. A-B. C. parkini, AM C.512610 A. Genitalia. B. Penial interior. C-D. C. albimaculosum, QM MO25791. C. Penial interior. D. Genitalia. Abbreviations: alb, albumen gland; bc, bursa copulatrix; cg, capsule gland; ep, epiphallus; fl, flagellum; her, hermaphroditic duct; ov, ovotestis; p, penis; pp, penial pilasters; pr, prostate; prm, penial retractor muscle; pt, penial tunica; pv, penial verge; ut, uterus; vd, vas deferens. Scale bars $=2 \mathrm{~mm}$.

lobes fused to form cephalic shield; shell lappets large, fused at both sides, covering most of shell, edged with reddish brown and with reddish brown longitudinal ridges (Fig. 32A).

Gentitalia. Bursa copulatrix long, swollen at base, duct slender, sac elongate. Penis moderate size, cylindrical, completely encased in penial tunica; penis interior with one raised penial pilaster and one smaller penial pilaster, each leading up to a rounded penial pilaster proximally; both pilasters pustulose; remainder of penis interior with longitudinal ridges becoming pustulose proximally. Epiphallus short, approximately penis length, enters penis through short verge of about 
a quarter penis length. Epiphallic flagellum moderately long, slender, without internal cryptae; one crypt present in adjacent part of epiphallus. Spermatophore with elongate capsule and long, thin tail-pipe sculptured with a single row of tiny teeth; a single short spine present at junction of tail-pipe and capsule (Fig. 33A-B).

Remarks. Cucullarion parkini was previously known only from The Knoll NP in SE QLD. Here we extend the range to include Binna Burra in Lamington NP. This rainforest species has only ever been found a handful of times, despite relatively frequent collecting in these locations. This may be due to its highly reduced shell and slender body, which would allow it to hide deeply in the base of palm trees (individuals have been observed emerging from palm trunks during rainstorms) or other crevices. However, it is also likely that this species is present in very low numbers.

The congener of this species, Cucullarion albimaculosum, is also found in Binna Burra, although the two species have not been collected together. Cucullarion parkini can be distinguished from C.albimaculosum by its slightly smaller size and paler colour, and by the lack of white pigment on its body. Anatomically, the two species differ in the length of the flagellum and the penis interior.

Cucullarion albimaculosum Stanisic, 2010

(Figs 32B, 33C-D)

Cucullarion albimaculosa Stanisic, 2010 (in Stanisic et al., 2010): 314-315, 332.

Material examined. Holotype. QMMO17249 (Collins Ck crossing, Border Ranges NP, N NSW, $28^{\circ} 26^{\prime} \mathrm{S}$, $153^{\circ} 09^{\prime}$ E, on trees, leg. Stanisic and Potter, 10/3/1987). Non-type material. See Table S1.

Diagnosis. Shell. Medium sized, 3.0 whorls, amber, ear-shaped, flattened; base and internal whorls completely membraneous, dorsal calcified area plate-like; shell glossy, no sculpture (Table 3).

Animal. Orange brown with spots of thick white pigment on tail, mantle lobes and shell lappets; tail keeled; caudal horn small. Mantle lobes large, left and median lobes fused to form cephalic shield; shell lappets large, fused at both sides, covering most of shell (Fig. 32B).

Genitalia. Bursa copulatrix long, swollen at base, duct slender, sac elongated. Penis moderate size, cylindrical, completely encased in penial tunica; penis inte- rior with diamond shaped pustules and four longitudinal pilasters at distal end. Epiphallus moderately short, approximately 1.5 times penis length, enters penis through short verge of about one fifth to one third penis length. Epiphallic flagellum very long, slender, without internal cryptae, tip attached by connective tissue to interior of left body wall; one crypt present in adjacent part of epiphallus. Spermatophore not observed (Fig. 33C-D).

Remarks. This species is found in the Border Ranges NP (NE NSW) and Lamington NP (SE QLD) (Fig. 34), from arboreal habitats in subtropical rainforest. It has been collected more frequently than C. parkini, despite its similarly cryptic nature. Cucullarion albimaculosum can be distinguished from other semislugs by the white pigment spots present on the tail, mantle lobes and shell lappets.

Peloparion Iredale, 1937

Peloparion Iredale, 1937a: 8.

Type species: Helicarion helenae Godwin-Austen, 1883, by subsequent designation of Iredale (1941); masculine

Diagnosis. Shell. Small, ear-shaped, flattened, last whorl large, umbilicus closed, shell glossy, protoconch with fine spiral grooves, teleoconch smooth (Table 3, Fig. 35).

Animal. Pale grey with bright red mucus. Mantle lobes and shell lappets well developed.

Genitalia. Ovotestis of four lobes, embedded in digestive gland. Talon and carrefour embedded in albumen gland. Spermoviduct folded twice. Free oviduct very long with no internal sculpture; capsular gland not externally visible. Bursa copulatrix moderately short, reaching less than halfway along spermoviduct; internally smooth; inserted on vagina. Vagina very short. Epiphallus enters penis through moderately long verge; epiphallic caecum absent; epiphallic flagellum with axial filament present; numerous internal cryptae present in part of epiphallus adjacent to flagellum but not in flagellum. Spermatophore a soft-walled capsule with hard tail-pipe; branching spines present on capsule; tail-pipe with only a single spine.

Remarks. Peloparion was originally introduced as a subgenus of Helicarion for Vitrina hyalina Pfeiffer, 1855 (Iredale, 1937c), but subsequently Iredale (1941) stated that the name was intended for Helicarion helenae Godwin-Austen, 1883. The genus was revised by Hyman (2007) and Hyman and Ponder (2010). 


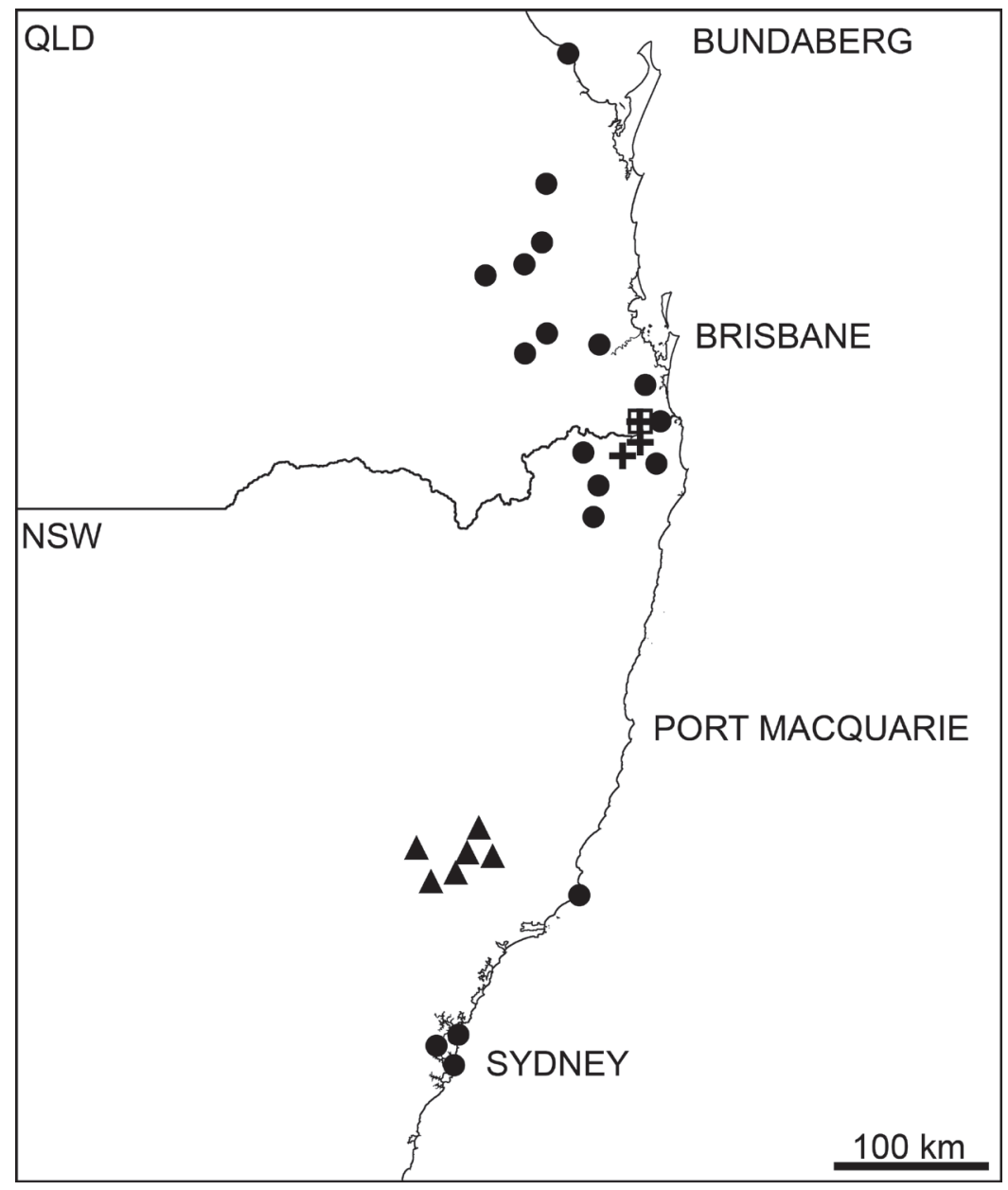

Fig. 34. Occurrence records of Cucullarion, Peloparion, and Ubuiquitarion from the malacological collection of the Australian Museum, Sydney. Symbols: $\mathbf{0}=U$. iridis, $\mathbf{\Delta}=P$. helenae, $+=C$. albimaculosum, $\square=$ C. parkini .
Peloparion helenae (Godwin-Austen, 1883)

(Figs 32C, 35A, 36)

Helicarion helenae Godwin-Austen, 1883: 146, pl. 41, figs 1-8; Tryon, 1885: 170, pl. 38, figs 50-51; Cox, 1909: 6.

Peloparion submissus Iredale, 1941: 7, fig. 8; Smith, 1992: 240.

Peloparion helenae: Iredale, 1941: 7; Smith, 1992: 240; Hyman and Ponder, 2010: 42; Stanisic et al., 2010: 310-311, 330 .

Material examined. Holotype (Peloparion submissus). AM C.101142 (Scone, NSW, 32³' S, 15052’ E, pre-1941; Fig. 35A).

Non-type material. See Table S1.

Diagnosis. Animal. Pale grey with faint spots on sides of body and lappets; appearing red from mucus.
Sole uniformly pale, foot border red; caudal horn large, edged with dark grey. Slime network visible. Mantle lobes and shell lappets well developed, lappets stained red and joined by a narrow collar; right lappet moderately large, rounded, edged with black, with a raised ridge on lower side; left lappet slightly shorter, rounded at tip, with a raised ridge on lower side (Fig. 32C).

Genitalia. Bursa copulatrix moderately short, sac tear-shaped and distinguishable from duct. Penis cylindrical, fully enclosed in penial tunica, internally with two main longitudinal pilasters broken up at proximal end into several smaller zigzagging threads; additional smaller longitudinal pilasters present; transverse ridges at proximal end; epiphallus moderately short, less than twice penis length, with numerous internal cryptae adjacent to flagellum; entering penis through thick, moderately long verge sculptured with transverse ridges. Spermatophore with approximately 


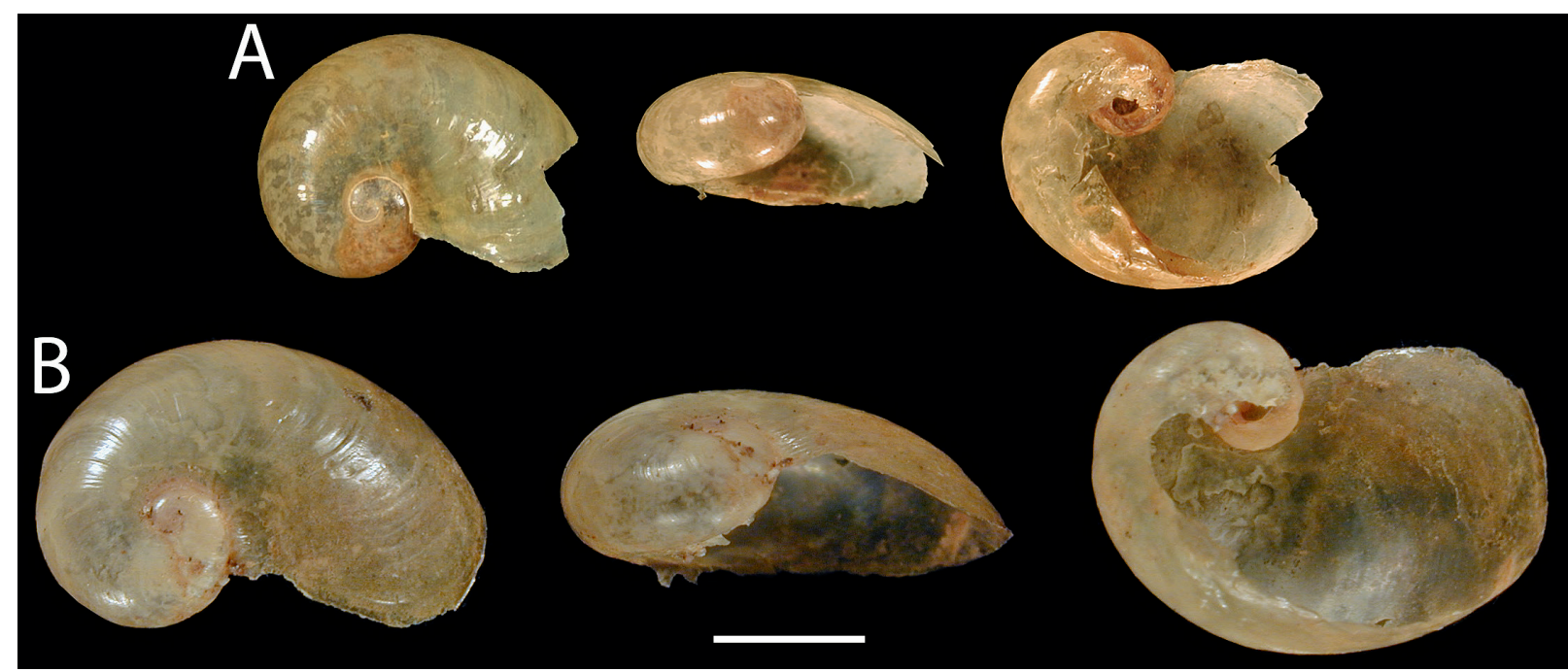

Fig. 35. Shells of Peloparion and Ubqiuitarion. A. Peloparion helenae: holotype of Peloparion submissus Iredale, 1941, AM C.101142 (size indicative; photographer: AM). B. Ubiquitarion iridis holotype AM C.456552. Scale bar = $3 \mathrm{~mm}$.

six branching spines present on capsule in a spiraling pattern and one spine on tail-pipe (Fig. 36).

Remarks. We follow Hyman (2007) and Hyman and Ponder (2010) in recognising the synonymy of Peloparion helenae and P. submissus, based on an examination of the type material.

Peloparion helenae is only known from Barrington Tops are in the Hunter Valley, living arboreally in beech forest and snow gum woodland. It is easily distinguished from other helicarionid semislugs by its small size and bright red mucus. It was previously grouped with Ubiquitarion iridis, another small semislug with rounded, dark-edged shell lappets. However, while some elements of the genitalia appear to be quite similar, there are considerable differences in the penial complex and spermatophore. In Peloparion helenae there are numerous internal cryptae in the epiphallus but none in the flagellum, giving rise to a spermatophore with long branching spines on the capsule but very few on the tail-pipe. In contrast, $U$. iridis has a thick muscular tunica obscuring the flagellum and adjacent part of the epiphallus, and a spermatophore with only a single branching spine on the capsule but a double row of numerous short, branching spines on the tail-pipe. The two species are also not grouped together based on mitochondrial DNA sequences, and as a consequence we have erected a new genus for Peloparion iridis. Peloparion helenae appears to be most closely related to Mysticarion, but is too anatomically divergent to be included in this group.
Ubiquitarion gen. nov.

Type species: Peloparion iridis Hyman, 2007

Description. Shell. Small, ear-shaped, flattened, last whorl large, underside membranous, umbilicus closed, shell glossy, protoconch and teleoconch with no visible sculpture (Table 3, Fig. 35B).

Animal. Beige with yellowish and black markings and iridescent specks of pigment. Mantle lobes and shell lappets well developed.

Genitalia. Ovotestis of one lobe, embedded near apex of digestive gland. Talon and carrefour embedded in albumen gland. Spermoviduct folded three times. Distal portion of free oviduct with small spherical capsular gland with no internal sculpture, remainder of free oviduct with longitudinal pilasters internally. Bursa copulatrix moderately long, reaching halfway along spermoviduct; internally with longitudinal pilasters (duct only); inserted on vagina. Vagina short, internally with longitudinal pilasters. Epiphallus enters penis through thickened ring; epiphallic caecum absent; descending arm of epiphallus (near flagellum) encased in a thick muscular sheath; epiphallic flagellum with axial filament present, also encased in thick muscular sheath. Spermatophore a soft-walled capsule with hard tail-pipe; one branching spine present on capsule; double row of branching spines present in spiraling pattern along tail-pipe.

Remarks. This genus is created for Peloparion irid$i$. This species is superficially similar to Peloparion 


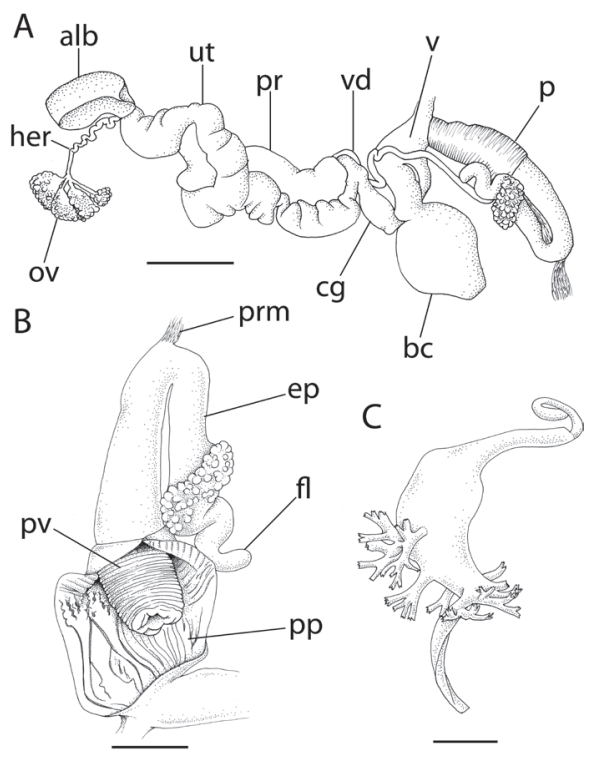

Fig. 36. Reproductive anatomy of Peloparion helenae, AM C.456546. A. Genitalia, scale bar $=4 \mathrm{~mm}$. B. Penial interior, scale bar $=2 \mathrm{~mm}$. C. Spermatophore, scale bar $=1 \mathrm{~mm}$. Abbreviations: alb, albumen gland; bc, bursa copulatrix; cg, capsule gland; ep, epiphallus; fl, flagellum; her, hermaphroditic duct; ov, ovotestis; p, penis; pp, penial pilasters; pr, prostate; prm, penial retractor muscle; pt, penial tunica; pv, penial verge; ut, uterus; vd, vas deferens.

helenae, but differs anatomically, particularly in the penial complex and spermatophore. Mitochondrial DNA sequences also show that the two species do not group together.

Etymology. Combination of ubique (Latin = "everywhere'; arion (Latin) referring to a 'kind of snail or slug'; masculine.
Ubiquitarion iridis (Hyman, 2007) comb. nov. (Figs 32D, 35B, 37)

Helicarion helenae; Godwin-Austen, 1883: 146, pl. 41, fig. 1 [live drawings only] (not Godwin-Austin, 1883: 146, pl. 41, figs 1-8).

Peloparion iridis Hyman, 2007: 90; Stanisic et al, 2010: 279, 310-311.

Material examined. Holotype. AM C.456552 (Sydney Harbour, Elizabeth Bay, NSW, pre-1877).

Non-type material. See Table S1.

Diagnosis. Animal. Beige, with a paler stripe along tail with dark stripes to either side. Mid field of sole cream; outer fields grey. Mantle lobes and shell lappets well developed, right lappet rounded and edged with black; left lappet short, elongate with rounded tip, bisected by black line and raised cream-coloured ridge; black spots on lobes and lappets (Fig. 32D).

Genitalia. Bursa copulatrix moderately long, sac oval-shaped and distinguishable from duct. Penis cylindrical, fully enclosed in penial sheath, internally with two main longitudinal pilasters and additional shorter longitudinal pilasters at proximal end, connected by transverse threads; epiphallus long, between two and three times penis length, entering penis through thickened ring; descending arm of epiphallus and epiphallic flagellum encased in a thick muscular sheath. Spermatophore a soft-walled capsule with hard tail-pipe; one branching spine present on capsule; double row of branching spines present in spiraling pattern along tail-pipe (Fig. 37).

Remarks. Two species of Peloparion were accepted for many years (Iredale, 1941; Smith, 1992; Smith et al., 2002), Peloparion helenae for specimens rang-
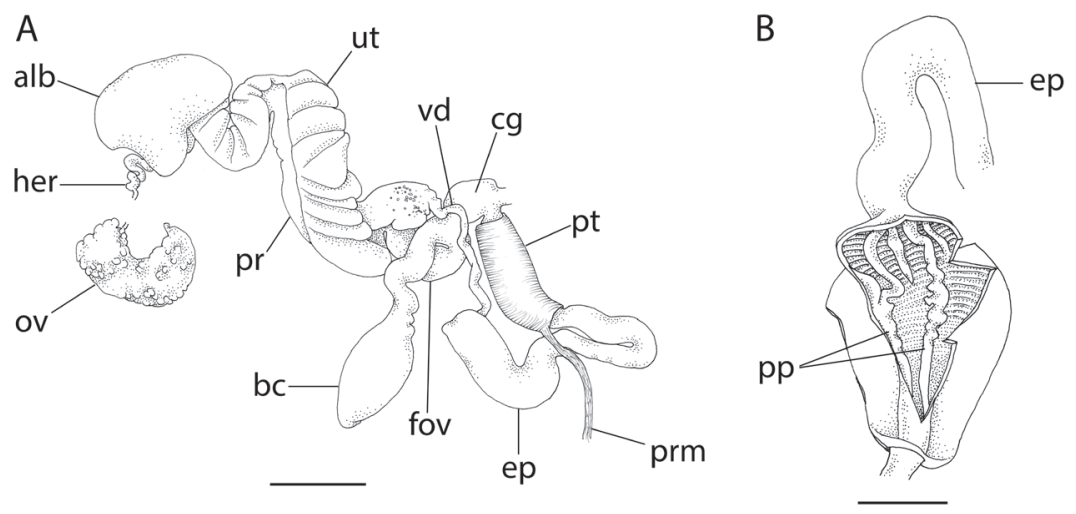

Fig. 37. Reproductive anatomy of Ubiquitarion iridis, AM C.512399. A. Genitalia, scale bar $=2 \mathrm{~mm}$. B. Penial interior, scale bar $=1 \mathrm{~mm}$. Abbreviations: alb, albumen gland; bc, bursa copulatrix; $\mathrm{cg}$, capsule gland; ep, epiphallus; fl, flagellum; her, hermaphroditic duct; ov, ovotestis; $p$, penis; pp, penial pilasters; pr, prostate; prm, penial retractor muscle; pt, penial tunica; pv, penial verge; ut, uterus; vd, vas deferens. 
ing from Sydney to southern Queensland and Peloparion submissus for specimens from Barrington Tops, until the discovery that the type specimens of both were identical (Hyman, 2007). The names were synonymised with the senior name, Peloparion helenae being retained for the Barrington Tops species and a new name, $P$. iridis, introduced for the more widely ranging species (see Hyman, 2007 for a more detailed account).

Given its unusually wide range, spanning over 750 $\mathrm{km}$ from Sydney to north of Brisbane in habitats rang- ing from dry vine thicket to rainforest, this species was extensively sampled in order to ensure that it was not a species complex. Both molecular and morphological investigations confirmed the presence of a single widespread species, with a disjunct range including populations around Sydney (where this species is thought to have been introduced around 1865; Hyman, 2007), a single known locality at Seal Rocks in central NSW and then populations ranging between Grafton in northern NSW and Gympie in southern QLD (thought to be the original range of the species; Hyman, 2007). 